\title{
EXPERIMENTAL ASSESSMENT OF ADVANCED THERMAL IMAGING FOR DETECTING VOIDS IN DUCTS
}

\author{
A Thesis \\ presented to \\ the Faculty of the Graduate School \\ at the University of Missouri-Columbia \\ In Partial Fulfillment \\ of the Requirements for the Degree \\ Master of Science \\ by \\ JAMES DAWSON \\ Dr. Glenn Washer, Thesis Supervisor \\ DECEMBER 2017
}


The undersigned, appointed by the Dean of the Graduate School, have examined the thesis entitled Experimental Assessment of Advanced Thermal Imaging for Detecting Voids in Ducts

Presented by James Richard Dawson,

A candidate for the degree of Master of Science, And hereby certify that, in their opinion, it is worthy of acceptance.

Professor Glenn Washer

Professor Brent Rosenblad

Professor Roger Fales 


\section{ACKNOWLEDGEMENTS}

First, I am extremely grateful for my advisor, Dr. Glenn Washer, for giving me this opportunity. He has mentored me and guided me on how to become a better

engineer and person. He trusted in me and granted me freedom to get the work done, yet still provided valuable insight when needed. I feel privileged to have had the opportunity to work with Dr. Washer. I would also like to thank the remainder of my thesis committee: Dr. Brent Rosenblad, and Dr. Roger Fales.

Special thanks are also due to Mike Carraher, Matt Marciniak, and Aaron Saucier for all of their technical support.

As you finish college, you realize that what is special about college is the amazing people you meet. Specifically, I would like to thank Andy Pelikan, Pedro Ruiz Fabian, Erik Morris, Josh MacGregor, Matt Stieglitz, Katy Beyer, Gabriela Clayton, Mohammad Mujtaba Hammed, Mohanned Al-Gharawi, and Ali Sultan. College wouldn't have been the same without you all.

I would like to thank my entire family for their continuous words of love and support, and for pushing me to continue when times became difficult. I could have written this entire page about my wife Lauren Dawson. She has been my biggest cheerleader, the person who has sacrificed the most, and the one who has willingly walked beside me this entire way. She is the backbone behind everything I have accomplished. I love you to the moon and back!

In loving memory: Ronald Pauley, Mary Pauley, Nanette "Gammy" Dawson, Earlene Clapp, and James "Pappi" Broughton. 


\section{TABLE OF CONTENTS}

ACKNOWLEDGEMENTS

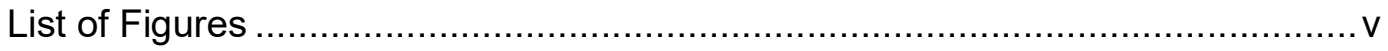

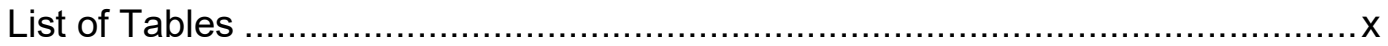

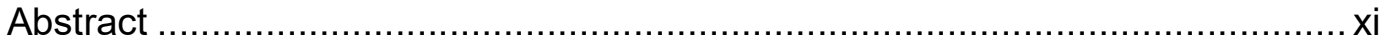

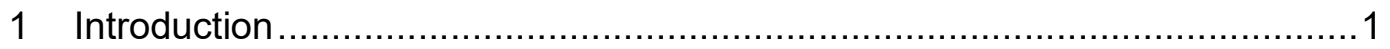

1.1 Problem Statement .....................................................................

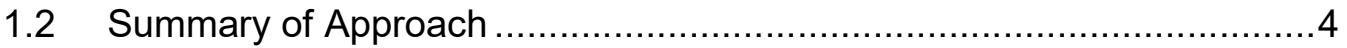

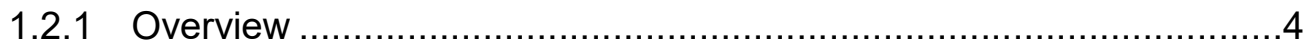

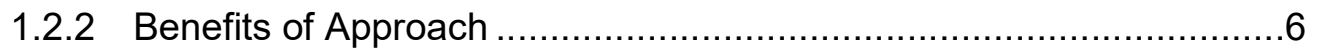

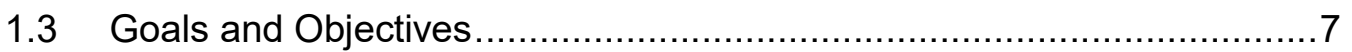

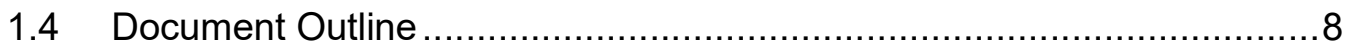

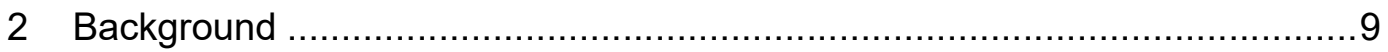

$2.1 \quad$ Concrete and Corrosion ............................................................ 10

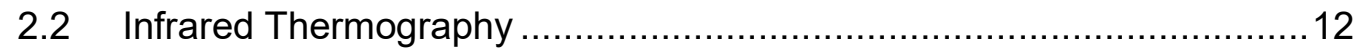

2.3 Infrared Thermography for Nondestructive Evaluation ......................12

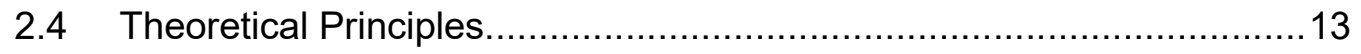

2.4.1 Infrared Radiation ......................................................... 13

2.4 .2 Steady-State Heat Flow................................................... 14

2.4 .3 Transient Heat Flow ......................................................... 15

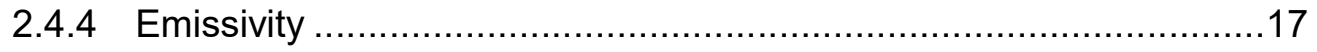

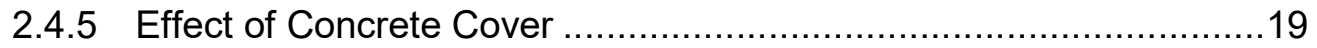

2.4.6 Environmental Effects.........................................................20

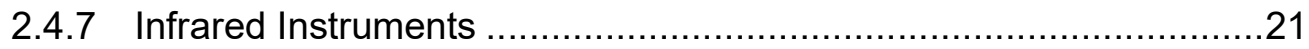

2.4 .8 IR-UTD Case Examples ....................................................... 31

2.5 Additional Void Detection Technologies ........................................39

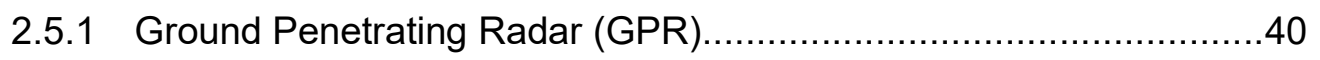

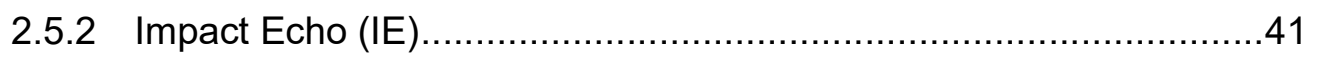

2.5.3 Electrically Isolated Tendons .............................................43

2.5 .4 Ultrasonic Testing (UT) ................................................. 44

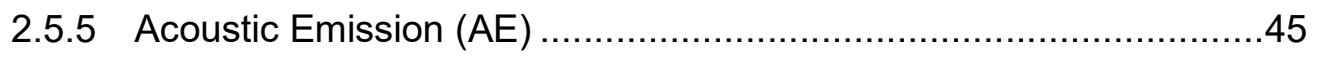




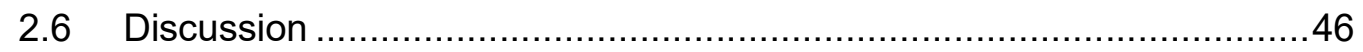

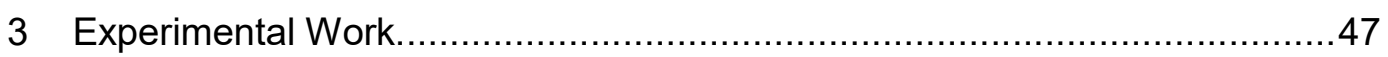

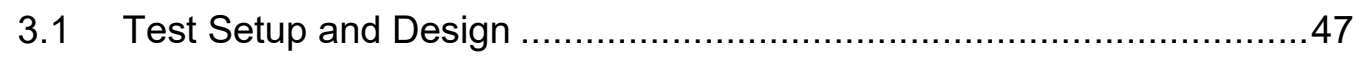

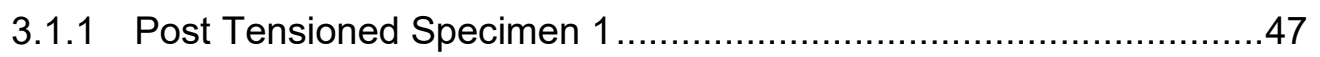

3.1.2 Post Tensioned Specimen 2 ............................................. 52

3.2 Post Tensioned Experiments ...................................................6

3.2.1 Data Collection Summary ..................................................60

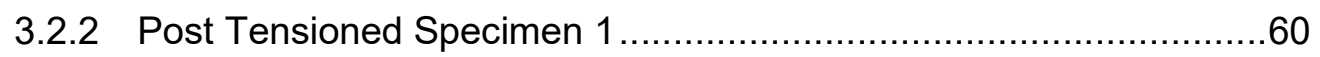

3.2.3 Post Tensioned Specimen 2 ............................................... 72

3.2.4 Processing Techniques ......................................................

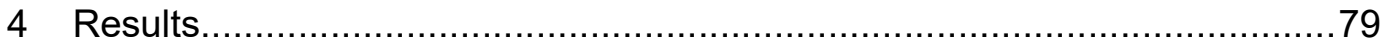

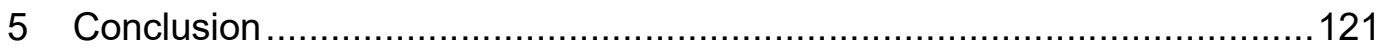

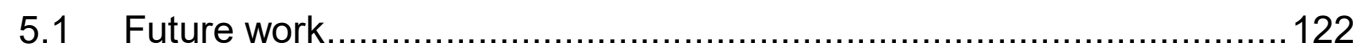

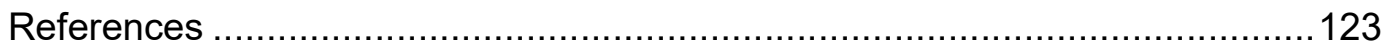




\section{LIST OF FIGURES}

Figure 1 - Cross-sections displaying a filled duct $(A)$, a partially filled duct (B) and an empty duct (C) 2

Figure 2 - Images of the pedestrian bridge failure at Lowe's Motor Speedway in 2000 . 4

Figure 3 - Demonstration of the test setup on the inside of a box girder bridge. 6

Figure 4 - Image visualizing the cracking and deterioration of reinforced concrete members. 12

Figure 5 - Visual representation of heat transfer properties.................. 19

Figure 6 - FLIR T620 hand-held infrared camera................................. 23

Figure 7 - Image of a bridge $\operatorname{deck}(A)$ and an IR image (B) of the same bridge deck area showing a subsurface defect............................................. 24

Figure 8 - Setup of the IR-DSS system on a truck............................. 26

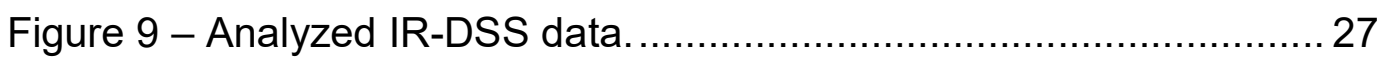

Figure 10 - All of the base parts that make up the IR-UTD system........ 28

Figure 11 - Image of the IR-UTD system mounted on a light pole base.. 29

Figure 12 - IR-UTD system set up in a portable DAQ system alongside the roadway. 30

Figure 13 - Side by side infrared (left) and visual image (right) taken during

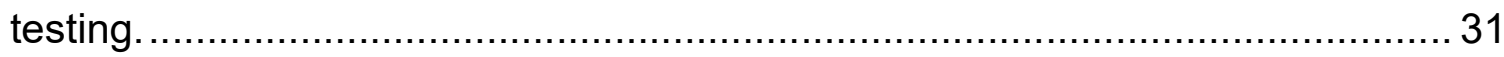

Figure 14 - Midway test block before the concrete is poured................. 32

Figure 15 - Midway Test Block weather data from September 16, 2014 to September 19th, 2014. 33

Figure 16 - Results from both the handheld infrared camera (left side) and the IR-UTD system (right side). 34

Figure 17 - IR-UTD system mounted on a light pole base on lowa Bridge. 36

Figure 18 - View of the lowa bridge deck from the IR-UTD system camera. 37

Figure 19 - Initial test results of the lowa Bridge. 38 
Figure 20 - Field drilling of a delamination accompanied by borescope image. 38

Figure 21 -From left to right; infrared image, hammer sounding image, overlay of both techniques. 39

Figure 22 - lowa Bridge weather data............................................... 39

Figure 23 - Image of a ground-coupled GPR system inspecting a RC bridge deck. 40

Figure 24 - Image of IE being used to confirm a subsurface delamination in a reinforced concrete bridge deck.

Figure 25 - Image displaying a general concept behind how the impedance measurements would be collected when using Electrically Isolated Tendons.... 43

Figure 26 - Image displaying how the UT system sends a wave into a material as well as the amplitude upon returning..... 45

Figure 27 -Acoustic Emission monitoring system visualization. .............. 46

Figure 28 - Construction drawings of the Post Tensioned (PT) Specimen created by Coreslab in Marshall, MO. 48

Figure 29 - Specimen construction process at Coreslab in Marshall, MO. 49

Figure 30 - Image displaying how spray foam was inserted into the ducts. 51

Figure 31 - Image A (left) displays plywood caps protecting the ducts while image $B$ (right) shows grout being poured into the ducts ................................. 52

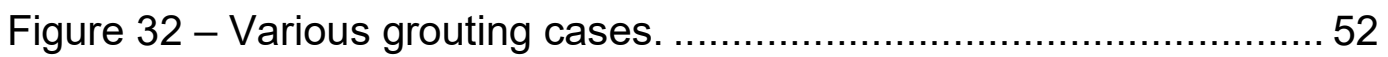

Figure 33 - Side and edge profile of Post Tensioned Specimen 2. ......... 53

Figure 34 - Defect and Thermocouple layout for Post Tensioned Specimen 2. 54

Figure 35 - Thermocouple locations along the depth of specimen 2 2......56

Figure 36 - Aerial view image of Post Tensioned Specimen 2 prior to pouring. 57

Figure 37 - Pouring of concrete for specimen 2. ............................. 57

Figure 38 - Broom finish on specimen 2 ....................................... 58 
Figure 39 - Specimen 2 after several days of curing in the mold. 58

Figure 40 - Gaps around the embedded ducts and rebar post pouring... 59

Figure 41 - Damaged side of Specimen 2 after resurfacing.................... 60

Figure 42 - Side wall drawing for the insulated structure. ........................ 64

Figure 43 - Multiple stages of construction for the insulated structure. .... 65

Figure 44 - Aluminum DAQ system for secured viewing ........................ 66

Figure 45 - Test setup for testing of specimen 1 prior to grouting of the ducts and to the insulated structure. 67

Figure 46 - Grouting profile for test 2 on specimen $1 \ldots \ldots \ldots \ldots \ldots \ldots \ldots \ldots \ldots . . .68$

Figure 47 - How Styrofoam insulation was attached to the side of Specimen

1. 69

Figure 48 - Inside of the insulated structure without air control. ............. 70

Figure 49 - Inside of the insulated structure with air control.................... 71

Figure 50 - Internal face of PT Specimen 2 during testing. ................... 73

Figure 51 - External surface of PT Specimen 2 during testing............... 73

Figure 52 - Test setup used during test 3 on specimen 2 ................... 75

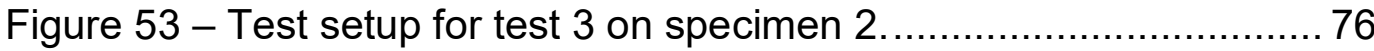

Figure 54 - Surface thermocouple data for PT Specimen 1 - Test 1 on June $21^{\text {st }}$

Figure 55 - Results after data processing on June $21^{\text {st }}, 2017 \ldots \ldots \ldots \ldots \ldots . . . . . .22$

Figure 56 - Thermocouple data collected during Test 2 on August $30^{\text {th }}$, 2017. 83

Figure 57 - Image produced from processing thermal data on August $30^{\text {th }}$, 2017 85

Figure 58 - Thermocouple data collected on PT Specimen 1 on September $10^{\text {th }}$

Figure 59 - Processed image from data collected on September 10 ${ }^{\text {th }}, 2017$. 88

Figure 60 - Thermocouple data from testing conducted on September $24^{\text {th }}$ September $25^{\text {th }}, 2017$. 89 
Figure 61 - Infrared results from testing on September $24^{\text {th }} \& 25^{\text {th }}, 2017$.

Figure 62 - Thermocouple data collected from September $30^{\text {th }}$ to October $1^{\text {st }}$ 93

Figure 63 - Infrared results from processing thermal data collected on September $30^{\text {th }}$ and October $1^{\text {st }}$. 94

Figure 64 - Thermocouple data collected during test 5 on October $16^{\text {th }} \&$ $17^{\text {th }}$. 95

Figure 65 - Processed infrared image from data collected on October $16^{\text {th }}$ and $17^{\text {th }}$. 96

Figure 66 - Thermocouple data collected on October $18^{\text {th }}$ and $19^{\text {th }}$ for test 5. 98

Figure 67 -Processed infrared image collected on October $18^{\text {th }}$ and $19^{\text {th }}$ for test 5 99

Figure 68 - Thermocouple data collected during test 6 on October $21^{\text {st }}$ and $22^{\text {nd }}$ 100

Figure 69 - Processed infrared image from testing on October $21^{\text {st }}$ and $22^{\text {nd }}$. 101

Figure 70 - All thermocouple data collected during test 1 on October $26^{\text {th }}$ and $27^{\text {th }}$. 103

Figure 71 - Processed infrared image for PT specimen 2 on October $26^{\text {th }}$ and $27^{\text {th }}$. 105

Figure 72 - Infrared image collected at the max difference between thermocouple 6 and thermocouple 3 . 106

Figure 73 - Collected thermocouple data along with the processing period used to detect the half empty ducts. 107

Figure 74 - Processed infrared image displaying the half empty and fully empty duct near the base of the specimen. 108

Figure 75 - Infrared image showing how to quantitatively show defective areas. 109 
Figure 76 - Normalized and averaged pixel values for the two sets of five rows outlined in Figure 75. 109

Figure 77 - Thermocouple data for October $2^{\text {nd }}$ and $3^{\text {rd }}$ 111

Figure 78 - Infrared images produced from processing conducted on infrared and thermocouple data collected on October $2^{\text {nd }}$ and $3^{\text {rd }}$. 112

Figure 79 - Singular infrared image collected during the peak difference at 3:27 PM on October $2^{\text {nd }}, 2017$.

Figure 80 - Image used for quantitative processing to detect the half empty duct......

Figure 81 - Averaged and normalized values of the five rows of pixel data called out in Figure 80. 115

Figure 82 - Thermocouple data for test 3 on specimen $2 \ldots \ldots \ldots \ldots \ldots \ldots \ldots . . . . .117$

Figure 83 - Infrared processing results for the baseline test on specimen 2.

Figure 84 - Quantitative outline for processing of ROC results. 120

Figure 85 - Quantitative results for the baseline test of specimen $2 \ldots . .120$ 


\section{LIST OF TABLES}

Table 1 - Thermal properties of common civil engineering materials. ..... 17

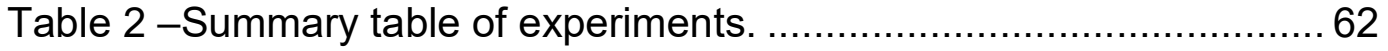




\section{ABSTRACT}

This research will evaluate the ability of a transient based Infrared Thermography (IRT) technology called the Infrared Ultra Time Domain (IR-UTD) system to detect defects in Post Tensioned (PT) ducts. In recent years, there has been an increasing number of bridges in the National Bridge Inventory (NBI) constructed using PT concrete design. Post Tensioning is a design concept in which steel tendons are placed inside plastic or galvanized steel ducts that are embedded within the concrete itself. If not constructed properly, voids are created during the construction process. These voids allow water and chlorides to ingress into the ducts and cause the steel tendons to corrode.

A PT specimen will be cast with embedded defects at known locations and exposed to diurnal heating and cooling cycles. The IR system will collect data while the specimen is fully exposed to the environment. Data will also be collected after an air controlled enclosure is constructed around the specimen to simulate the temperature gradient that the outer wall of a box girder bridge is subjected to.

This research shows that in direct sunlight, the IR-UTD processing produced indications from implanted defects of varying sizes inside of a galvanized steel duct. Additionally, the effect from having air control on the inside of the structure didn't significantly affect the results. To obtain a full scope of the abilities of the IRT system, a procedure to properly insulate the specimen to prevent uneven thermal gradients will be necessary. Testing during the summer months where the sun is in the sky for a longer period would also be beneficial. 


\section{INTRODUCTION}

The following section describes the goals and objectives of this research. This research explores the development of new methodologies for applying Infrared Thermography (IRT) for the detection of defects in post tensioned (PT) concrete. These defects are voids in the PT ducts that originate from poor construction, design, or materials.

In the mid-1960s, the Bickton Meadows footbridge in the United Kingdom collapsed, due to serious corrosion problems in the steel tendons. Though there were similar events that had previously occurred, this event was the start of a several decades-long search to determine how to reliably detect defects in Post Tensioned (PT) ducts. Now, decades later, additional issues associated with PT construction have been discovered, and there continues to be no suitable Nondestructive Evaluation (NDE) techniques to reliably detect defects in PT bridges. The development of new methodologies for applying IRT for the detection of critical defects in PT concrete bridge members would have an immediate impact on improving the safety of PT bridges.

\subsection{Problem Statement}

According to the National Bridge Inventory (NBI), approximately $23.4 \%$ of more than 610,000 bridges in the United States are structurally deficient or functionally obsolete [1]. These data portray the significant challenge of maintaining a safe and efficient infrastructure because of the considerable number 
of deficient bridges in the US and their on-going deterioration as these bridges age.

In recent years, there has been an increasing number of bridges in the National Bridge Inventory (NBI) constructed using PT concrete design. Post Tensioning is a design concept in which steel tendons are placed inside plastic or galvanized steel ducts that are embedded within the concrete itself. A typical PT cross-section is shown in Figure 1.

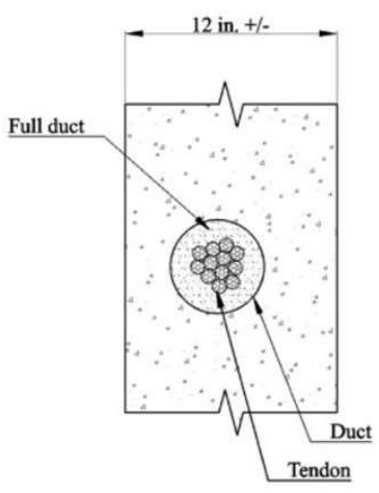

A

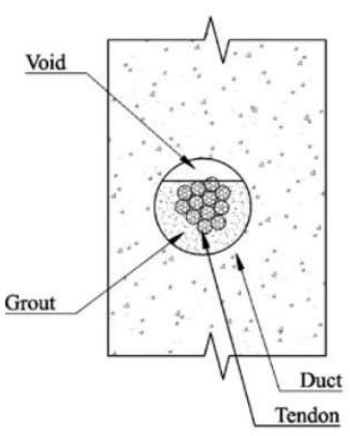

B

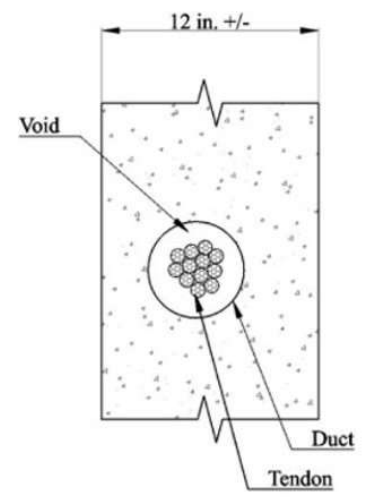

C

Figure 1 - Cross-sections displaying a filled duct (A), a partially filled duct (B) and an empty duct (C)

As shown in the figure, both the PT ducts and steel tendons are embedded within the concrete framing of the structural member. This construction technique of embedding the tendons in grout and the ducts in concrete is called "bonded" PT construction. "Un-bonded" PT construction describes when the steel tendons are not embedded in grout. In both cases, the steel tendons, which are typically formed from high-strength (tensile strength $=270 \mathrm{ksi}$ ) seven or nineteen strand 
steel, are tensioned and then released after the concrete outside of the duct is poured and partially cured. This process results in compressive stresses acting in the concrete. These compressive stresses counterbalance flexural and/or tensile forces in the concrete. This is important because PT construction reduces concrete cracking and deflections, which allows for longer, lighter (less concrete needed) structures across a wide range of applications.

In 1985, the Ynys-y-Gwas Bridge in the United Kingdom suddenly collapsed; Malle Bridge collapsed in 1992 [2]. Though there had been PT failures preceding these, the issues associated with the collapse of these bridges are both consistent and typical; voids in the ducts acted as ingress for chlorides and water leading to the corrosion of post tensioned tendons [3]. In 2000, the Florida Department of Transportation (FDOT) reported several post tensioned tendon failures due to premature corrosion. The cause of these failures was primarily due to soft grout, voids in the grout, and water infiltration into the voids. Since that time, even more tendon failures caused by the duct systems not being air tight and also grouting defects [3] have been discovered.

Figure 2 provides a visual representation of the danger associated with corrosion in steel tendons from the collapse of a pedestrian bridge at Lowe's Motor Speedway in 2000. The bridge was constructed in 1995, but poor-quality grout resulted in rapid corrosion of the tendons in the bridge. The corrosion weakened the steel tendons; this caused the tendons to fracture (Figure 2B) and the bridge to collapse under the weight of the pedestrians. More than 100 pedestrians were injured when an 80 -foot section of the bridge fell to the ground below. 


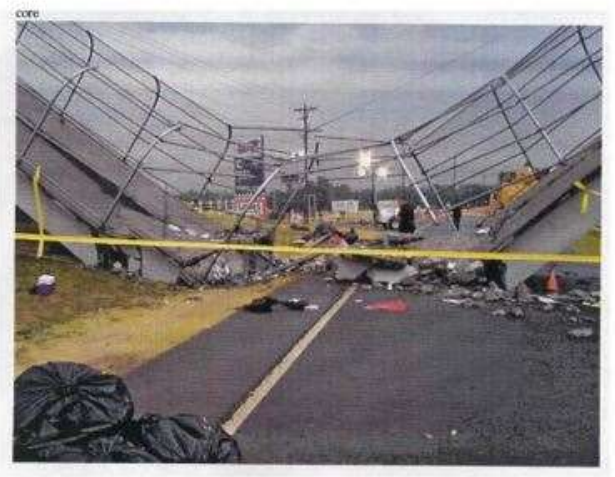

A

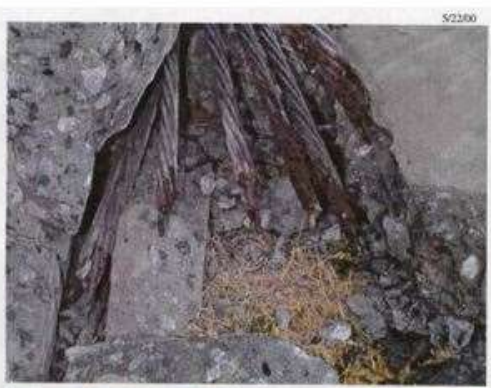

B

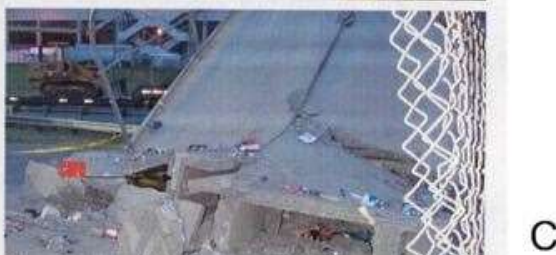

C

Figure 2 - Images of the pedestrian bridge failure at Lowe's Motor Speedway in 2000.

A common method currently used to determine if there are voids is to drill through the concrete and into the duct. Due to the naturally damaging effects of destructive evaluation, a new technique is needed for the detection of defects in PT ducts. Nondestructive Evaluation (NDE) techniques offer many intriguing benefits and should be thoroughly evaluated as a vehicle for solving these problems. Infrared Thermography is a promising NDE technique for PT void detection.

\subsection{Summary of Approach}

\subsubsection{Overview}

This research will evaluate the ability of a transient based IRT system to detect defects in PT ducts. Transient IR differs from conventional IR because 
images are collected over time, resulting in more comprehensive data for analysis. A PT specimen will be cast and exposed to diurnal heating and cooling cycles. The IR system will collect data while the specimen is fully exposed to the environment. Data will also be collected after an air controlled structure is constructed around the specimen to simulate the temperature gradient that the outer wall of a box girder bridge is subjected to.

As shown in Figure 3, the space inside of the box girder is large, and typically accessible. Once inside, the IR-UTD system could be easily set up to collect data for as long as needed. The arrows in the figure represent the thermal energy emitted at the surface. As shown in the figure, heat transferring through the walls of the box girder will affect the emitted energy, and should provide suitable energy for analysis. This is all in contrast to some of the ways these tendons are inspected; from the outside face. Inspections from the outside face are impractical. Traffic control and special equipment is needed, and even then, the inspection process becomes increasingly dangerous. 


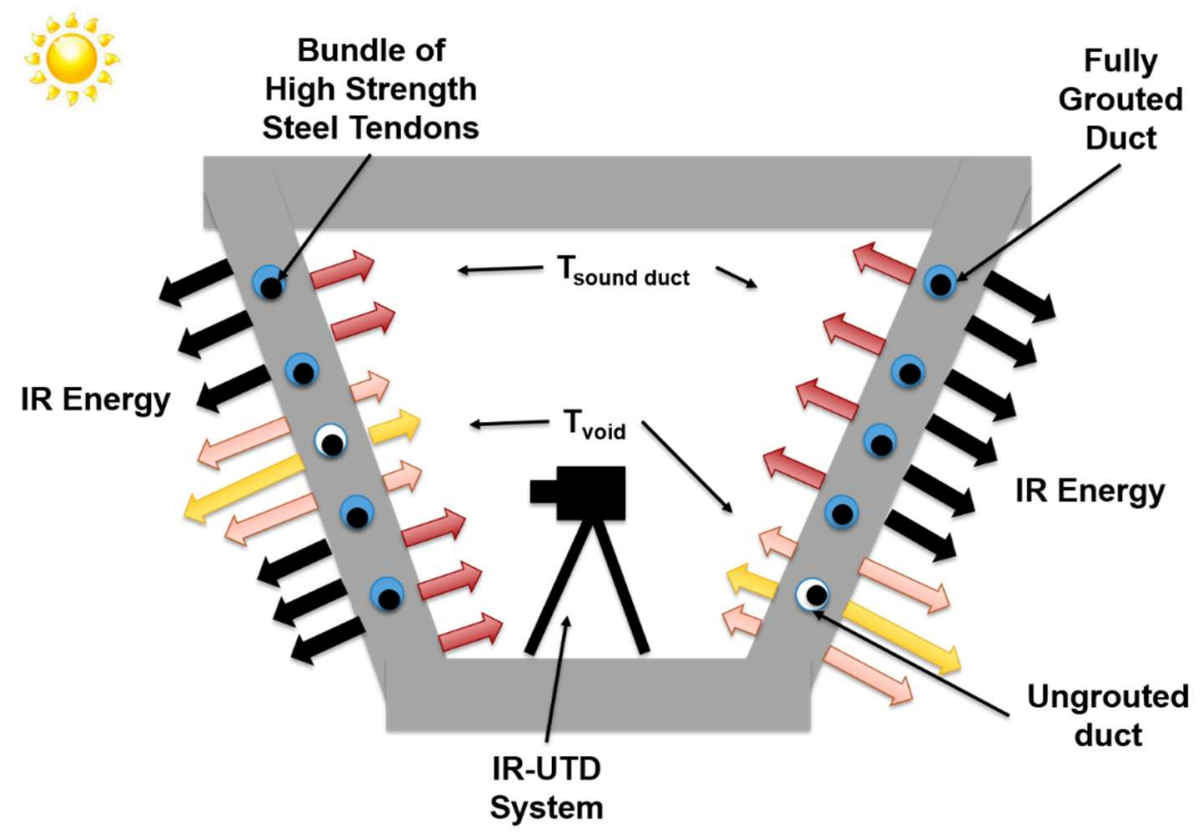

Figure 3 - Demonstration of the test setup on the inside of a box girder bridge.

\subsubsection{Benefits of Approach}

Infrared technology has been used as an effective tool to determine both the location and relative depth of a defect in concrete bridge decks and other structures [4]. If successful in detecting defects in Post Tensioned ducts, the transient based Infrared Thermography (IR) system will provide inspectors with easy to interpret images of defects in several civil applications, including:

- Embedded PT ducts in concrete bridges

- Defects in tunnel construction

- Larger, thin-shelled buildings

Using IRT for inspections is also highly beneficial because:

- IRT is Nondestructive to the structural member under evaluation 
- The data acquisition system can be set up on the inside of a box girder bridge and left to collect data while workers attend to other projects

- Performing inspections on the inside face of a box girder bridge is safe, convenient and cheap

- The inspector can analyze a large surface area encompassing multiple ducts during the same test

- The natural diurnal heating and cooling patterns can be used, so additional heating source are not required

- IRT could provide both the location of the defect and an estimation of its depth

\subsection{Goals and Objectives}

The goal of this research is to ensure the safety and serviceability of Post Tensioned concrete structures. This research will study two newly constructed post tensioned concrete specimens, each with embedded defects of varying sizes and locations. The objectives of this research are as follows:

- Assess the capabilities of transient Infrared Thermography to detect defects in galvanized steel ducts embedded within a concrete PT specimen.

Completion of this objective could lead to the broadening of IRT techniques with the discovery of how to use natural weather patterns in place of a heating source and could be applicable in a broad range of circumstances. 


\subsection{Document Outline}

The subsequent chapters will provide an in-depth look into the research performed. Chapter 2 will provide an overview of the IRT used throughout experimentation. Prior work conducted with IRT and other commonly used technologies will be described. The theoretical foundation, as well as the rationale for the experiments conducted, will be outlined. Chapter 3 will be devoted to describing the test design and setup. Images of the test setup, the location of testing, materials tested, and the data collection and analysis procedures will be provided. The testing procedures for each experiment will be thoroughly described. Chapter 4 will list the results and analysis of each test described in Chapter 3. The concluding chapter will review the goals and objectives of the research, the results shown during the testing described in Chapter 4, and the conclusions to the testing results. Additional research needed to complete the outlined goals of these experiments will also be discussed. 


\section{BACKGROUND}

The steel tendons are critical to PT bridges due to the compressive stresses transferred to the concrete. Therefore, protecting these steel tendons is of key importance. Civil structures are exposed to natural weather variations; therefore, corrosion protection is paramount in maintaining healthy structures over their entire life. In bonded PT construction, cementitious grout is used to fill the inside of the duct surrounding the tendons so as to finalize several layers of corrosion protection. This goal is accomplished as the grout placement displaces water and provides a high $\mathrm{pH}$ environment in which corrosion cannot occur. However, cementitious grout fails when voids form within the ducts due to grout shrinkage, loss of fill pressure, or entrapped air. All of these defects are very common if and when construction techniques are not followed properly; these kinds of defects have all played a part in the collapse of structures in the past. The collapse occurs when the grout void, which often fills with water and chlorides, exposes the highstrength steel strands to a corrosive environment. Over time, this environment eventually leads to steel strand fracture. These failed strands reduce the overall strength of the structure and may lead to cracking, excessive deflection or even structural collapse. This is why the detection of voids in PT ducts is critical for ensuring the safety and long-term stability of PT concrete structures.

Due to the construction process of PT ducts, the abundant issues associated with PT ducts become exponentially more difficult to detect after the ducts are filled with grout. The easiest way to detect these defects is a destructive inspection technique. One of, if not the, most common destructive technique is to drill a hole into a PT duct in an area of question at an attempt to find a defect. If a 
void is discovered, a borescope is used to evaluate the extent of the void. The void can then be filled after the inspection. However, the probability of success in detecting all possible voids along the length of a duct is incredibly low; this is important to note, as there needs to be only one void present to cause enough corrosion to fracture the high-strength steel tendons.

Figure 1 gives a visual representation of common grouting conditions that occur within bonded PT ducts. The duct cross-sectional area is required to be at least two and a half times the total cross sectional area of the strand bundle [3]. The ducts are either galvanized steel or high-density polyethylene (HDPE) piping. As shown in Figure 1, grout in the duct may completely fill the duct and surround the steel tendons (Figure 1A), partially fill the duct (Figure 1B), or the duct may be completely empty (Figure 1C). Partially filled or empty ducts are voids that allow water and chlorides to congregate and create a localized corrosive environment that is difficult to detect. These voids can create critical defects in the high-strength steel strands that need to be detected and repaired to ensure the safety of the structure. Detection problems arise because the voids are embedded within the duct which is embedded within the concrete. Therefore, there are few practical NDE technologies that could be used in detecting these critical voids.

\subsection{Concrete and Corrosion}

Concrete is the main material used in the Unites States' four-million-mile transportation system (FHWA 2007 Publication) and the more than 610,000 bridges in the National Bridge Inventory. Since reinforced concrete is both cheap and strong, it is utilized for structural members, bridge decks, and substructures. 
Concrete does not come without its own problems as deterioration causes continuous additional costs and issues. The main cause behind reinforced concrete deterioration is the corrosion of the embedded reinforcing steel.

As water and chlorides penetrate the concrete to the depth of the rebar, the steel converts to iron oxide through the corrosion process. Corrosion causes steel to expand creating localized tensile stresses in the concrete. These tensile stresses cause the concrete to crack locally at the interface between the reinforcing steel and the concrete [4]. Eventually, as more cracks form at additional reinforcing rebar, the cracking propagates parallel to the surface, connecting together, creating a subsurface delamination as shown in Figure 4. Over time, this crack will turn perpendicular and make its way to the surface and create a spall, leaving the underlying rebar exposed to additional deterioration. When the spall has reached the surface, both the structural capacity and the service level of the structure can be reduced.

Not unlike the ingress of water and chlorides into a concrete deck, a void inside of a PT duct creates an easily accessible space for water and chlorides to mix together. This mixture will be in direct contact with the high strength steel strands, quickly initiating the corrosion process described in this section; the steel will corrode, expand, lose capacity, and fracture. Due to these facts, early stage deterioration detection is critically important for maintaining cheaper, safe, and efficient structures. 


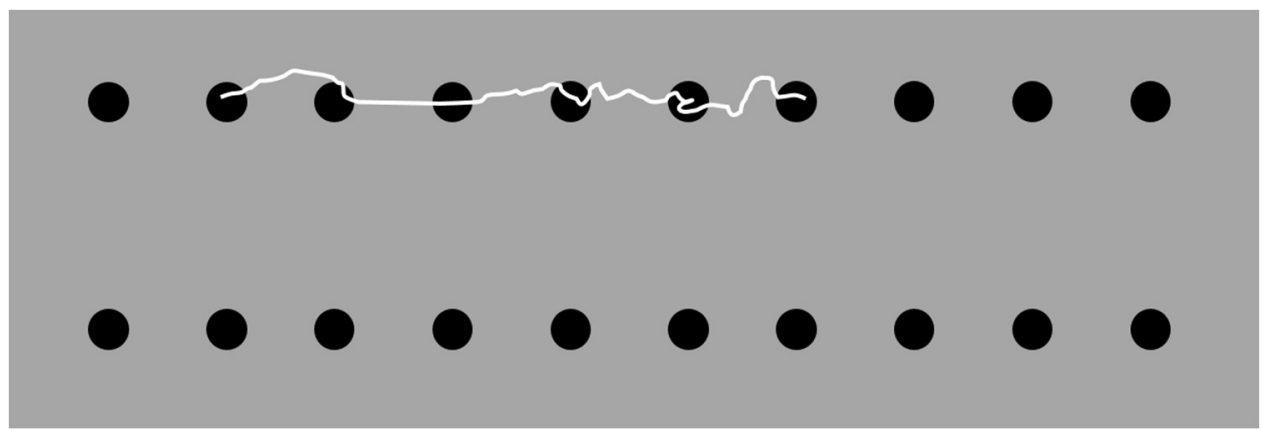

Figure 4 - Image visualizing the cracking and deterioration of reinforced concrete members.

\subsection{Infrared Thermography}

This section describes the fundamental theory behind Infrared Thermography (IRT). The benefit of using transient processing techniques and diurnal weather patterns in tandem with IRT is included. Previous research and applications of the combination of said technology and technique is discussed in this section.

\subsection{Infrared Thermography for Nondestructive Evaluation}

Infrared Thermography (IRT) has been used in civil engineering for more than 30 years. As heat is transferred through a structure, a defect will disrupt the heat flow and will manifest itself by emitting increased amounts of thermal energy at the defect location. Infrared (IR) cameras capture the thermal energy emitted from a material and convert that into a temperature and lastly an infrared image. Previously conducted research has shown that under favorable weather conditions, subsurface defects produce visible surface temperature variations by use of an IR camera $[4,5]$. Not only are the defects measurable, but IRT has proven to be convenient and economical when inspecting large structures such as parking garages, underground tunnels, and bridge decks [6]. IRT is not only 
beneficial for large structures, but is sensitive enough to detect small defects such as hot spots inside a computer, underground heating/cooling pipes, and improper insulation. The following sections will describe the theoretical principles, typical instruments, and the advantages and limitations of this technology.

\subsection{Theoretical Principles}

\subsubsection{Infrared Radiation}

All materials above absolute zero $\left(-273.15{ }^{\circ} \mathrm{C}\right.$ or $\left.0{ }^{\circ} \mathrm{Kelvin}\right)$ emit infrared radiation. This radiation is electromagnetic energy emitted generally within two spectrum windows; 3-5 $\mu \mathrm{m}$ and 8-14 $\mu \mathrm{m}$ [7]. The rate at which an object's energy is released is based on both the emissivity and temperature of the material. Since IR cameras collect the electromagnetic energy emitted by an object, IR cameras do not actually measure the temperature of the material, but rather the radiation emitted by or reflected off the surface of the material [8]. The radiant energy released by a material is defined by the Stefan-Boltzmann equation:

$$
E=\varepsilon \sigma T^{4}
$$

Equation 1

$E=$ emitted energy by a surface

$\varepsilon=$ material emissivity

$\sigma=$ Stefan-Boltzmann constant $\left(5.67 \times 10^{-8}\right) \frac{\text { Watts }}{\text { meter }^{2} \times{ }^{\circ} \text { Kelvin }^{4}}$

$\mathrm{T}=$ Temperature $\left({ }^{\circ}\right.$ Kelvin$)$

As shown in this equation, the energy emitted caries to the fourth power of the temperature. 


\subsubsection{Steady-State Heat Flow}

Heat is transferred across a solid object at varying rates. When the object is in a steady-state, the heat transfer can be expressed using a Fourier equation:

$$
q_{x}=-k A_{x} \frac{d T}{d x}
$$

Equation 2

$\mathrm{q}_{\mathrm{x}}=$ rate of heat transfer (watts)

$\mathrm{k}=$ thermal conductivity $\left(\frac{\text { Watts }}{\text { meter } x^{\circ} \text { Celcius }}\right)$

$A_{x}=$ surface area perpendicular to heat flow $\left(\right.$ meter $\left.^{2}\right)$

Because the above Fourier equation represents an object in a steady-state, it portrays a highly simplistic relationship for heat transfer in materials in that time isn't considered. In reality, due to the effects of time and varying thermal properties, heat transfer becomes much more complicated.

A substantial portion of civil structures are exposed to the environment, so convective heat transfer plays a much larger role when compared to unexposed structures. Convective heat transfer can be expressed by the following equation:

$$
q_{c}=h_{c} A_{s}\left(T_{s}-T_{a}\right)
$$

Equation 3

$$
\begin{aligned}
& \mathrm{q}_{c}=\text { rate of heat transfer }\left(\text { by the surface area, } \mathrm{A}_{\mathrm{s}}\right) \\
& \mathrm{h}_{\mathrm{c}}=\text { convective heat transfer coefficient }\left(\frac{\text { Watts }}{\text { meter }^{2} x^{\circ} \mathrm{Kelvin}}\right) \\
& \mathrm{A}_{\mathrm{s}}=\text { Surface area }\left(\text { meter }^{2}\right) \\
& \mathrm{T}_{\mathrm{s}}=\text { Surface Temperature }\left({ }^{\circ} \mathrm{Kelvin}\right) \\
& \mathrm{T}_{\mathrm{a}}=\text { Air Temperature }\left({ }^{\circ} \mathrm{Kelvin}\right)
\end{aligned}
$$


The convective heat transfer coefficient, $h_{c}$, is an empirical value that is dependent upon several variables, including air density and wind speed [9]. As an example, when the wind speed increases, the convective heat transfer coefficient, $h_{c}$, is also affected and, therefore, increases. This leads to a higher rate of heat transfer $\left(q_{c}\right)$ without any direct change in surface temperature or air temperature.

The effect of this increase in heat transfer can quickly mask surface temperature differences caused by subsurface defects. Due to this effect, mandated procedures have been put in place for using Infrared Thermography during field testing. These procedures include setting a limit on wind speed during periods of inspection (ASTM D4788-03).

\subsubsection{Transient Heat Flow}

Transient, or time based, heat flow in a one dimensional solid can be expressed by using the diffusion equation [10]:

$$
k \frac{\partial^{2} T}{\partial x^{2}}-c \rho \frac{\partial \mathrm{T}}{\partial \mathrm{t}}=-H \quad \text { Equation } 4
$$

$\mathrm{k}=$ material thermal conductivity $\left(\frac{\text { Watts }}{\text { meter } x^{\circ} \text { Kelvin }}\right)$

$\mathrm{T}=$ material temperature $\left({ }^{\circ} \mathrm{Kelvin}\right)$

$x=$ depth into a semi-infinite plate (meter)

$\mathrm{c}=$ material specific heat $\left(\frac{\text { Joules }}{\text { Kilograms } x^{\circ} \text { Kelvin }}\right)$

$\rho=$ material density $\left(\frac{\text { Kilograms }}{\text { meters }}{ }^{3}\right)$

$\mathrm{t}=$ time 
The above equation may easily be solved for a semi-infinite plate where the surface temperature is spontaneously increased and held at a constant temperature, such that transient heat flow is created inside of the plate until equilibrium is reached [11]. The heat flow within the plate is then in a transient state and can be expressed as a function of time in accordance with the relation:

$$
\left(T_{d}-T_{i}\right)=\left(T_{i}-T_{\infty}\right) \operatorname{erf}\left(\frac{x}{2 \sqrt{\alpha t}}\right)
$$

Equation 5

$T_{d}=$ Plate temperature at any depth $(x)$ into of the plate

$T_{i}=$ Initial material temperature

$\mathrm{T}_{\infty}=$ Constantly applied surface temperature

erf $=$ Gaussian error function

$\mathrm{x}=$ Depth into the plate

$\alpha=$ Material thermal diffusivity

The material thermal diffusivity, $\alpha$, can be described by an equation that includes the specific heat (c), density $(\rho)$ and thermal conductivity(k) of said material [11]:

$$
\alpha=\frac{k}{\rho c}
$$

Equation 6

This equation brings a basic understanding of how quickly a material's temperature changes under transient loading conditions. By quantitatively solving this equation with properties of common civil engineering materials, as shown in Table 1, a broader understanding of these materials can be reached. For example, steel has a specific heat that is almost half of that of concrete (i.e., it takes much less energy to change the temperature of an equal mass of steel relative to 
concrete.) The thermal conductivity of steel is also relatively high when compared to concrete, which means that when comparing the rate of heat flow, steel will be much larger, and therefore, the diffusivity is also.

Thermal properties of air are also very important; air has a specific heat that is between that of steel and concrete. However, the thermal conductivity is much lower than both steel and concrete. Due to these properties, the rate of thermal transfer is significantly impacted by air pockets in civil structures, such as in subsurface delaminations. Additionally, the specific heat of water is much larger than that of concrete, which results in a difference in thermal diffusivity. This difference causes civil structures that have more moisture, or pockets of water, to heat and cool at different rates. The difference in the properties of these materials can make the interpretation of thermal images more challenging as the moisture content within civil structures isn't known. Localized areas saturated with moisture will heat and cool at much slower rates relative to dry concrete.

Table 1 - Thermal properties of common civil engineering materials.

\begin{tabular}{|c|c|c|c|c|}
\hline Material & $\begin{array}{c}\text { Specific Heat } \\
\left(\mathrm{J} \mathrm{Kg}^{-1}{ }^{\circ} \mathrm{C}^{-1}\right)\end{array}$ & $\begin{array}{c}\text { Density } \\
\left(\mathrm{Kg} \mathrm{m}^{-3}\right)\end{array}$ & $\begin{array}{c}\text { Thermal } \\
\text { Conductivity } \\
\left(\mathrm{W} \mathrm{m}^{-1}{ }^{\circ} \mathrm{C}^{-1}\right)\end{array}$ & $\begin{array}{c}\text { Thermal Diffusivity } \\
\left(\mathrm{m}^{2} \mathrm{Sec}^{-1}\right)^{\star} 10^{-6}\end{array}$ \\
\hline Concrete & 800 & 2400 & 1 & 0.53 \\
\hline Steel & 440 & 7900 & 46 & 13 \\
\hline Air (defect) & 700 & 1.2 & 0.024 & 33 \\
\hline Water & 4180 & 1000 & 0.6 & 0.14 \\
\hline
\end{tabular}

\subsubsection{Emissivity}

Emissivity is the rate at which the surface of an object emits radiation. This rate is simplified as a ratio between a black body object and the object being imaged. A black body is a perfect emitter, meaning that it absorbs all radiation 
regardless of type of wavelength or orientation, and has a ratio of 1 (i.e., there is no reflection of radiation by the object). Any other object will be less than that of a black body; 0.5 is for an object that emits radiation that is half of that of a black body and 0 has no emissivity. Engineering materials are not black body materials, and therefore, not all radiation is absorbed, and a portion is reflected. Emissivity values of engineering materials, such as concrete or steel, are commonly known, and therefore, the IR radiation can be used to solve for the temperature of the object being imaged. As previously stated, emissivity is the rate at which the surface of an object emits radiation. Therefore, the same type of engineering material, with varying surface features (coated, painted, scratched, rough, smooth, etc.), will appear to differ in temperature even though the difference is in the emissivity while the temperature stays the same. Additionally, emission from a black body is equal at all orientations. For engineering materials, the emitted radiation is dependent on the orientation. Commonly known emissivity values are collected perpendicular to the objects surface; therefore, the true emissivity of a surface may differ when the object is observed from a different angle. Figure 5 provides a visual representation of the multiple heat transfer properties described in this section. 


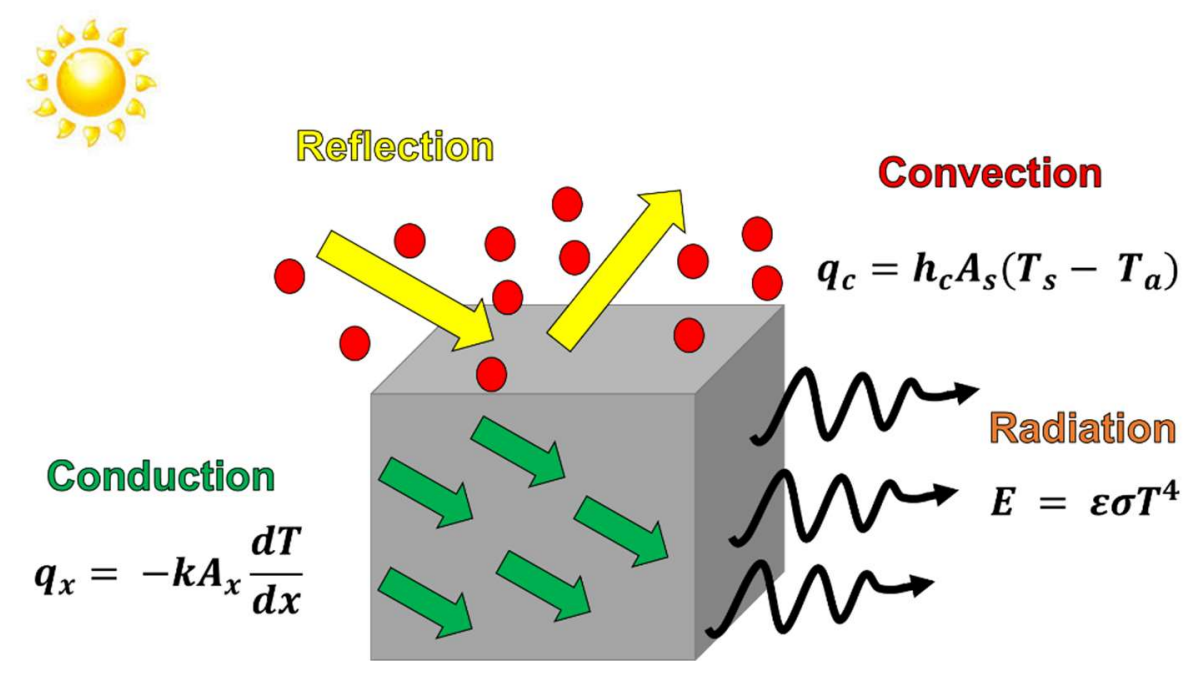

Figure 5 - Visual representation of heat transfer properties.

\subsubsection{Effect of Concrete Cover}

In addition to the previously described properties of heat transfer, the depth of concrete cover between an infrared instrument and a delamination can dramatically affect the surface temperature differential [12]. This is due to a reduced temperature differential with delamination (target) depth.

In 2000, Maldague published findings that suggested that deeper defects would be detected later in time with a lesser contrast when compared to more shallow defects [13]. His findings can be described by this relationship:

$$
t \approx \frac{z^{2}}{\alpha}
$$

Equation 7

$\mathrm{t}=$ observation time

$z=$ delamination (target) depth (meter)

$\alpha=$ material thermal diffusivity $\left(\frac{\text { meter }^{2}}{\text { time }^{2}}\right)$

Maldague also proposed a relationship between the reduction in thermal contrast and increased depth. This relationship can be described by the equation: 


$$
c \approx \frac{1}{z^{3}}
$$

Equation 8

$\mathrm{c}=$ loss in thermal contrast due to defect depth $\left(\frac{{ }^{\circ} \text { Kelvin }}{\text { meter }^{3}}\right)$

$z=$ defect depth (meters)

Maldague suggests that for theoretical test setups, the radius of the defect under testing should be one to two times larger than its concrete cover. This is only valid for homogenous isotropic materials, as anisotropy is more complex [13]. These results can act as a generalized case for the behavior of the entire concrete structure.

\subsubsection{Environmental Effects}

Civil structures are exposed to the environment, therefore, several factors affecting heat transfer must be considered. These factors affect the ability of thermography to detect subsurface defects. It is agreed that solar loading, temperature changes, and wind speed have the greatest impact. Some literature presents relative humidity as a factor, but on a lesser scale [14].

One of the largest factors in creating thermal gradients in concrete structures is solar loading [8]. Radiant energy is emitted from the sun and comes in contact with a concrete surface. The surface area soaks up the radiant energy, which causes the material to increase in temperature. For concrete, the surface of the material heats up at a faster rate than the core, causing a thermal gradient. From physics it is known that materials want to achieve equilibrium. To achieve this, heat must transfer through the thickness of the concrete (conduction) until it

achieves thermal equilibrium throughout the specimen. Solar loading can be described as the radiant energy emitted from the sun at any point in time. 
The difference in the air temperature surrounding a concrete structure will also cause a thermal gradient. During the early morning and into the early afternoon, when temperatures are typically increasing, the air temperature is usually higher than that of the concrete. Heat is then transferred into the concrete as to create thermal equilibrium with its surroundings [10]. As described in the previous paragraph, this causes a thermal gradient between the surface and core. The larger the difference in temperature between the air temperature and the concrete specimen, the larger the thermal gradient. Consequentially, the diurnal weather patterns that cause the ambient temperature to change is a main contributor to the detectability of subsurface defects and is a reason why defects are detectable even when solar loading isn't present [8]. In other words, it isn't the ambient temperature that has a large effect on the thermal gradient of the specimen if it is in equilibrium with the environment. If the ambient temperature was constantly at $60^{\circ} \mathrm{F}$, or constantly at $32^{\circ} \mathrm{F}$, the concrete would also be that temperature with no thermal gradient. In contrast, if in the morning the ambient temperature is $32^{\circ} \mathrm{F}$ at $6: 00 \mathrm{AM}$ and increases to $60^{\circ} \mathrm{F}$ by $12: 00 \mathrm{PM}$, a thermal gradient would exist. The thermal gradient would be identical if the temperature changed from $42^{\circ} \mathrm{F}$ to $70^{\circ} \mathrm{F}$, or from $52^{\circ} \mathrm{F}$ to $80^{\circ} \mathrm{F}$ during the same period of time, assuming the initial core temperature was identical in both cases.

\subsubsection{Infrared Instruments}

\subsubsection{Overview}

Infrared cameras produce images of the thermal distribution across the surface of the object being imaged. These images can be taken accurately from 
distances of 100 feet or more away from the area of focus to be imaged depending on the camera lens that is being used [4]. This technology can improve the quality and safety of inspections without the need for traffic control or hands-on access. Recently, two advanced infrared cameras and their processing programs have been developed. Each of these can be used for varying environmental conditions or accessibility restrictions.

The following section outlines three distinct types of infrared instruments;

the hand-held camera, the IR-DSS system, and the IR-UTD system. The hand held and IR-DSS systems will be described to give background information on previously utilized infrared instruments and their uses. The IR-UTD system is the system that this research will focus on, and the following section will describe why this system is the best option for this research.

\subsubsection{Hand-Held Infrared Camera}

This section is included to give background information on previous and other commonly used infrared technologies. The hand-held camera was the first and still the most commonly used form of infrared instrumentation. The hand-held infrared camera is lightweight, compact, and able to be used for hours at a time without tiring an inspector. Figure 6 displays an image of a typical hand-held infrared camera, the FLIR T620. Developing methodologies for bridge deck inspections by use of a hand held infrared camera was the starting point for using infrared technologies for the inspection of civil structures.

When applied to bridge inspections, it can produce images along the roadside without the use of traffic control. Images of the underside of the bridge 
deck (i.e., the soffit) can be taken from the ground level as well. The produced IR images reveal subsurface defects within the bridge deck; displayed as a thermal variation in the infrared image as shown in Figure 7. As previously described, the subsurface damage in a bridge deck is typically caused by the expansion of the reinforcing steel bars when they start to corrode, though there are also other environmental issues that cause subsurface defects such as traffic loading, chlorides, and others.

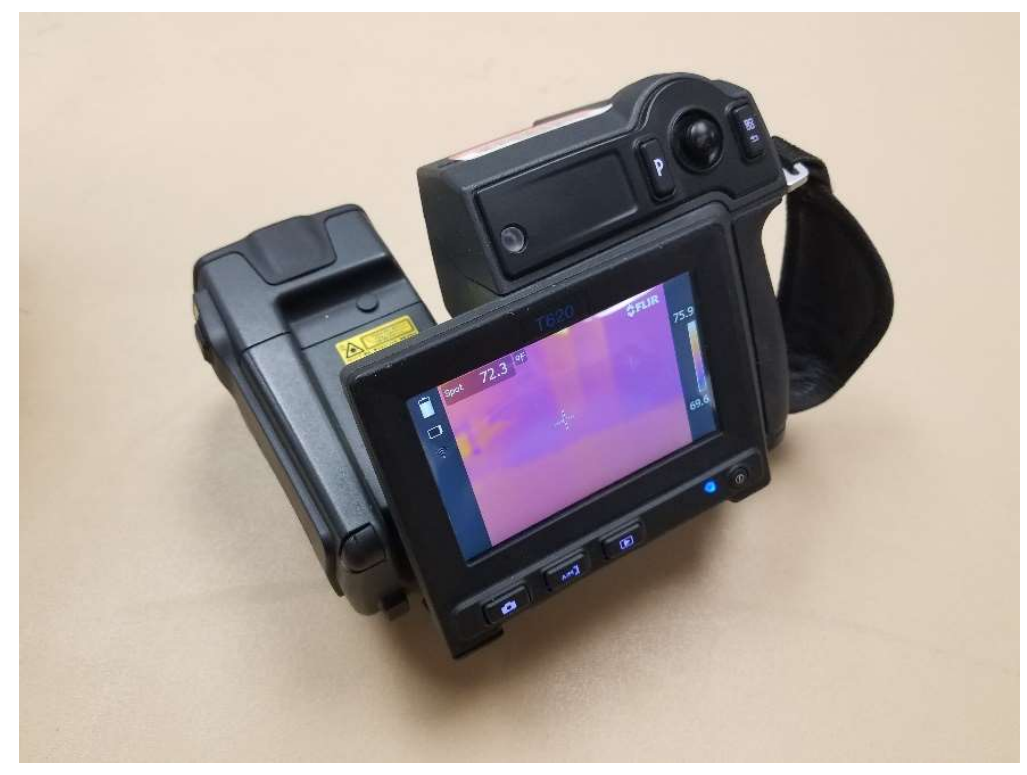

Figure 6 - FLIR T620 hand-held infrared camera.

Figure 7 shows a photograph of an area of a bridge being inspected that appears to be in good condition on the surface. Figure 7B is an IR image of the same area of bridge deck Figure 7A is imaging. Figure 7B shows the thermal distribution across the surface of the bridge deck, with the reddish-white area indicating a higher thermal signature (i.e., a subsurface delamination). Both Figure 7A and Figure 7B were captured simultaneously with the handheld camera along the roadside while the bridge was still open to traffic. Delaminations detected 
through IR are then confirmed by an additional inspection technique. Though this section has only outlined the hand-held cameras use in bridge deck inspection, it serves as a baseline to show the applications for this technology go far beyond a singular application.

Due to the inherent nature of infrared radiation, the inspector must be in the right place at the right time. That is, the inspector needs to be physically close enough to a defect near its peak values to not only detect the defect, but to accurately estimate the size and depth of the defect.
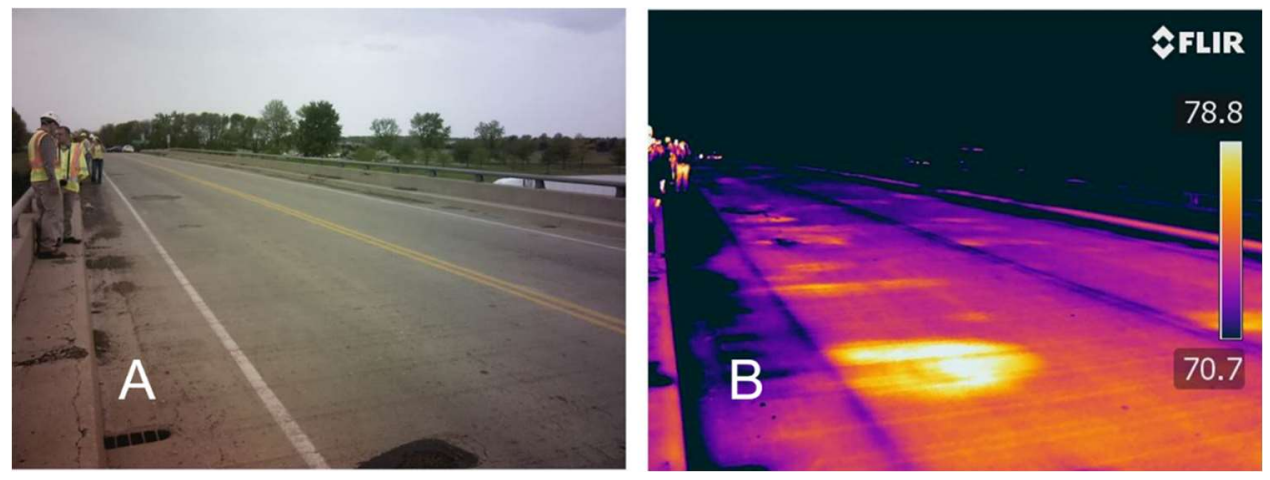

Figure 7 - Image of a bridge deck (A) and an IR image (B) of the same bridge deck area showing a subsurface defect.

\subsubsection{Infrared Deck and Soffit System (IR-DSS)}

This section is included to give background information on previous and other commonly used infrared technologies. The IR-DSS system is not unlike a handheld infrared camera, except that it is bolstered by additional equipment. The IR-DSS system was previously developed to reduce the inspection time on bridge decks, tunnels and other civil structures. This system has been used in the past to inspect local bridges under the jurisdiction of the state of Missouri. 
Figure 8 shows a photograph of the IR-DSS testing system setup. The figure shows a camera bolted to a plate, attached to a mast, which is connected to the hitch on the truck. The camera collects data from 10 feet above the surface of the deck and collects a visual and infrared image. An encoder wheel, which is attached to the base of the frame, connects the camera and itself to both the data acquisition (DAQ) module and the visual display via a cable. The interactive display and DAQ system have a long cable and can be placed in a convenient location inside the cab of the truck. This allows for the IR-DSS system to be controlled by an individual located within the cab of the vehicle.

The IR-DSS system can be mounted on any vehicle with a standard 2-inch tow hitch, providing ease of use on most trucks. The system can also be mounted on many additional moving devices due to a camera head mount that allows for multiple orientations of the system. This allows for the system to be used in small spaces where a traditional vehicle can't access, such as a culvert. Since the camera head can be rotated, bridge soffits can also be inspected by inverting the camera head and driving beneath the bridge.

The IR-DSS system collects both visual and infrared images. The interactive display allows the user to enter preset distances of when these images are to be collected along the traveled path. A proprietary program then spatially connects these images to form a singular aerial view image. An example of the final output is displayed in Figure 9.

Due to the inherent nature of infrared thermography, identical to that of the hand held infrared camera, the inspector must be physically present at the correct 
times of the day to detect defects. Though using the IR-DSS system allows the inspector to cover exponentially more surface area when compared to the handheld camera, it is still limited to only being beneficial during only certain time periods each day.

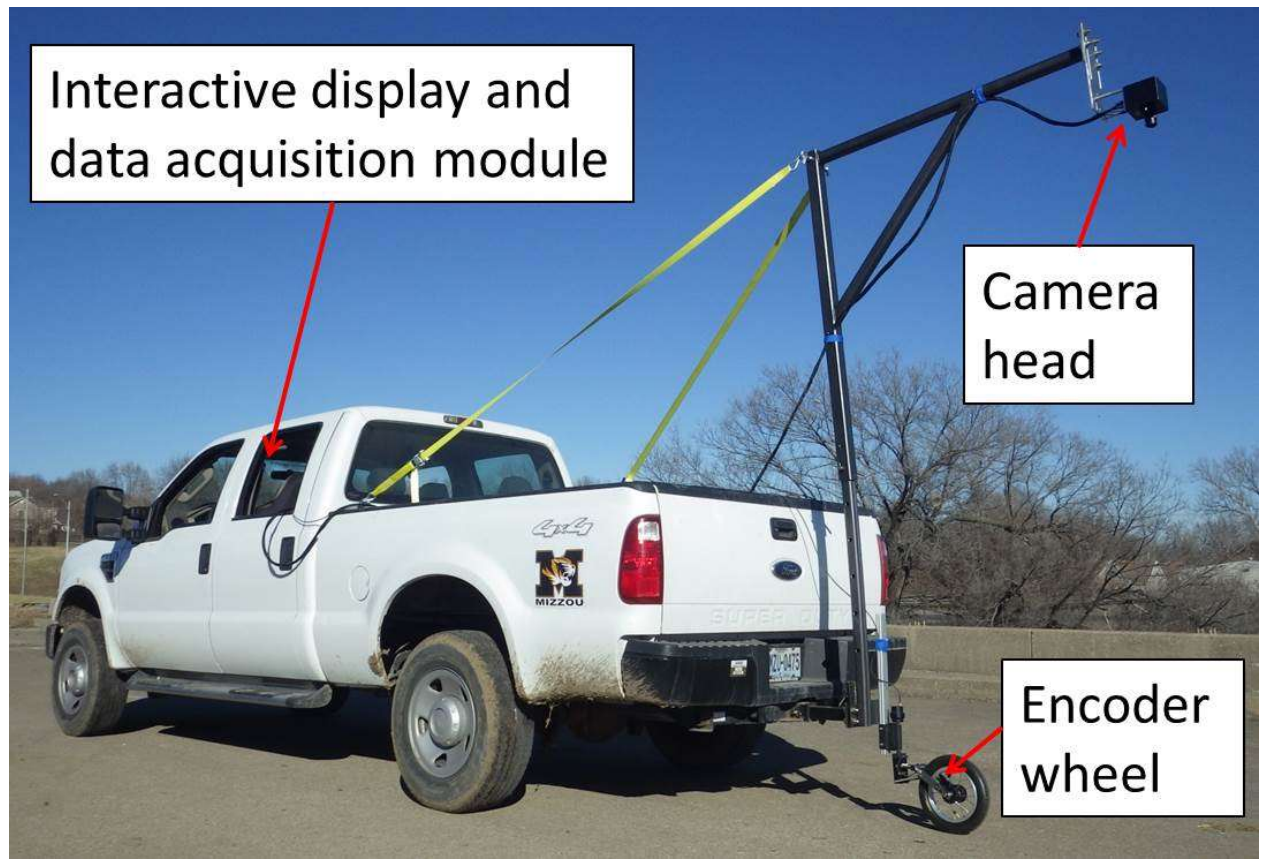

Figure 8 - Setup of the IR-DSS system on a truck. 


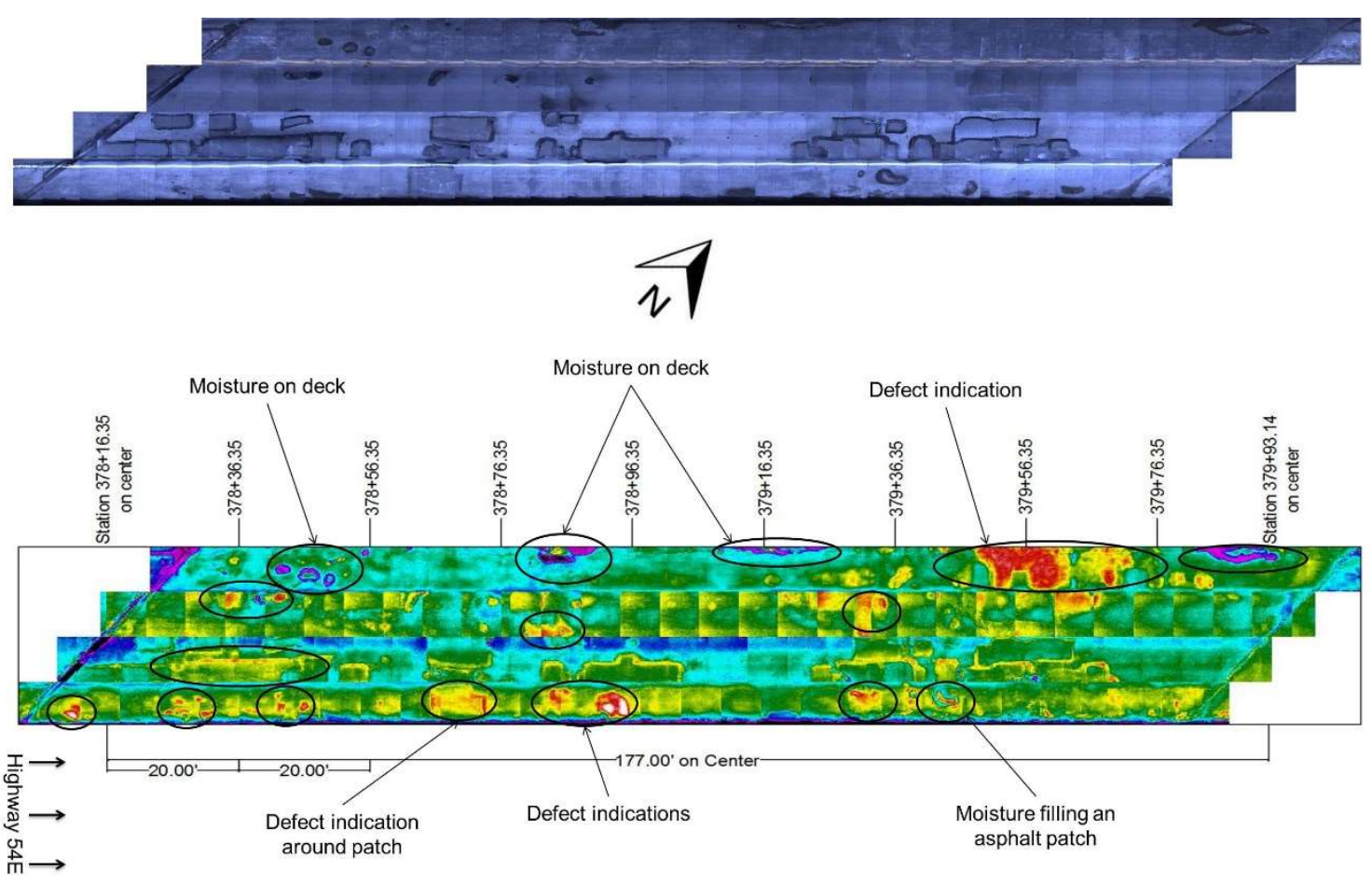

Figure 9 - Analyzed IR-DSS data.

\subsubsection{Infrared Ultra Time Domain (IR-UTD)}

Unlike the hand held and IR-DSS infrared systems, the IR-UTD system is not as restrictive when it comes to inspection intervals. This system can be set up in the field to collect sequential images at a pace selected by the inspector. Collecting these sequential images allows the system to consider the change in thermal inertia over time. All of the images can then be processed by a proprietary program that will allow for the defects to not only be detectable, but the size and depth could be accurately determined. Due to the nature of the processing techniques used, the IR-UTD system is better equipped at not only detecting defects that heat and cool at different rates when compared to surrounding sound portions of material, but it can also create more well-defined images than a typical IR camera. 
As the depth at which the defect is located inside of the specimen increases, the rate and magnitude of heating and cooling at the surface changes. This also changes when a defect is located inside of a separate material. Since the IR-UTD system has the capabilities to detect subtle changes in heating and cooling over the course of time, this technology is ideally suited for cases such as this. Because of these benefits, this is the technology that will be utilized and discussed throughout this report.

The Infrared Ultra Time Domain (IR-UTD) system has been designed to be operable on several field testing setups according to available space and restrictions. The IR-UTD camera can be bolted to a pole that is then attached to a bridge parapet; the camera can be hoisted into the air to collect data without interfering with traffic. Figure 10 shows all the various parts that make up the IRUTD system.

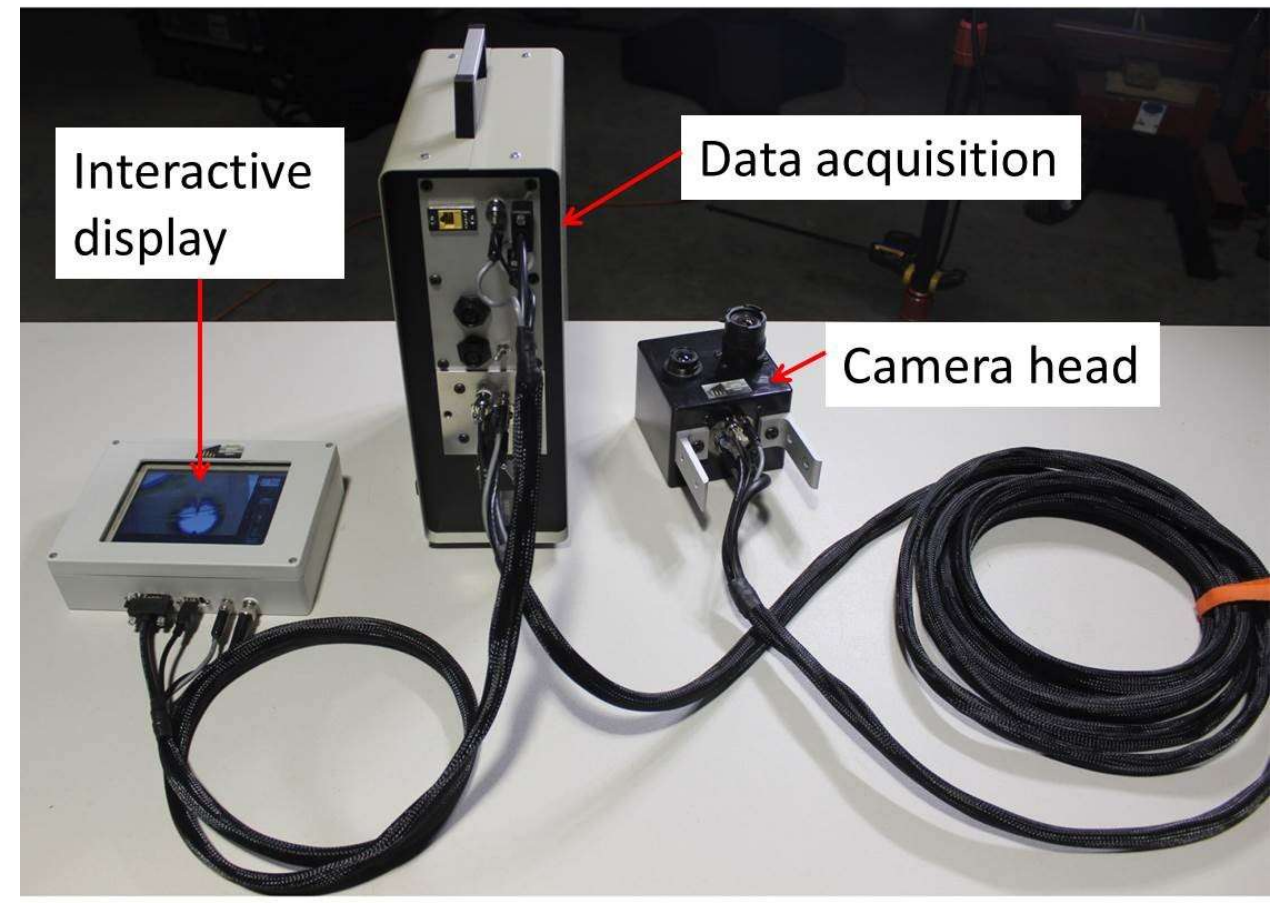

Figure 10 - All of the base parts that make up the IR-UTD system. 
Figure 11 shows the IR-UTD system set up on a light pole base. Another field testing setup is shown in Figure 12, which shows that the camera can be attached to a portable mast system that can be moved via a tow hitch. This setup can be set up off of the bridge deck or in the breakdown lane, and can be easily moved if needed. Both IR-UTD setups house a secure Data Acquisition (DAQ) enclosure for equipment security.

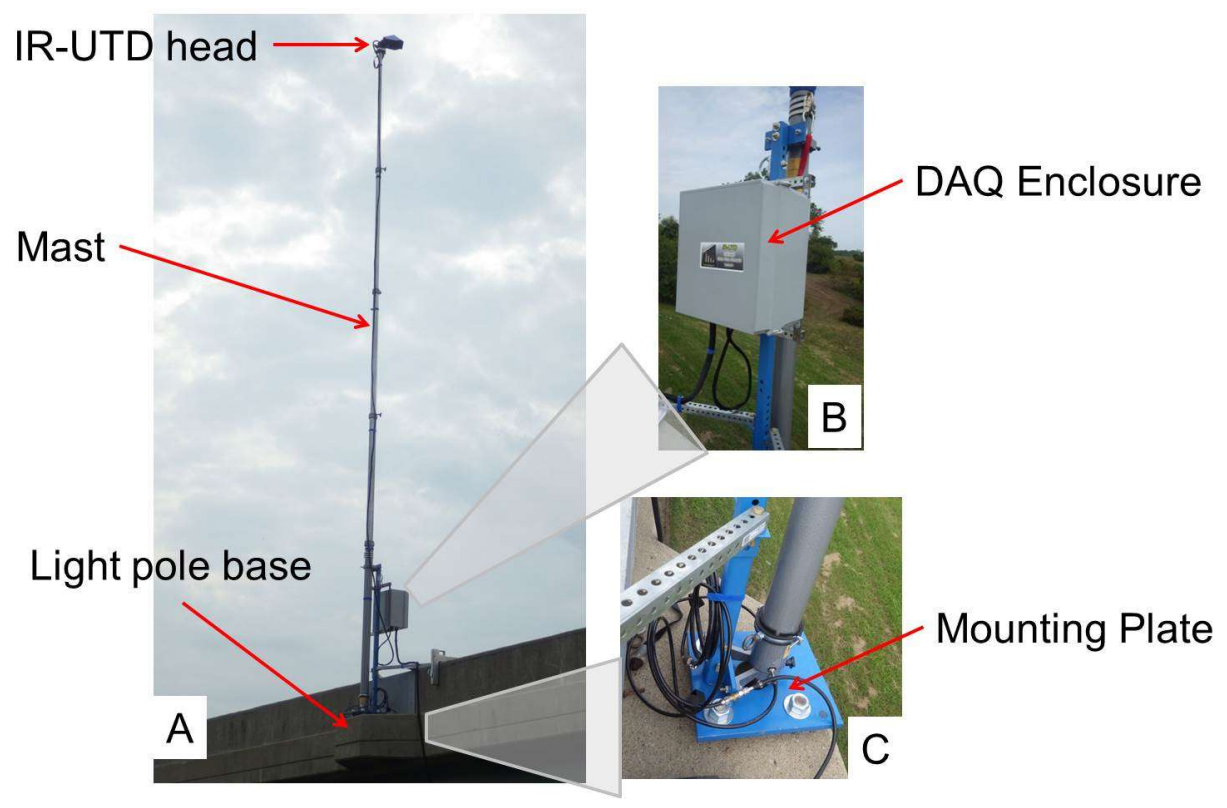

Figure 11 - Image of the IR-UTD system mounted on a light pole base. 


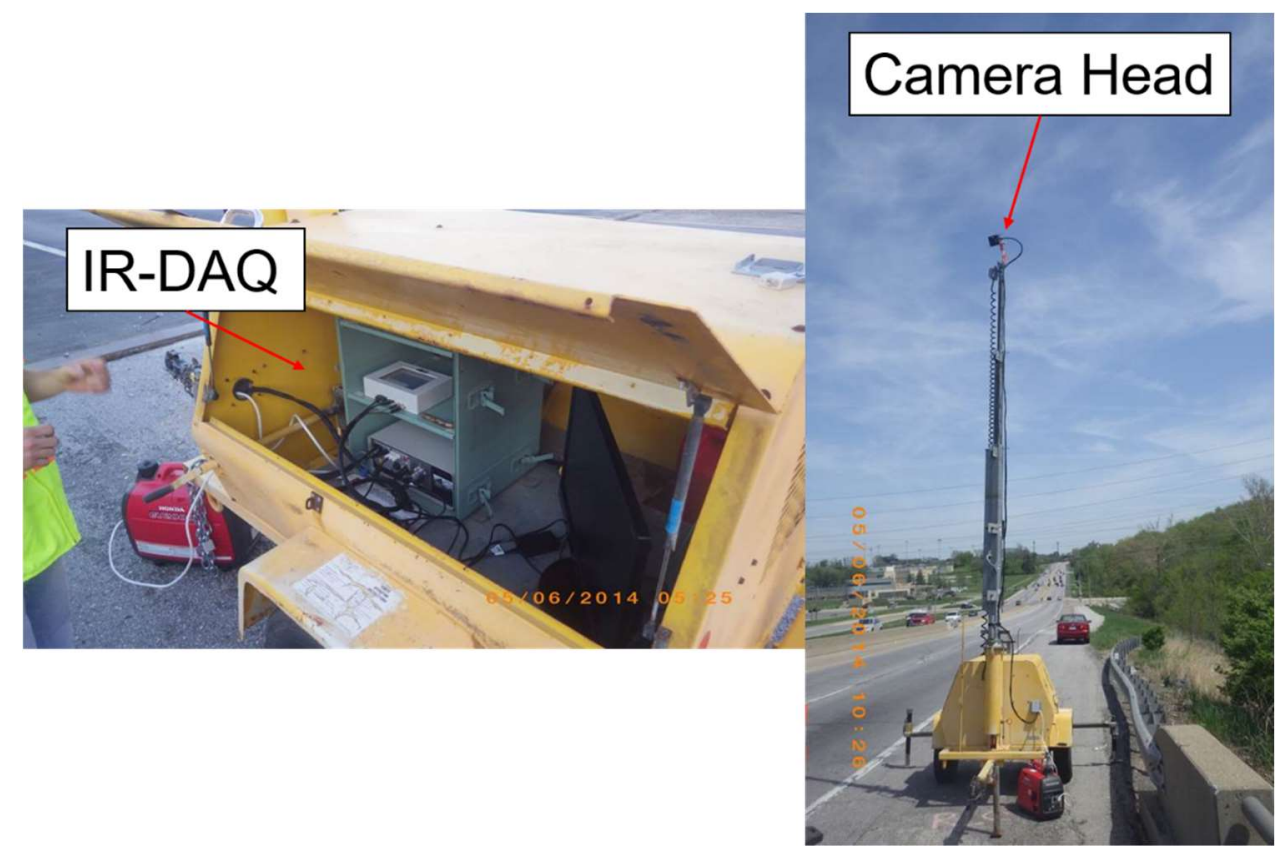

Figure 12 - IR-UTD system set up in a portable DAQ system alongside the roadway.

Figure 13 shows how large areas (or full bridge decks) can be analyzed with relative ease. Once the images are collected, they are analyzed using a proprietary program to identify differences in the thermal behavior of the concrete. The differences are then analyzed more closely with the visual images to determine if they were caused by subsurface defects, moisture, loose materials, or other anomalies which would cause these results. Perceived subsurface defects can be verified through additional void detection technologies. Since the IR-UTD is a thermal gradient based system, it has seemingly endless applications and will be the technology featured in the remainder of this report. 


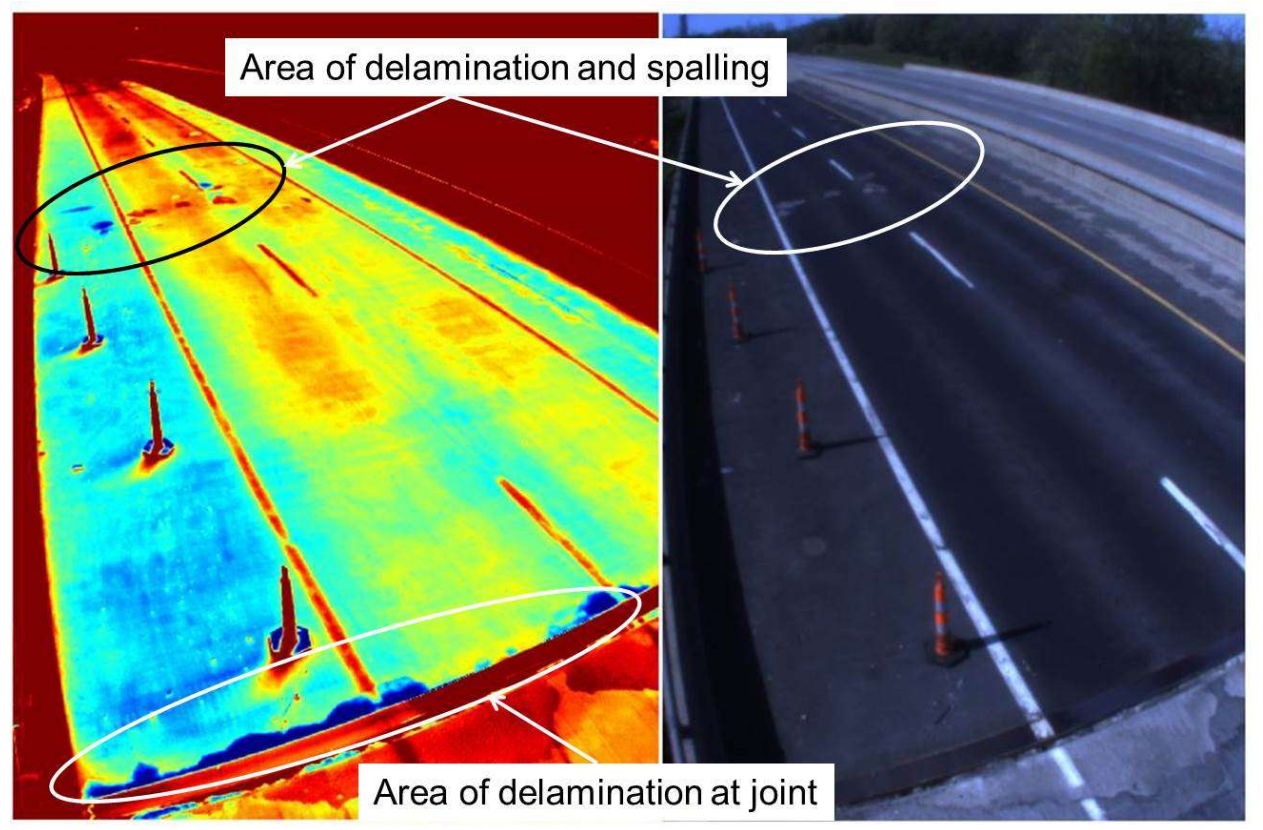

Figure 13 - Side by side infrared (left) and visual image (right) taken during testing.

\subsubsection{IR-UTD Case Examples}

The following section will give examples that demonstrate the advantages of transient thermography as compared to conventional thermography. These examples will also show that the IR-UTD system appears to produce more comprehensive results than a standard handheld infrared camera, and is comparable to standard testing techniques such as hammer sounding. The Midway test block was tested to observe the depth measurements effects of the IR-UTD system against a known condition, while the lowa bridge test was conducted to evaluate the capability of the IR-UTD system to detect delaminations in a bridge deck open to traffic. 


\subsubsection{Midway Test Block}

The purpose of the construction and testing of the Midway Test Block was to observe the depth measurement effects of the IR-UTD camera against a known condition. Subsequently, the IR-UTD system was used to compare the IR-UTD systems result to that of traditional infrared camera results. Styrofoam targets at known depths were placed into a concrete block for testing. Figure 14 shows the Styrofoam target locations before the concrete was poured.

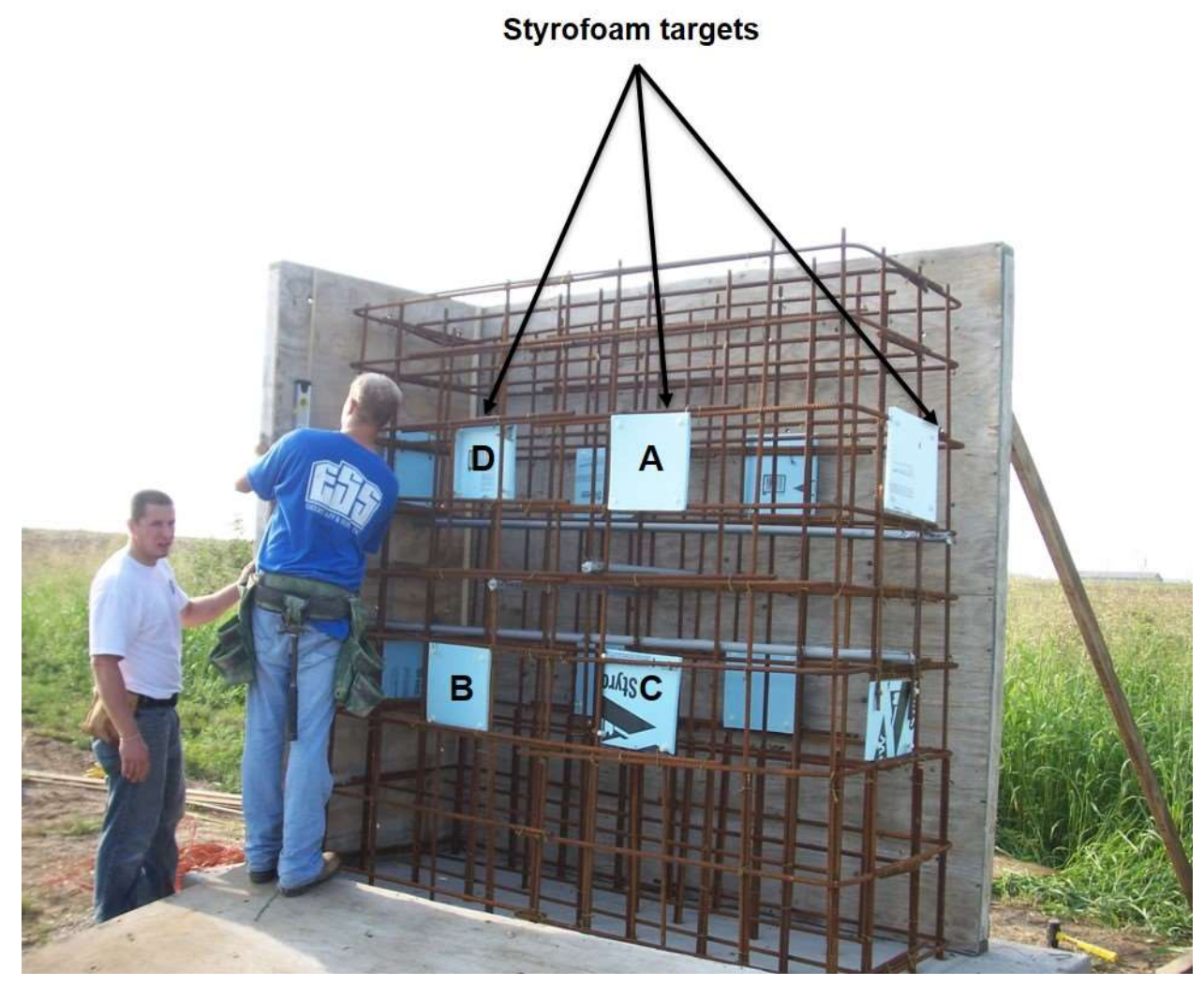

Figure 14 - Midway test block before the concrete is poured.

The target depths are 1" (25 mm), 2" (51 mm), 3" (76 mm) and 5" (127 mm) depths, corresponding, respectively, to the letters "A", "B", "C" and "D". These depths are of importance because they correspond to typical steel reinforcement depths in concrete bridge decks; where the majority of delaminations are formed. 
The test was conducted over a period of three days, from September $16^{\text {th }}, 2014$ until September 19th 2014 . Figure 15 represents the ambient weather changes during the three-day testing period.

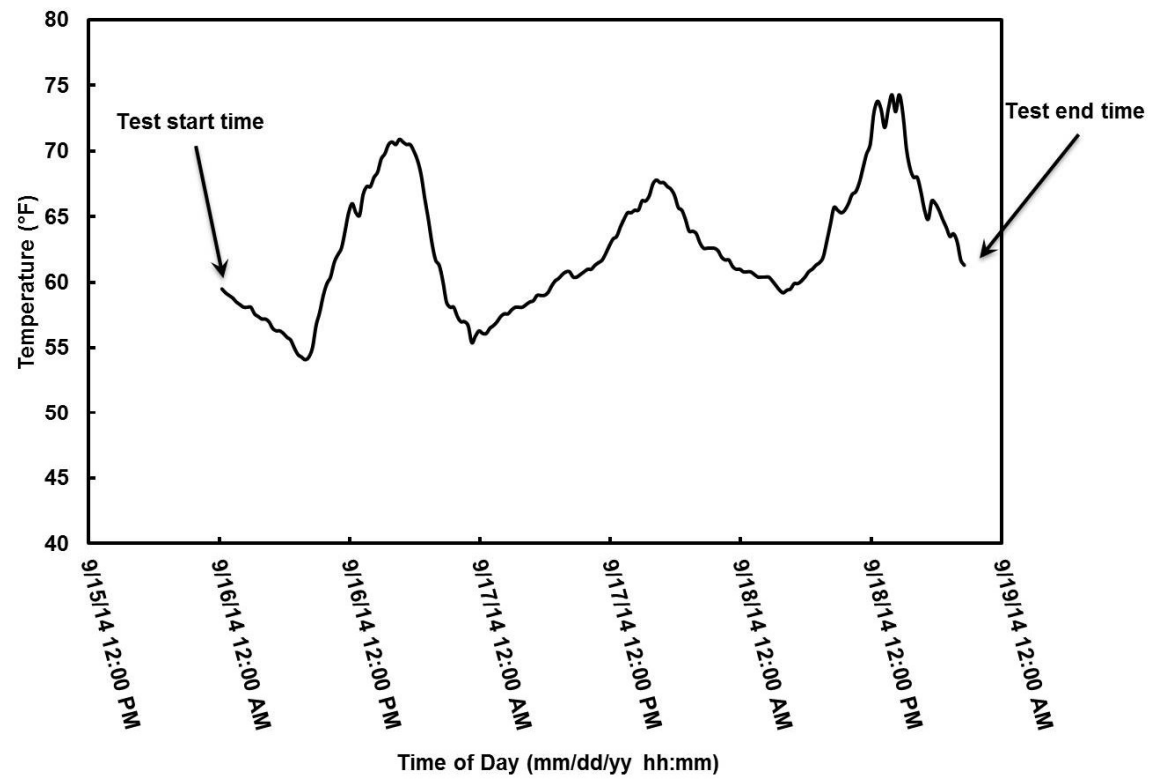

Figure 15 - Midway Test Block weather data from September 16, 2014 to September 19th, 2014.

Following the analysis of the concrete test block, comparisons could be made about the differences between conventional handheld infrared cameras and the IR-UTD system. Figure 16 displays the results from both the handheld infrared camera (left side) and the IR-UTD system (right side). Each of these images have labels $A$ through $D$, corresponding to the depth of the Styrofoam defects mentioned previously. Comparing these images side by side brings up several important characteristics. In the handheld image on the left side, target " $D$ " (5") is largely not observed. In the IR-UTD image, target "D" (5") can be observed. Not only is target 
"D" (5") observable in the IR-UTD image, but all of the other defect indications are more pronounced than the indications in the handheld infrared camera image.
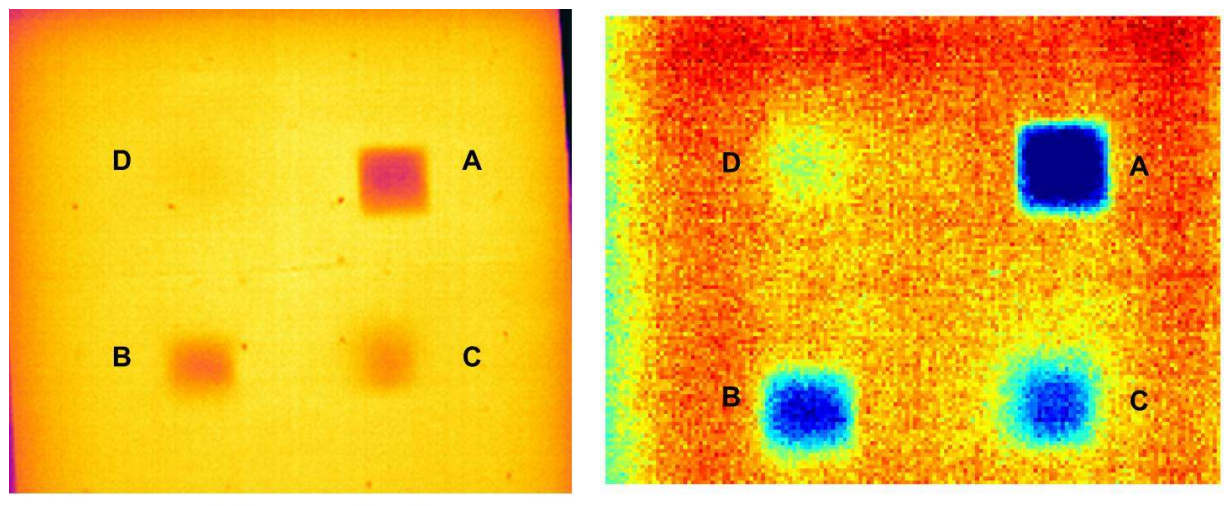

Figure 16 - Results from both the handheld infrared camera (left side) and the IRUTD system (right side)

The IR-UTD system delivers noticeably better results at each depth because, as previously stated, the IR-UTD system produces an image that considers the change in thermal inertia over time. The traditional infrared camera only considers the instantaneous thermal inertia detected in each pixel. When observing the results in order from most shallow to deepest, "A" to "D", there are noticeable differences in color. The shallowest Styrofoam piece takes on a dark shade of blue, while the deepest is a light shade of green. When comparing the results from the handheld camera and the IR-UTD system, the results produced by the IR-UTD system appear well defined. This shows that not only does the IRUTD system appear to be more accurate and more pronounced in terms of defect identification, but as the general depth of the delamination increases, a change in color is observable. 


\subsubsection{2 lowa Bridge}

The purpose of testing the lowa Bridge was to:

- Evaluate the capability of the IR-UTD system to detect delaminations in a bridge deck open to traffic.

The testing on the lowa Bridge started at 11:54 AM on September 8th, 2014. The IR-UTD system was mounted to the side of the bridge as shown in Figure 17, and was hoisted into the air, imaging approximately 3200 square feet of the bridge deck. Figure 18 shows the bridge deck area imaged by the IR-UTD system when hoisted into the air. Infrared data was collected and compared against data from the inspector. From these data, defect locations were determined, as well as general defect depth. 


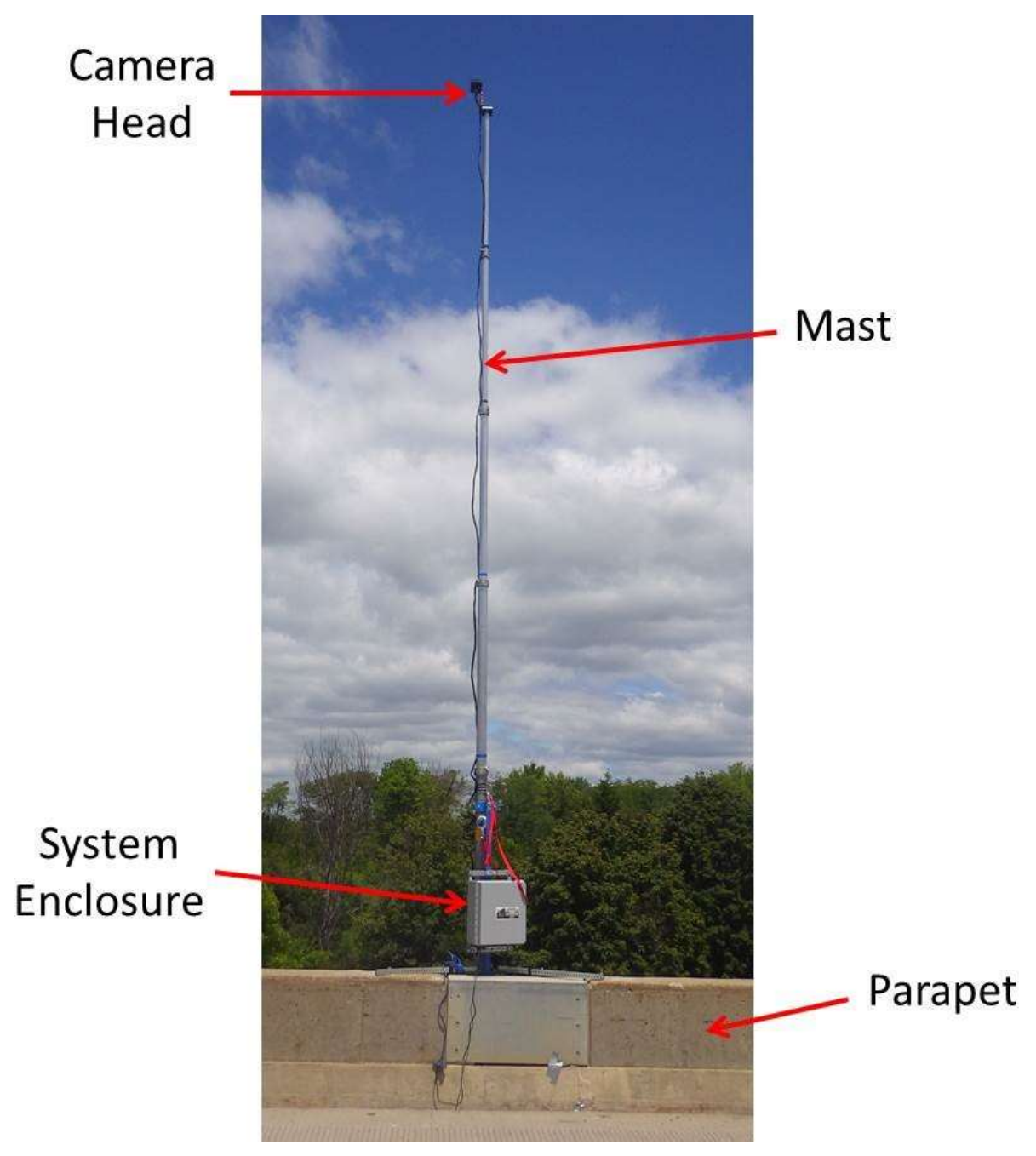

Figure 17 - IR-UTD system mounted on a light pole base on lowa Bridge.

Figure 19 displays the location of the delaminations determined by the IRUTD system. Drilling was also conducted on a specific defect on the bridge deck. Drilling was conducted to measure the depth of delaminations at this location. The drilling location and measured depths of each delamination can be seen in Figure 20 and Figure 21. In Figure 20, the infrared color data is compared to the depth of delamination at each drilling point. Figure 19 demonstrates the ability of the IRUTD to indicate the general depth of delaminations based on color; red being deeper and blue being more shallow under the color spectrum used. 


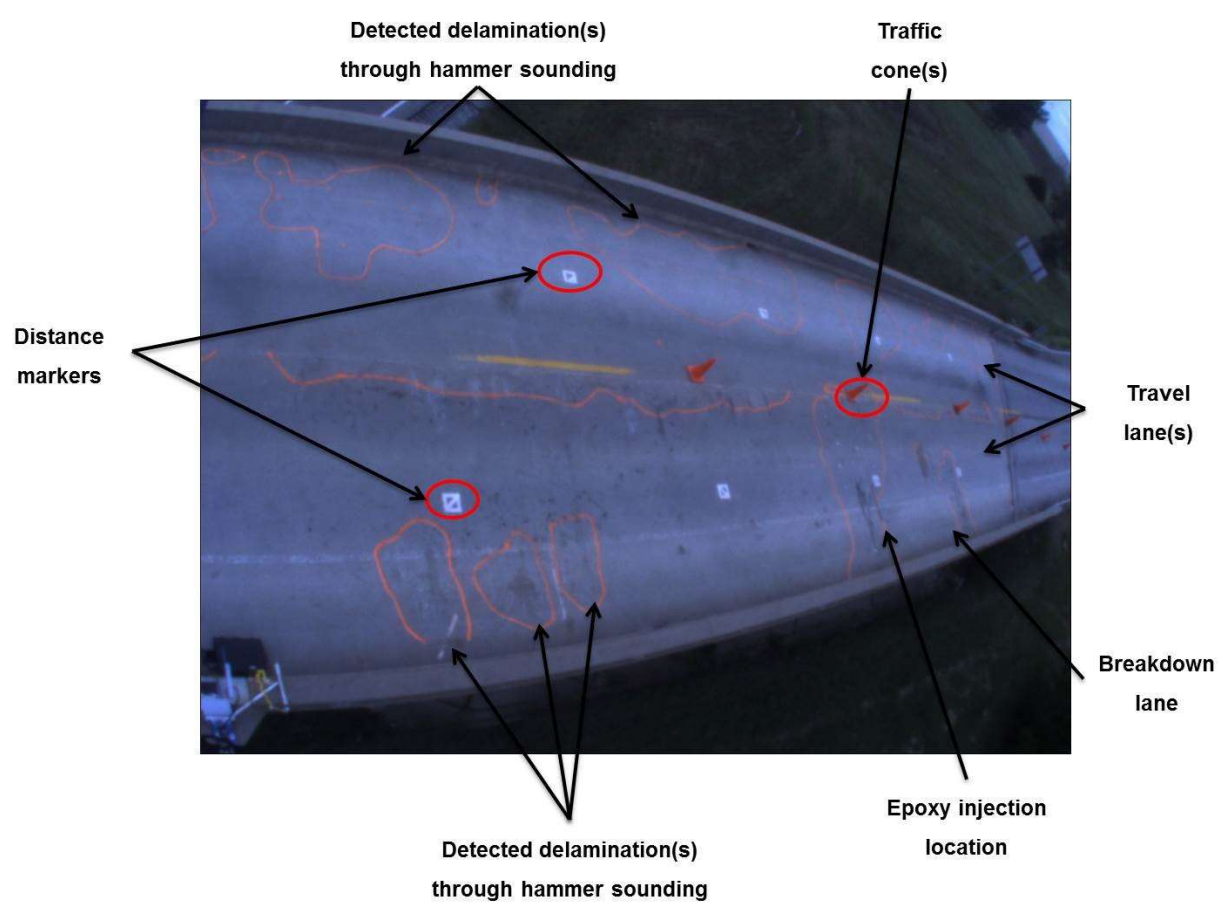

Figure 18 - View of the lowa bridge deck from the IR-UTD system camera.

Figure 21 is an image with three different pictures. From left to right, there is an infrared image of testing conducted on the lowa Bridge, a visual image with the hammer sounding results marked out on the bridge deck from a trained lowa inspector, and an overlay of the results of the two testing techniques. The camera angle in Figure 19 is different than that in Figure 21, but both images are nearly identical in spatial recognition of subsurface defects. Consequently, these data displayed the ability of the IR-UTD system to offer test repeatability. The results from hammer sounding and infrared testing are also nearly identical, highlighting the system accuracy when compared to a typically used inspection technique such as hammer sounding. Figure 22 is the weather data collected during the lowa Bridge Test. 


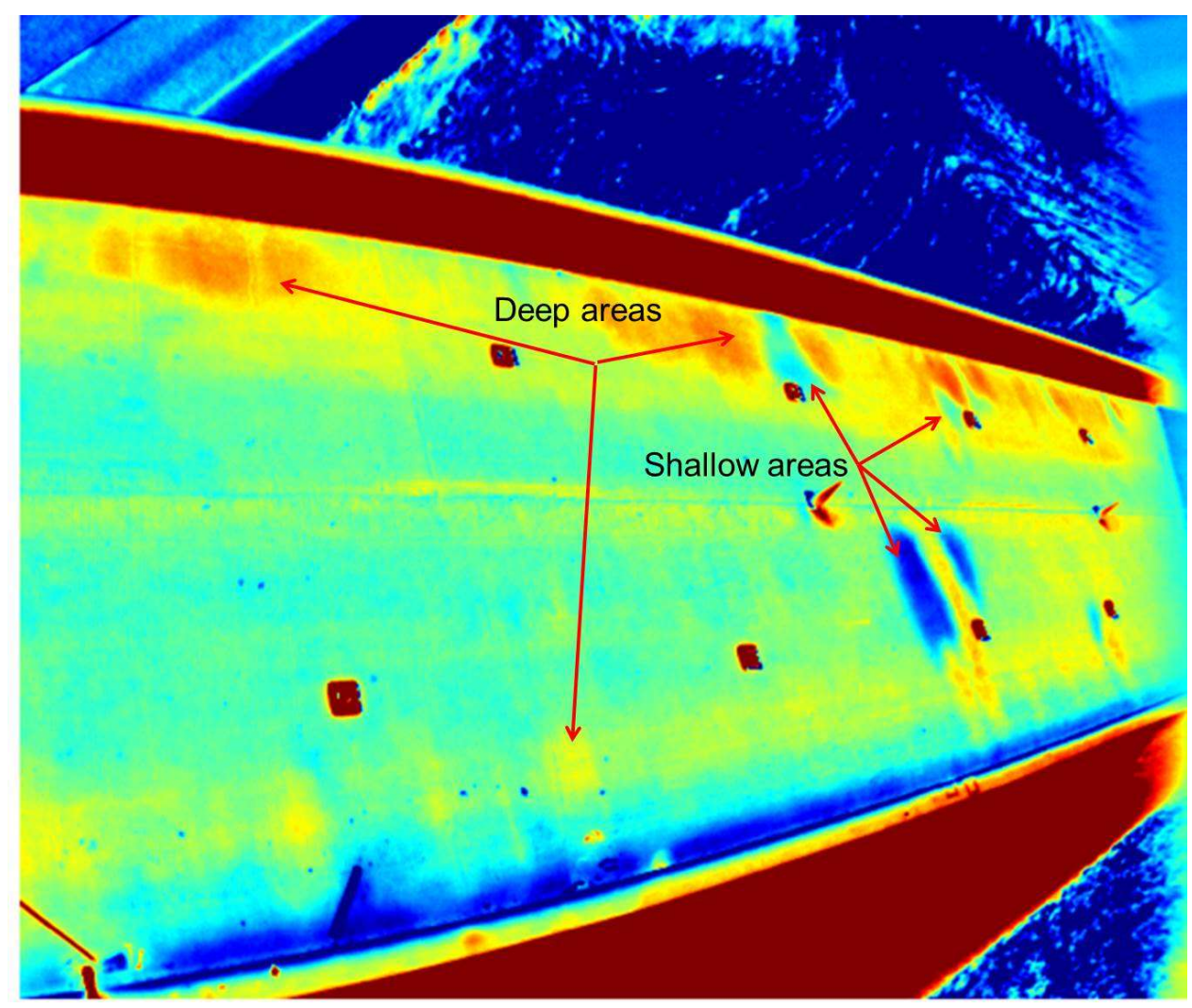

Figure 19 - Initial test results of the lowa Bridge.

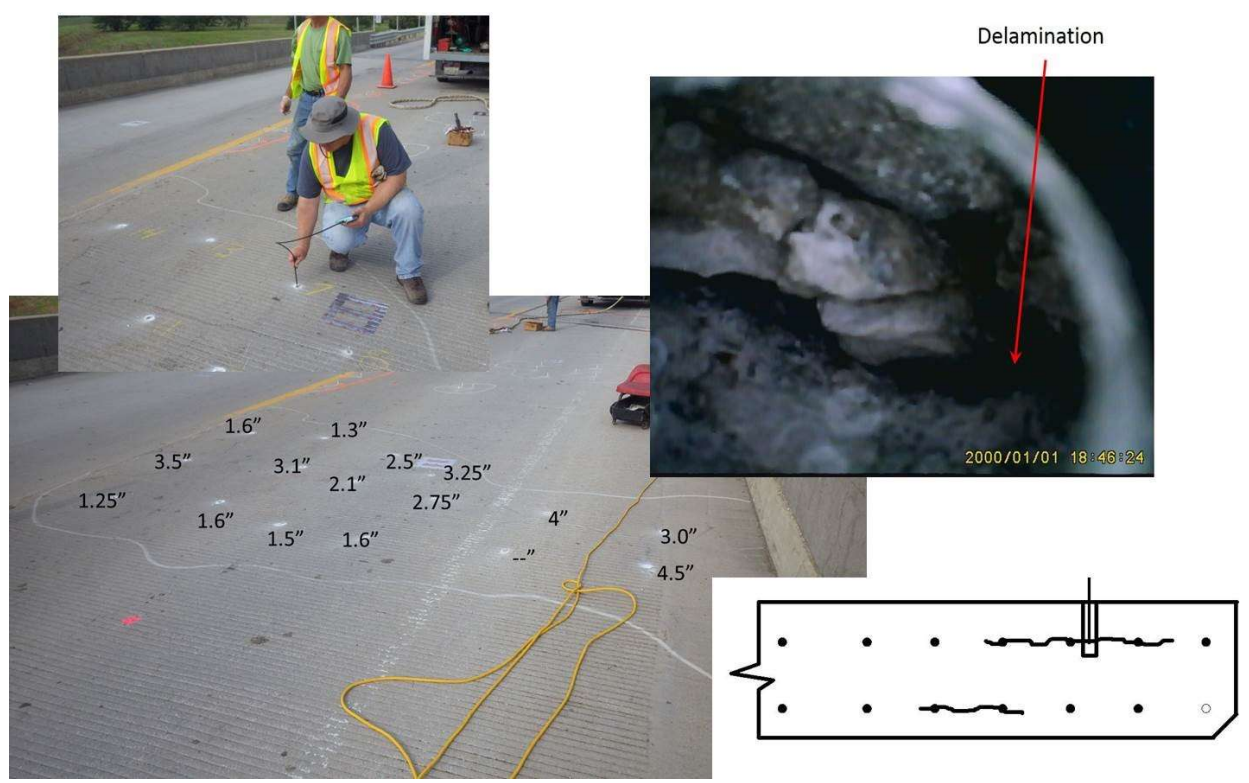

Figure 20 - Field drilling of a delamination accompanied by borescope image. 

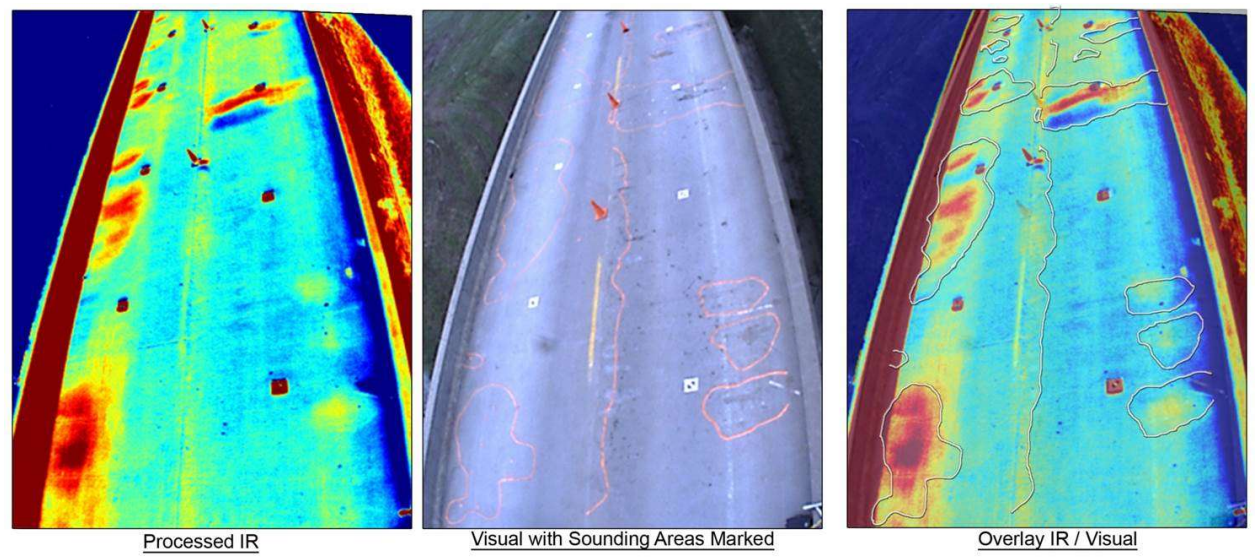

Figure 21 -From left to right; infrared image, hammer sounding image, overlay of both techniques.

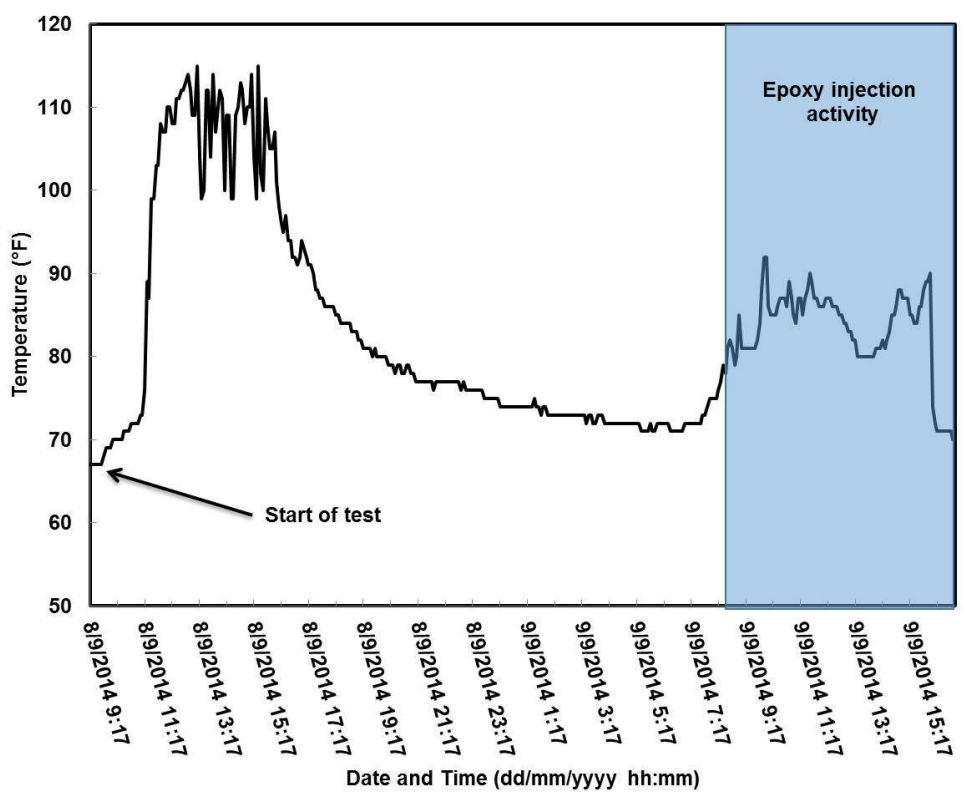

Figure 22 - lowa Bridge weather data.

\subsection{Additional Void Detection Technologies}

There are currently many state-of-the-art Nondestructive Evaluation (NDE) techniques being explored for the detection of voids in PT ducts including Ground Penetrating Radar (GPR), Impact Echo (IE), Electrically Isolated Tendons, Ultrasonic Methods, and Acoustic Emission among others. Nondestructive 
Evaluation (NDE) refers to evaluation techniques that do not alter the physical properties of the material being evaluated. The following section outlines the approach of each technology to this unique problem, along with their benefits and limitations.

\subsubsection{Ground Penetrating Radar (GPR)}

Ground Penetrating Radar is a commonly used technique for varying reinforced concrete applications. Figure 23 shows a ground-coupled GPR system consisting of an SIR-3000 data acquisition controller device, a $16000 \mathrm{~Hz}$ antenna and encoder to measure distance traveled. This instrument is being used to inspect a reinforced concrete bridge deck.

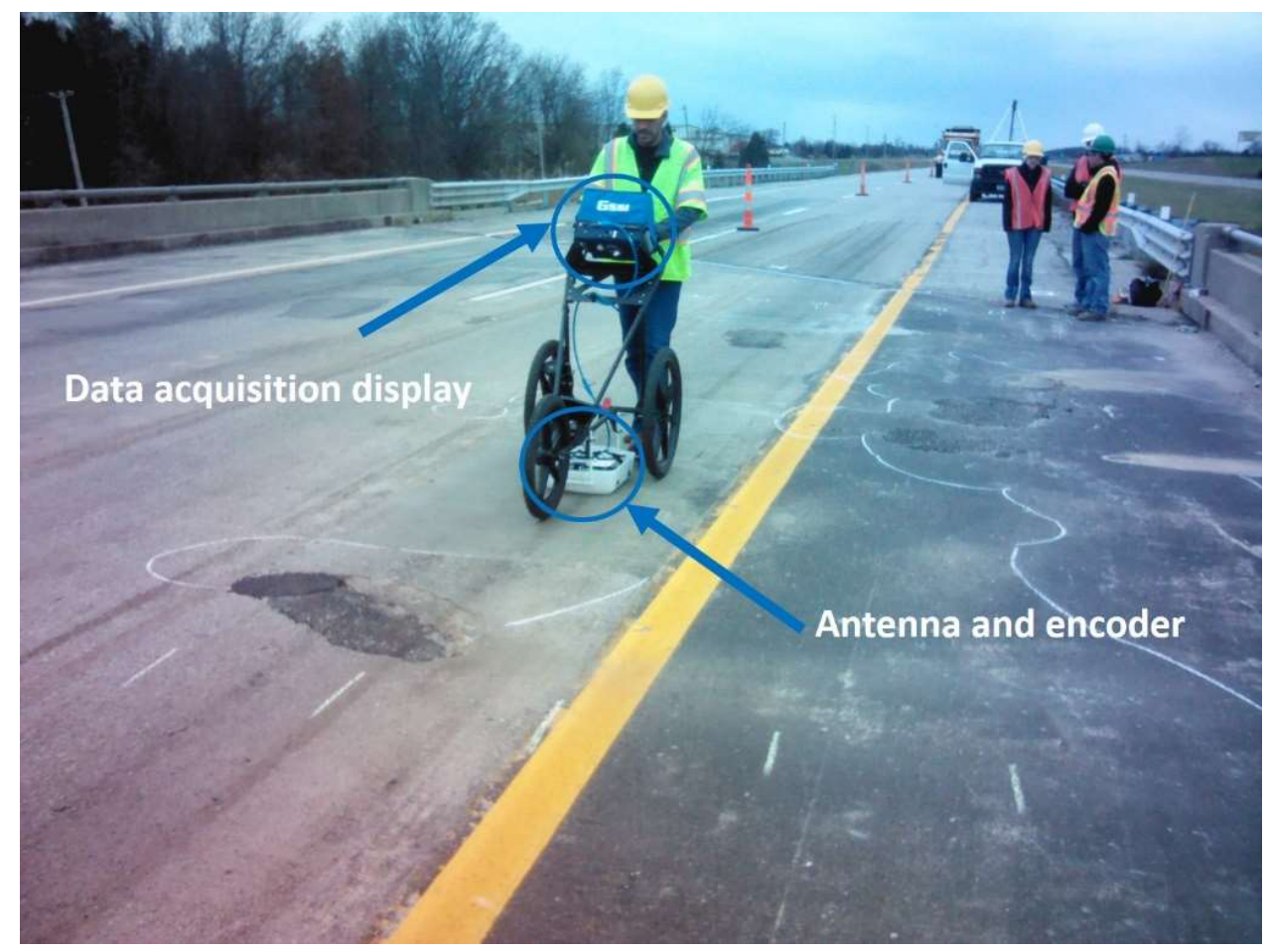

Figure 23 - Image of a ground-coupled GPR system inspecting a RC bridge deck. 
As the cart is moved, an encoder prompts the system to send an electromagnetic pulse into the structure at very high frequencies. The pulse that returns back to the receiving antenna is the reflection, or echo, from the point at which the material is no longer homogenous (air-material interface, different materials along the direction the impulse is traveling, metallic reinforcement in the concrete, airmaterial interface on the opposite side of the structure) [15]. These data are then recorded in the system based on the location of the received reflection. In this way, a 2-D geometric layout of reinforcing steel rebar, steel ducts, and other nonhomogeneous occurrences can be recorded [16]. A drawback of GPR is that multiple layers of overlaid metallic materials cannot be detected as the electromagnetic wave will reflect off the first defect, leaving the underlying defect

undetected. Additionally, for realistic results, the temperature of the material, the moisture content, the salt content, pore structure, and pulse frequency are all needed to determine the propagation time of the impulse, and therefore, the location/depth of the reflected surface [17].

\subsubsection{Impact Echo (IE)}

Impact Echo (IE) is a very commonly used stress wave propagation method [18]. Figure 24 shows an IE machine being used to detect subsurface delaminations in a reinforced concrete bridge deck. 


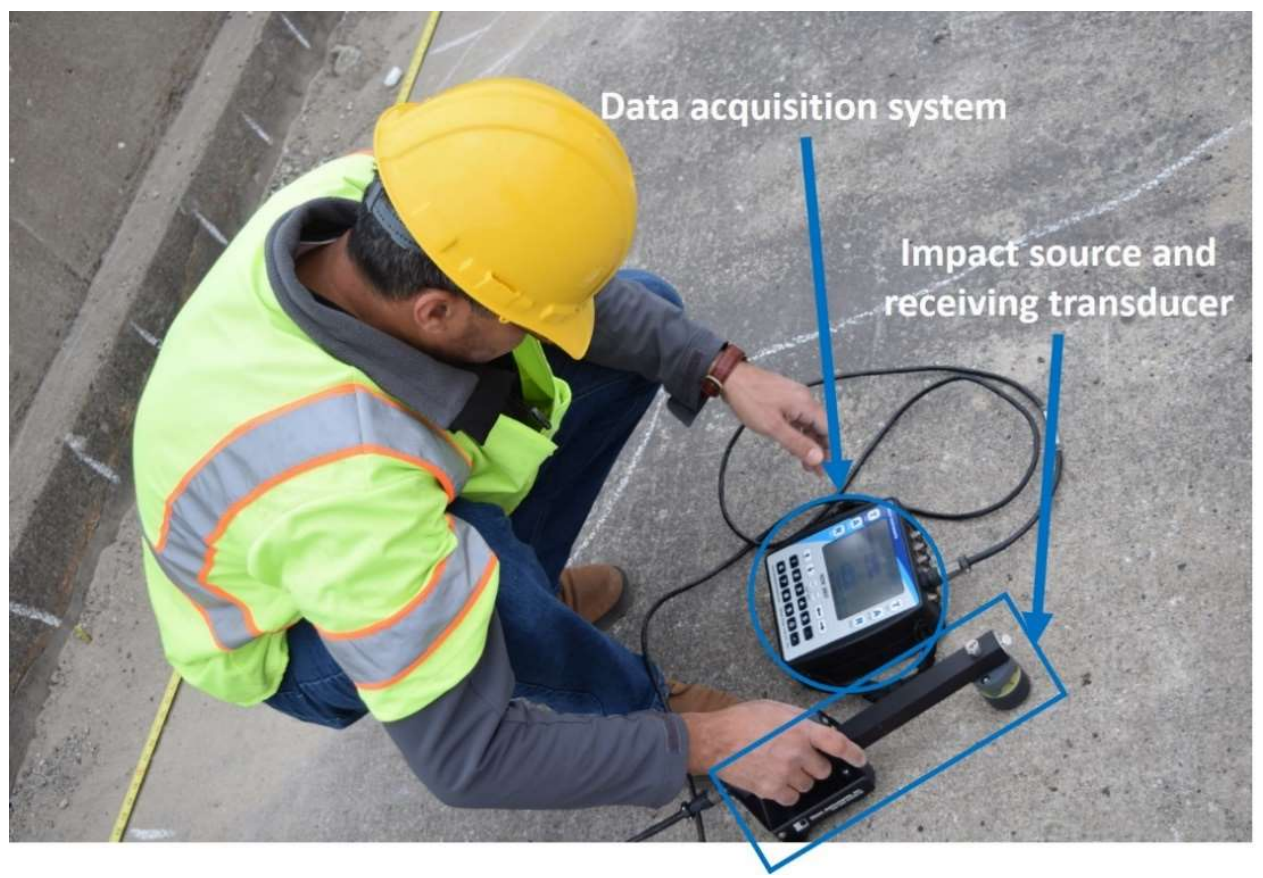

Figure 24 - Image of IE being used to confirm a subsurface delamination in a reinforced concrete bridge deck.

A stress wave is induced when the IE machine strikes the surface of the structure; this creates an $S$ (shear), $P$ (pressure), and $R$ (Rayleigh) wave [19]. In this application, the P-wave phenomenon is of the most interest. Not unlike the GPR's electromagnetic pulse, the P-wave is sent into a structure to be reflected back to the IE's receiver. The P-wave will be reflected back at the interface of materials that have differing acoustic properties [19]. If the speed of the P-wave acting in the material is known, the location of non-homogeneous materials (subsurface defects, material interface, honeycombing, etc.) can be detected $[18,20]$. These data can then be graphed in 2-D or 3-D images to better visually display the results [21]. A drawback of IE is that multiple layers of overlaid metallic materials cannot be detected as the stress wave will reflect off the first defect, leaving the underlying 
defect undetected. Also, as shown in Figure 24, IE is typically done by hand and requires a large amount of time and effort on the part of the inspector.

\subsubsection{Electrically Isolated Tendons}

Electrically Isolated Tendons refers to a monitoring system that improves and tracks the corrosion protection of the high-strength steel tendons during the service life of the structure. The corrosion protection is improved by using thick corrugated plastic ducts, as opposed to galvanized steel ducts. This creates a tight envelope that helps to avoid chloride ingress to the high strength steel and avoid stray electrical current on the tendon steel [22]. Corrosion protection monitoring is achieved by recording the impedance between the tendons and the concrete-reinforcing rebar. This monitoring can be accomplished by use of an LCR

meter, which measures the inductance $(L)$, capacitance $(C)$, and resistance $(R)$ between two metallic materials. Figure 25 shows the general principle behind measuring the electrical impedance of a PT tendon with an LCR meter.

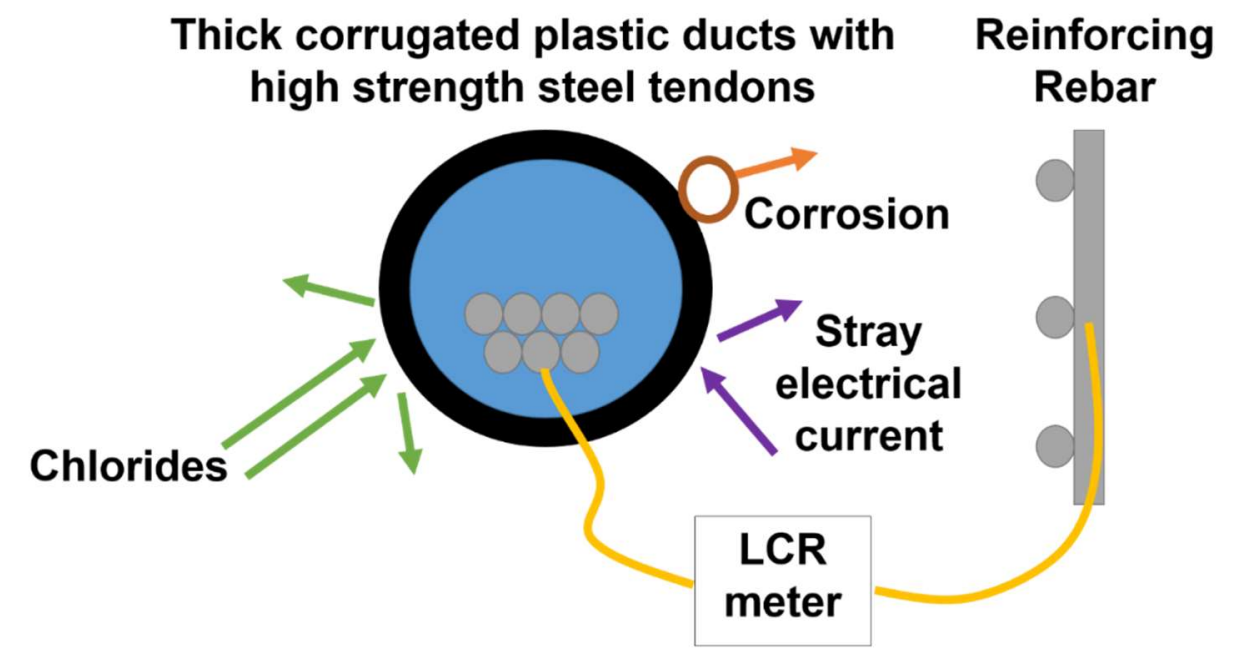

Figure 25 - Image displaying a general concept behind how the impedance measurements would be collected when using Electrically Isolated Tendons. 
When an AC current is applied to the tendons, an electric field is created that can then be detected by the monitoring system that is set up on the anchors on both ends of the duct. In this way, when a defect occurs (short circuit, chloride ingress, etc.), the location of said defect can be pin-pointed along the length of that duct where the current is leaving the strand. However, typical PT structures have tens if not hundreds of ducts, creating a need for constant large-scale data collection and analysis. Another limitation is that this monitoring system can only be implemented while using plastic ducts to house the high-strength steel tendons, as steel ducts would cause incorrect impedance readings [23]. This monitoring system is typically implemented before the start of construction to ensure proper installation, although retrofit options on select previously built structures are available [24].

\subsubsection{Ultrasonic Testing (UT)}

Ultrasonic testing (UT) uses high frequency sound energy to examine and characterize material properties. At the upper bound, ultrasonic testing can be used in a destructive manner, such as cutting or cleaning materials. However, when used for Nondestructive Testing, there is no change in the properties or performance of the materials being evaluated [25]. Typical Ultrasonic systems are made up of a display window, a transducer, and a pulsar/receiver. The UT system can be utilized in detecting defects by sending a low amplitude wave through a material. This wave is picked back up by the receiver, which can measure the time of travel and change in intensity [25]. Figure 26 displays how the UT system operates; a shallow defect would be detected before the backside of the plate and 
would have a lesser reflected amplitude due to the scatter of the wave encountering the defect. Figure 26 also illustrates an example of what the display might look like following a test. One limitation of UT is the need for access to the surface of the object under evaluation.

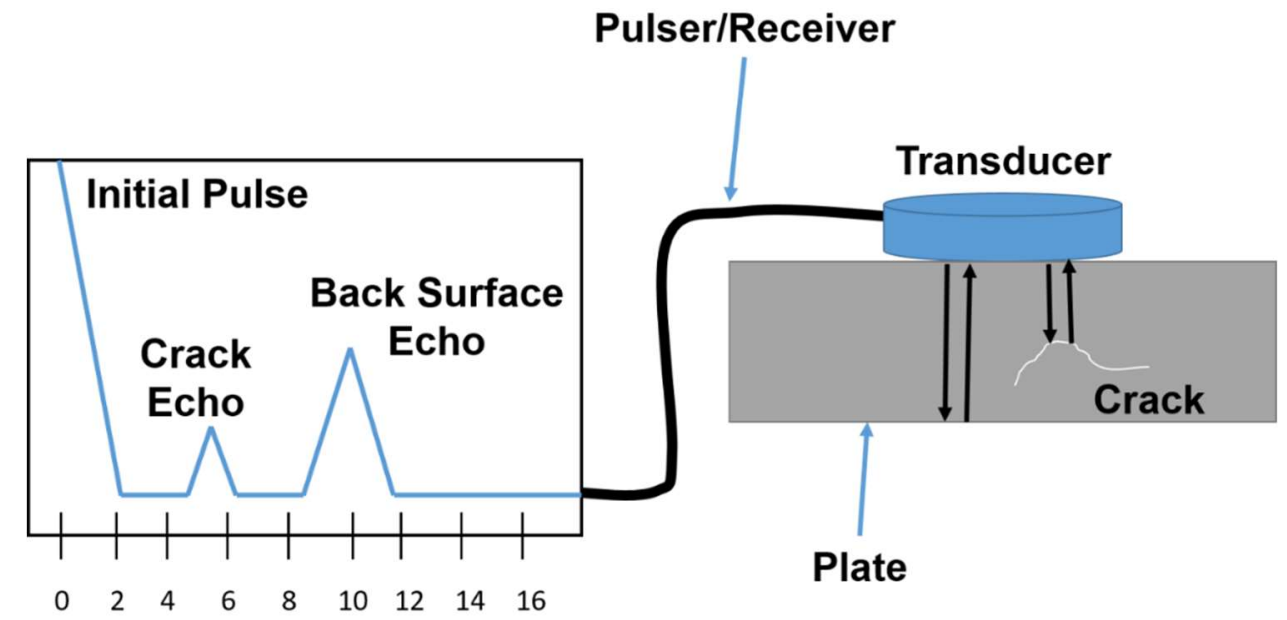

Figure 26 - Image displaying how the UT system sends a wave into a material as well as the amplitude upon returning

\subsubsection{Acoustic Emission (AE)}

Acoustic Emission is used to detect wire fractures, impacts, or active flaws in structures by detecting elastic waves caused by the release of energy [26, 27]. Due to the nature of detection, a long term data acquisition system with a sufficiently quick acquisition rate needs to be implemented for the best possible monitoring $[26,27]$. For accurate spatial data, sensors must be placed at many locations across the structure. If the structure is being monitored for small releases of energy (i.e., crack propagation in concrete), sensors should be placed at smaller spatial intervals as the released energy will dissipate at shorter distances than that of larger releases of energy (i.e., steel tendon fracture). However, in the case of 
grouted (bonded) post tensioned ducts, as opposed to ungrouted (unbonded), a larger number of sensors are needed for accurate detection due to the quicker dissipation of wave energy into the concrete surrounding the tendons [26]. An added benefit of placing additional sensors is that more accurate real-time 1-D, 2$D$, or 3-D rendering can be used to detect the exact location of a flaw [26]. Figure 27 gives a visual representation of the setup of an $A E$ monitoring system and how it would collect data on a structure. While the ability to detect when a fracture or flaw occurs is beneficial, it would be of greater value to preemptively determine all the locations at which defects could occur.

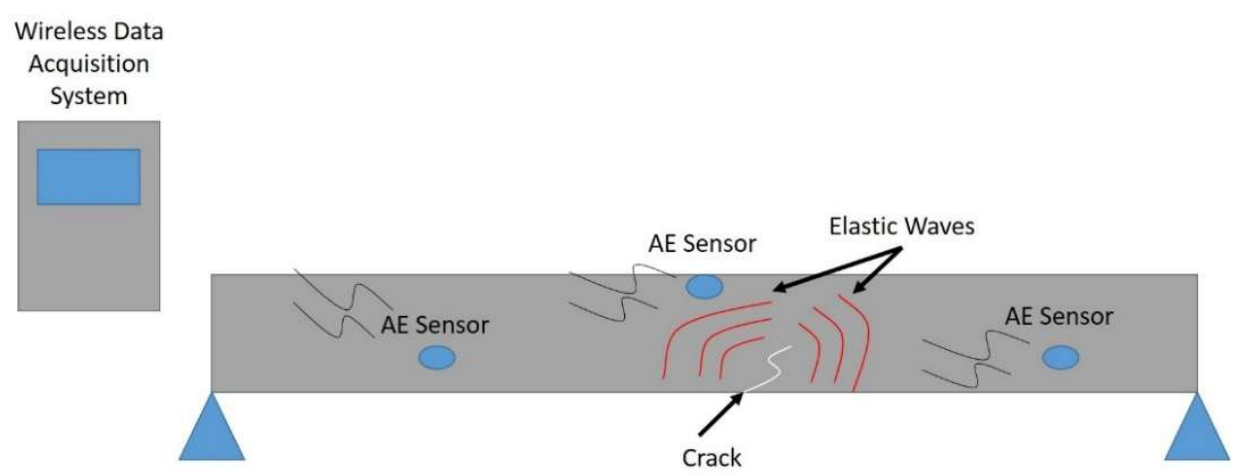

Figure 27 -Acoustic Emission monitoring system visualization.

\subsection{Discussion}

Each of the previously discussed technologies presents a unique advantage and limitation to the problem of Post Tensioned void detection. These technologies allow for the detection of defects after they have occurred, but are inconsistent in preemptive void detection. In contrast, Infrared Thermography is a nondestructive method that has been proven to be reliable for defect detection in reinforced concrete structures [4]. The experimental work performed to detect defects in post tensioned box girder bridges is outlined in the following section. 


\section{EXPERIMENTAL WORK}

The following section outlines the test setup, design, the materials used in each experiment. Figures and diagrams of the test setup, the location of testing, and the number and type of tests are included.

\subsection{Test Setup and Design}

This research was conducted to assess the ability of the Infrared Ultra Time Domain (IT-UTD) system to detect defects in galvanized steel ducts embedded within a post tensioned box girder bridge member. Thermal energy is transferred in a box girder bridge differently when compared to a bridge deck, and as such, a realistic experimental setup was needed to model typical field conditions.

\subsubsection{Post Tensioned Specimen 1}

Post Tensioned Specimen 1 was a $10 \times 4 \times 1 \mathrm{ft}$. concrete specimen containing three PT ducts. A company local to the University, Coreslab, in Marshall, Missouri, volunteered and donated their materials and labor to construct our post tensioned Specimen 1. The mix design included limestone, Kaw River sand and a water cement ratio of approximately 0.40 . The 28 -day design strength of the specimen is 7000 psi. Figure 28 displays the construction drawings for the specimen provided by Coreslab.

\subsubsection{Design and Construction}

Specimen 1 measures ten feet long by four feet high and one foot thick. These dimensions were selected based on discussion with the Florida Department of Transportation (FDOT) and guidelines determined from previous research [16, $28,29]$. The state of Florida has many PT bridges, and was the reason discussions 
were held with them to determine adequate geometry. There are three, $3 \mathrm{in}$. diameter galvanized steel ducts embedded in the specimen. Each of these ducts contain 3 7-wire high strength steel strands, and therefore, meet the minimum internal duct area ratio requirements ( $\frac{\text { internal duct area }}{\text { strand area }}$ ) of 2.5 required by FDOT specification 960-2.2.1.4 (C). The ducts were placed in the specimen such that the concrete cover was three and a half inches from one face of the specimen, and five and a half inches between the opposite face. All three ducts are equally spaced laterally at 1 -foot intervals on center. Two lifting hooks were located about two ft. from either end
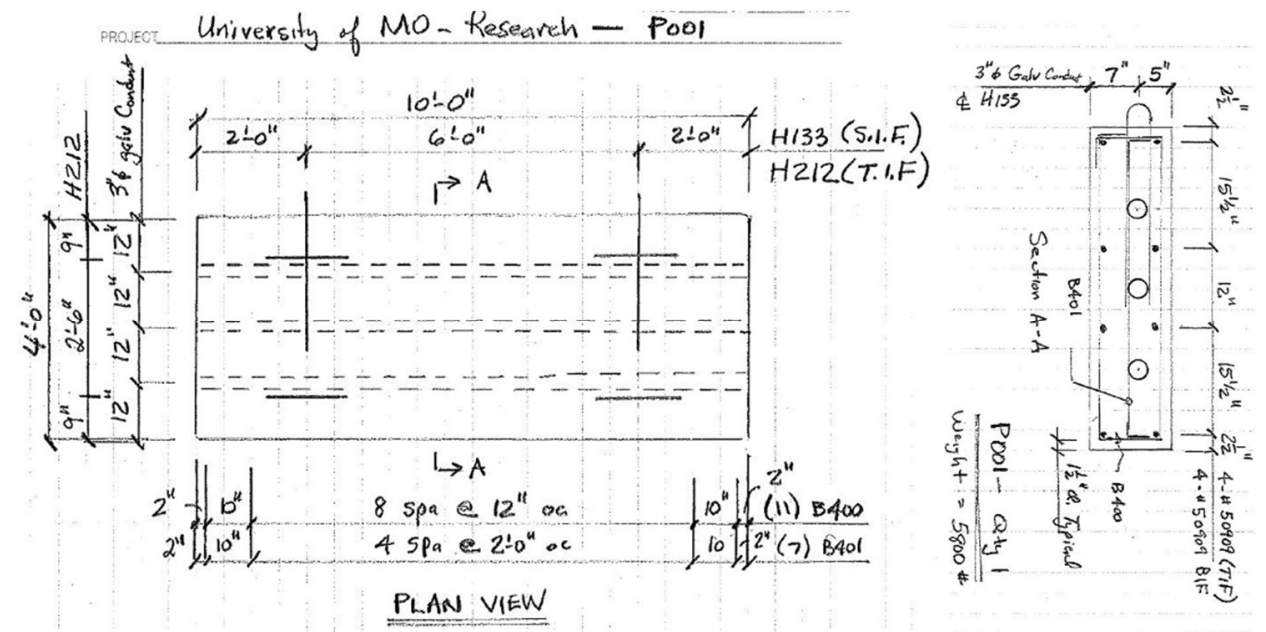

Figure 28 - Construction drawings of the Post Tensioned (PT) Specimen created by Coreslab in Marshall, MO.

The specimen cast by Coreslab was constructed to mimic one of the side walls of a box girder bridge section. Figure 29 displays the construction process of the specimen at Coreslab. Image A in Figure 29 is the form used to cast the specimen, with all the internal components displayed. Image B and C in Figure 29 
display two separate stages in the pouring process. Image D is the specimen after the pouring is finished and the smoothing of the surface has been completed.

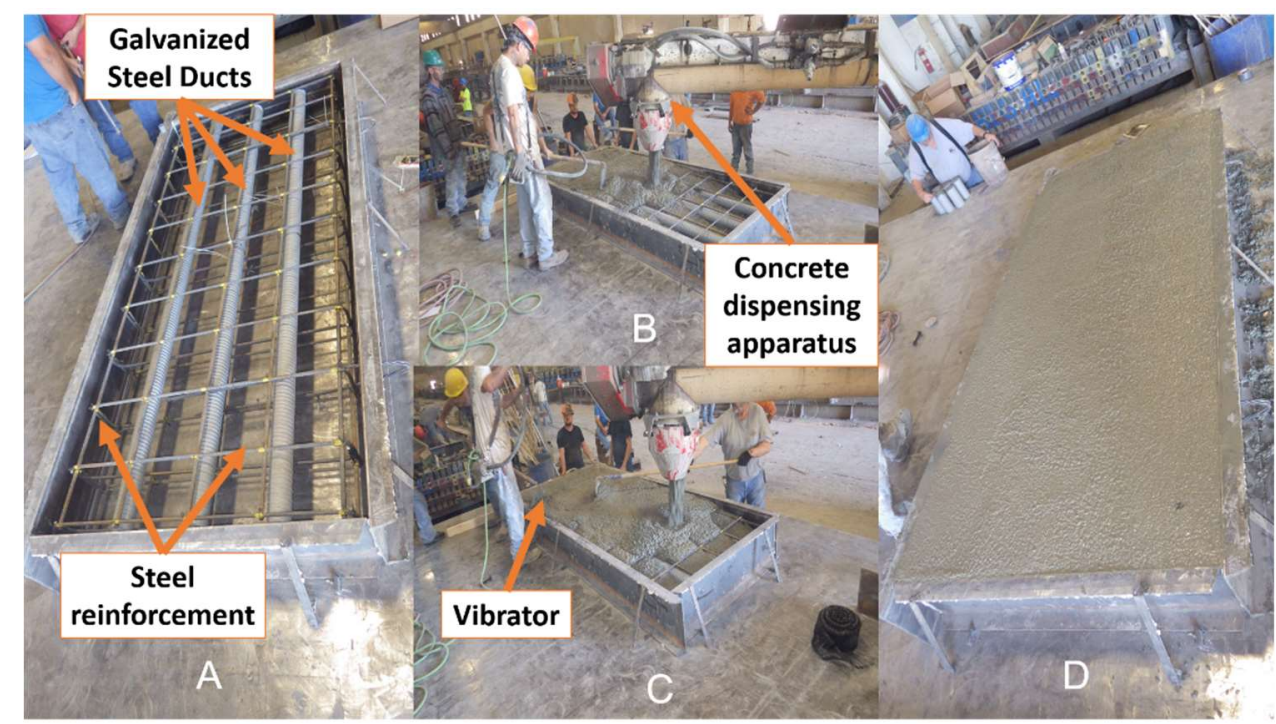

Figure 29 - Specimen construction process at Coreslab in Marshall, MO.

\subsubsection{Embedded Defect Locations}

Following the curing of the specimen, defects were to be placed inside of the ducts. Since the ducts were already embedded inside of the concrete, the process of placing defects at specific locations required the use of a rigid foam to represent voids. Cans of spray foam were used during this process and was implemented for two main reasons:

1. The thermal conductivity of foam is nearly the same as air

2. Expandable foam can be easily used to create different compartments in each duct for varying air void and grout layouts.

To place the foam within the duct, the hard-plastic spray nozzle from the can of foam was slipped inside one end of a long flexible plastic tube of a smaller, but similar, diameter to that of the nozzle. This was performed to create a tight fit 
to avoid leakage and pressure loss. This flexible tube was premeasured to a certain length, so that the spray foam could be expelled into the duct at a specific location to create a compartment. The flexible tube was then attached at multiple locations along the length of a rigid copper rod via tape. The depth inside of the duct where a new compartment needed to start was marked on the copper rod. The rod was then hand fed into the duct, and spraying commenced until the predetermined amount of foam was injected into the duct.

Before the placement of foam began, several tests were run to determine what the expansion rate was in terms of the linear length along the beam (i.e. if 1 linear inch of foam was sprayed inside the 3-inch diameter duct, how much would it expand linearly along the length of the duct). Testing on a spare 3-inch galvanized duct concluded that the foam expanded at approximately a rate of $4: 1$ (i.e. if 1 linear inch of foam was sprayed inside the 3-inch diameter duct, the ending result will fill the duct 4 linear inches). These tactics were used to accurately place spray foam defects along the length of the duct at the locations and sizes called out in Figure 30. 

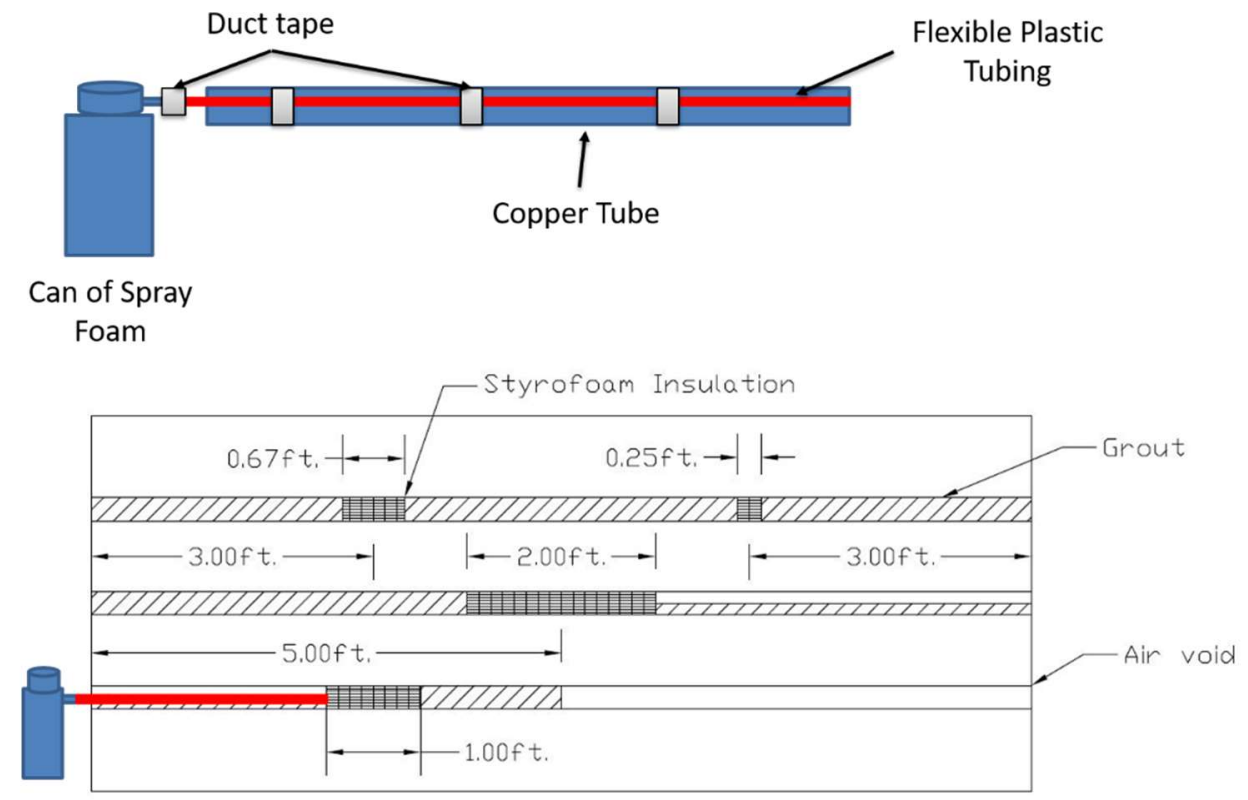

Figure 30 - Image displaying how spray foam was inserted into the ducts.

The ducts were grouted using Euco Cable Grout PTX, a type of commonly used grout in the state of Florida for PT ducts. The grout was donated by the Euclid Chemical Company. The grout was placed using a gravity feed, which required that the specimen be positioned differently for each defect. Maneuvering of the specimen was completed multiple time until the final layout was nearly identical to that in Figure 30. Image A of Figure 31 shows a plywood cap placed on top of the ducts to seal the compartment for curing while image B displays grout being placed inside of the ducts prior to capping. Figure 32 displays what ducts look like when they are filled with grout, partially filled with grout, or completely empty. 


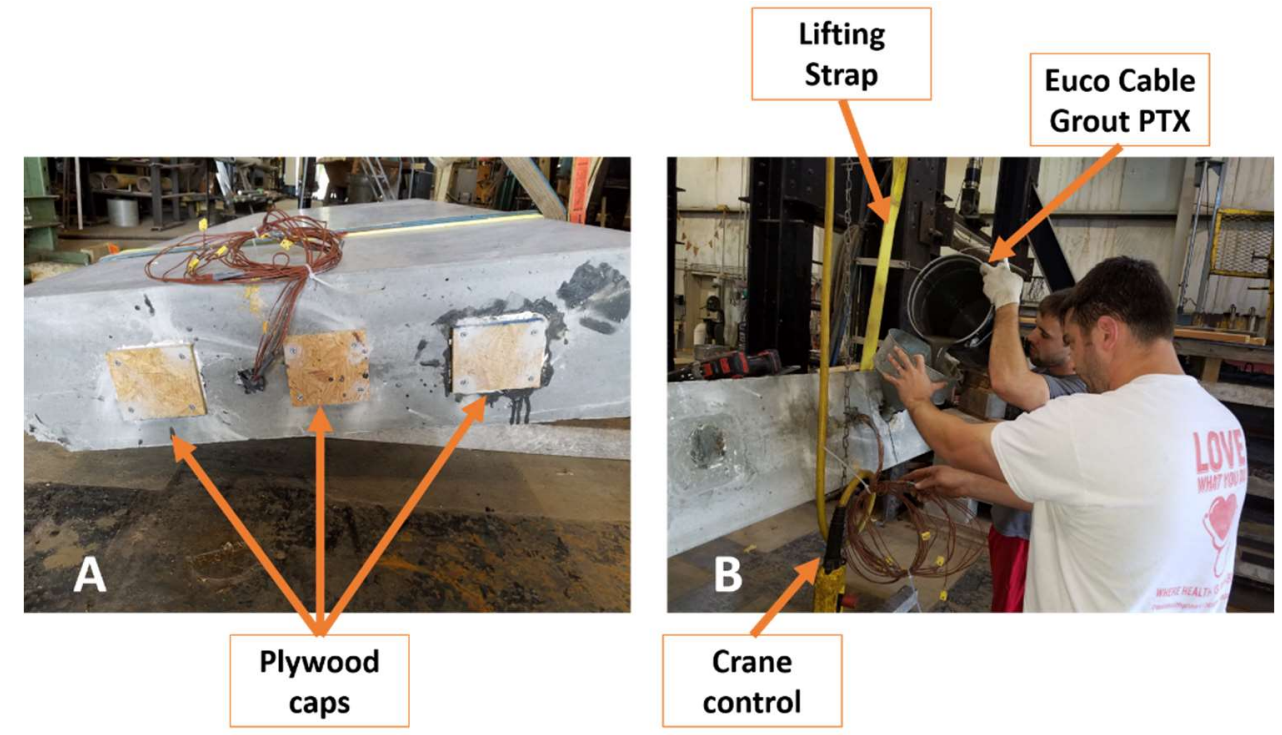

Figure 31 - Image A (left) displays plywood caps protecting the ducts while image $B$ (right) shows grout being poured into the ducts.

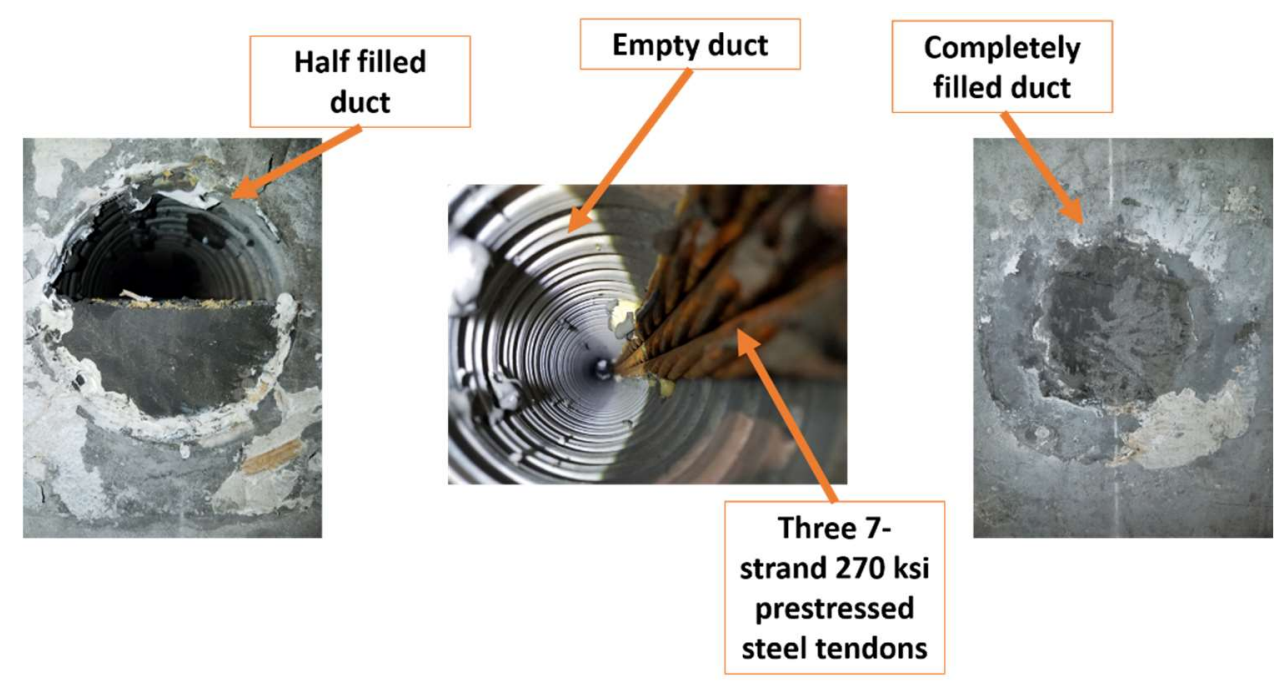

Figure 32 - Various grouting cases.

\subsubsection{Post Tensioned Specimen 2}

\subsubsection{Design and Construction}

Post Tensioned Specimen 2 was designed and built at the University of Missouri - Columbia using MoDOT Type B2 concrete. Figure 33 displays the profile of the new specimen, with dimensions called out. 

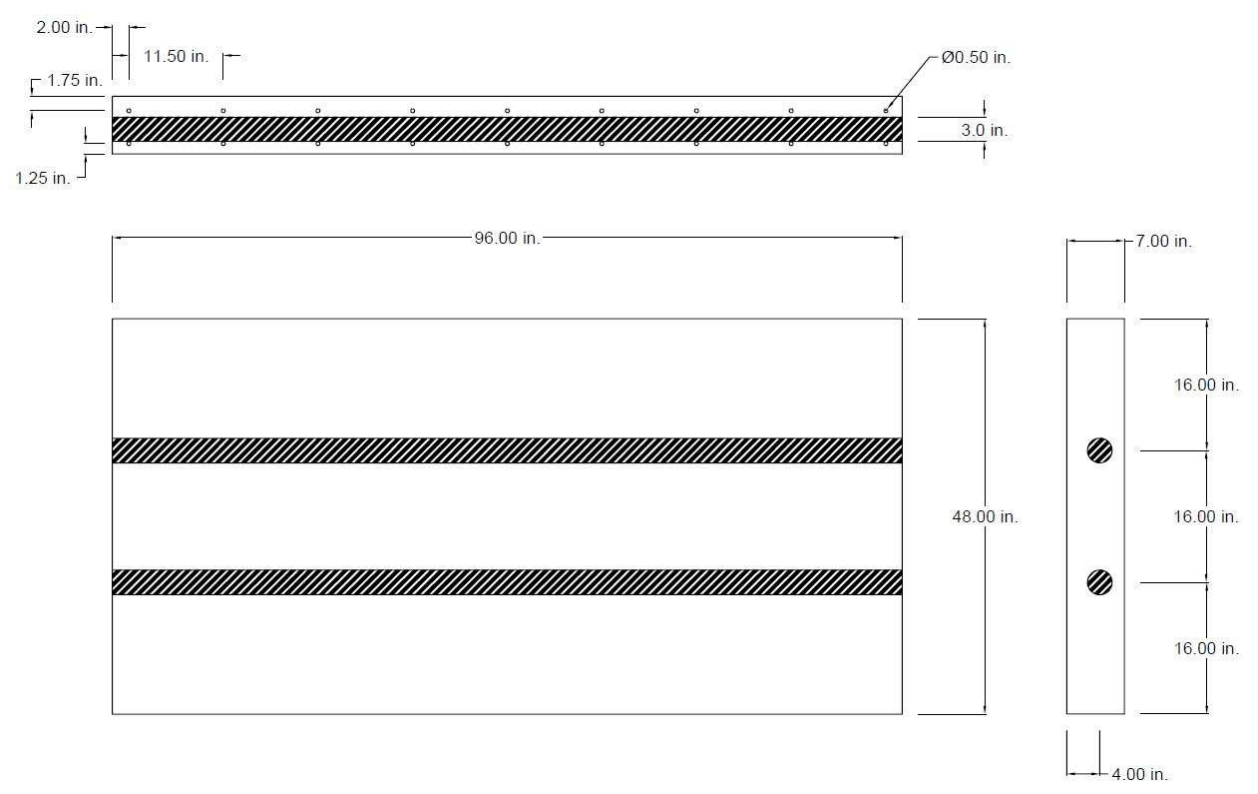

Figure 33 - Side and edge profile of Post Tensioned Specimen 2.

Specimen 2 measures $8 \mathrm{ft}$. $x 4 \mathrm{ft} . \times 7$ in. Specimen 2 was designed to have a smaller concrete cover than Specimen 1.

There are two 3 in. diameter galvanized steel ducts that were embedded into the concrete, identical to the ducts in specimen 1. Each of these ducts contain steel strands, and meets the minimum internal duct area ratio $\left(\frac{\text { internal duct area }}{\text { strand area }}\right)$ of 2.5 required by FDOT specification 960-2.2.1.4 (C). These ducts were placed so that there was a concrete cover of 1.5 inches from one face and 2.5 inches from the opposite face. The ducts were equally spaced laterally along the height of the specimen at 16 -inch intervals. Additionally, there are two lifting hooks each spaced two feet from either end.

Of the two full length ducts used in Specimen 2, one was labeled "A" and the other labeled " $B$ ". Both full-length ducts were cut up into different 
compartments. Each compartment of each duct had a number associated with it; B1, B2, etc. Figure 34 shows the numbering of each compartment for both ducts.

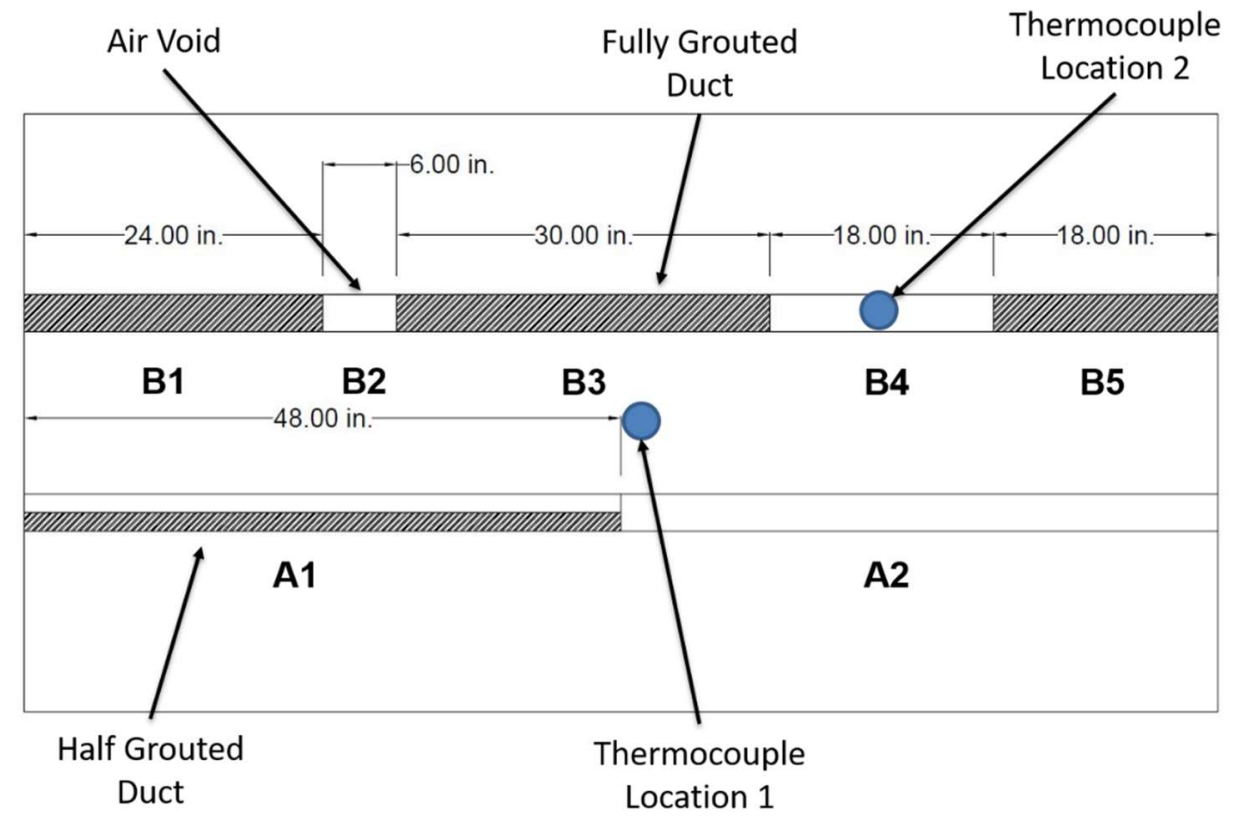

Figure 34 - Defect and Thermocouple layout for Post Tensioned Specimen 2.

The defects inside of the ducts for Specimen 2 were implanted prior to embedding them into the concrete. This provided better quality control during construction as compared to the methods used to construct Specimen 1. Defect placement was accomplished by cutting the steel ducts into compartments, filling them with the desired grout, and then welding them all back together. The welds were not continuous around the circumference of the galvanized duct, so duct tape was used to prevent concrete intrusion inside of the duct.

When filling the ducts with grout, duct tape was also placed at the cut ends of the ducts to contain the grout prior to setting. This created a seal so that the grout wouldn't leak out, and was easy to remove when the grout was finished curing. 
Thermocouples were embedded inside of specimen 2 to record changes in temperature through the thickness of the specimen. A total of six thermocouples were used; three to detect through thickness heating and cooling of sound concrete and three to detect through-thickness heating and cooling in the area of a void. For the sound portion of the concrete, thermocouples were placed through the thickness of the specimen at the center point. A thermocouple labeled "1" was placed on the bottom side of the bottom layer of rebar, approximately 5.75 inches deep into the concrete. Thermocouple "2" was strung 3.5 inches deep into the concrete between the two layers of rebar by use of wire ties to keep it in place. Thermocouple " 3 " was placed on the top side of the upper layer of steel reinforcement, approximately 1.75 inches in depth. Figure 35 labels the center point of the 8-ft. x 4-ft. side "Thermocouple Location 1."

"Thermocouple Location 2" in Figure 35 refers to the location thermocouples were placed to capture thermal data as heat radiates through the specimen in the area of an empty duct. The top and bottom thermocouples were placed at identical depths to that of location 1; Thermocouple " 4 " was placed at the bottom rebar, and Thermocouple "6" was placed at the top most rebar. Thermocouple " 5 " was placed at the center most point of the duct, and was embedded approximately 0.5 inches further into the specimen than Thermocouple "2". Figure 35 displays the described thermocouple layout. 


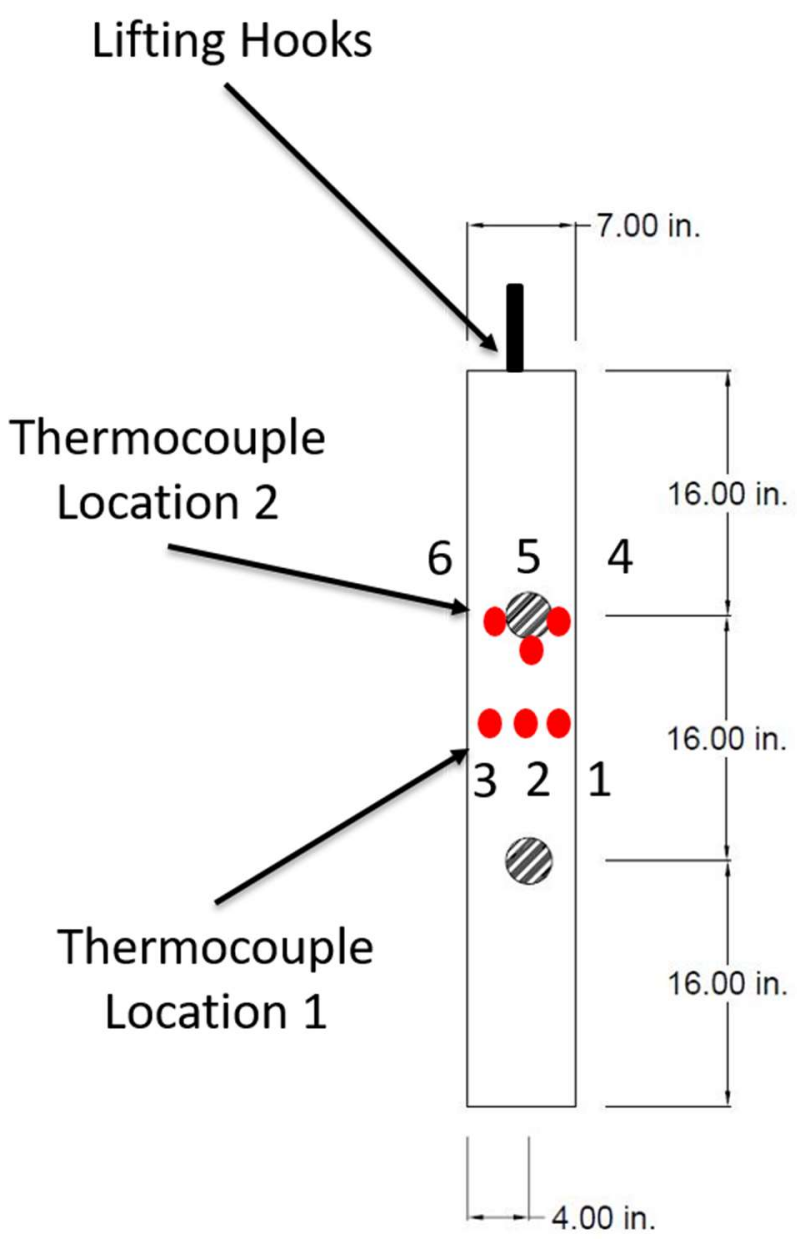

Figure 35 - Thermocouple locations along the depth of specimen 2

\subsubsection{Construction}

Figure 36 is a Plan view image of PT Specimen 2 prior to pouring concrete. All of the reinforcing rebar, lifting hooks, galvanized steel ducts and thermocouples are visible in the image. Figure 37 depicts the pouring process for specimen 2. After the concrete surface was broom finished, as shown in Figure 38, a water was sprayed onto the concrete and a black tarp was placed over the top. Figure 39 shows specimen 2 after several days of curing in the forms. 


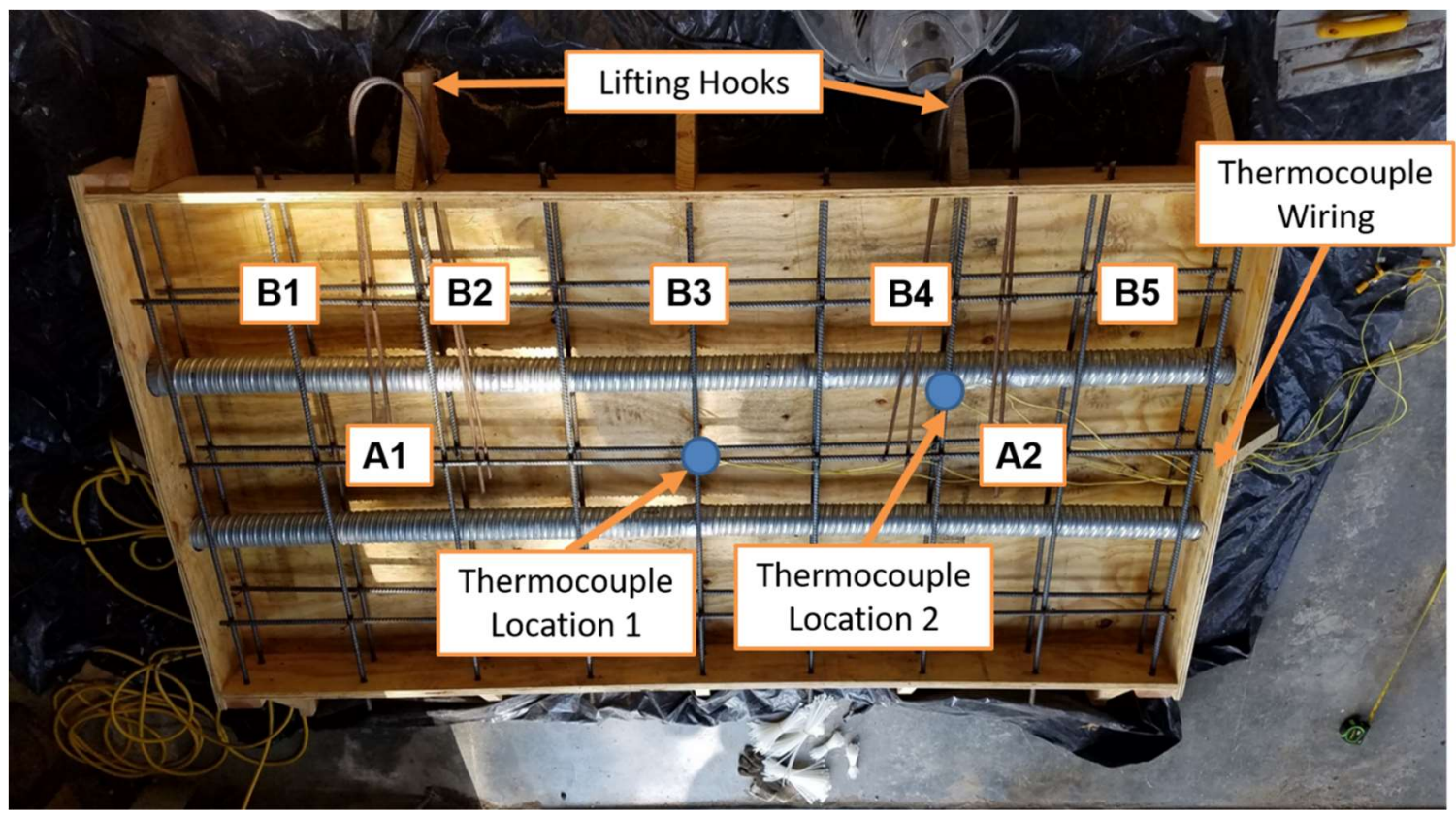

Figure 36 - Aerial view image of Post Tensioned Specimen 2 prior to pouring.

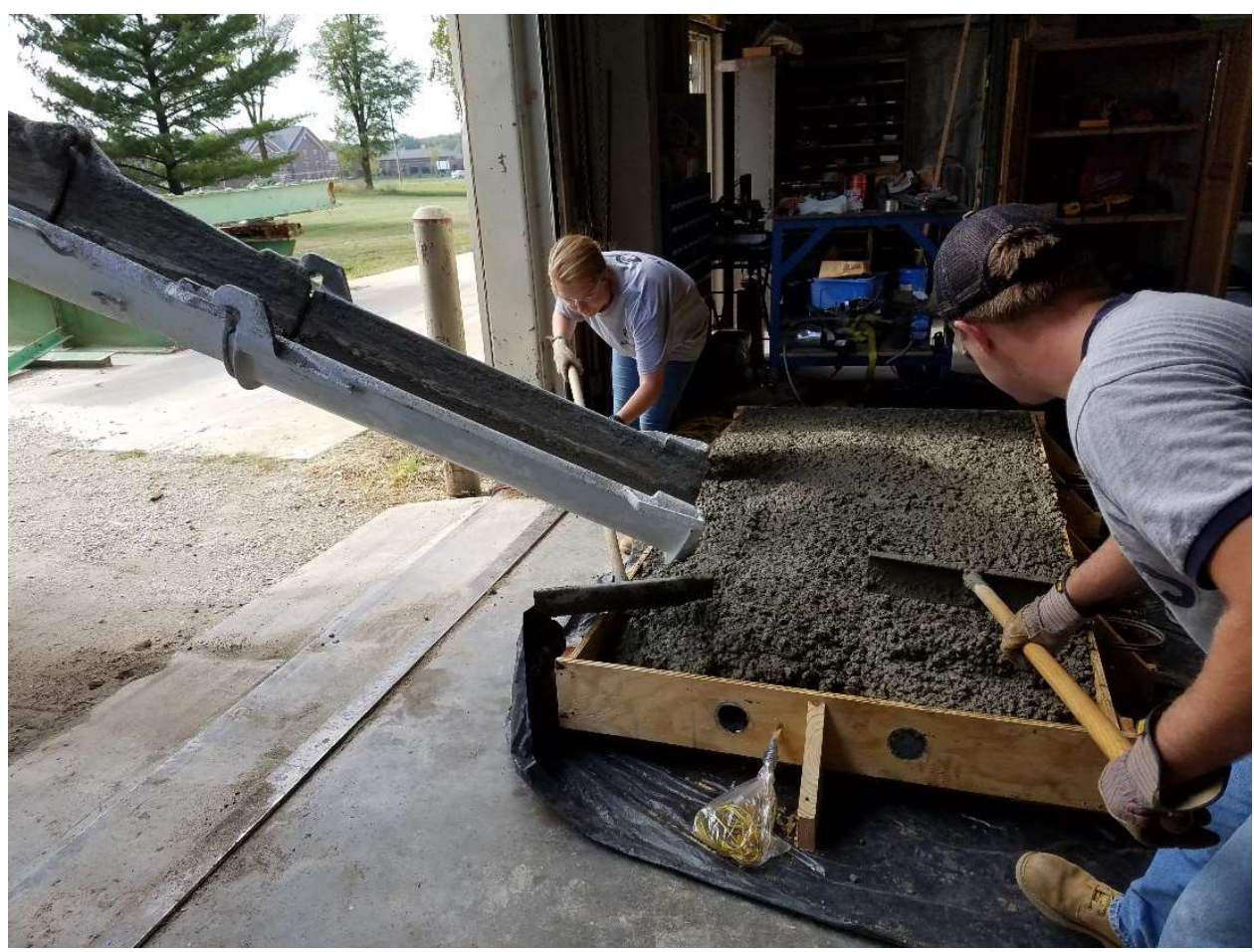

Figure 37 - Pouring of concrete for specimen 2. 


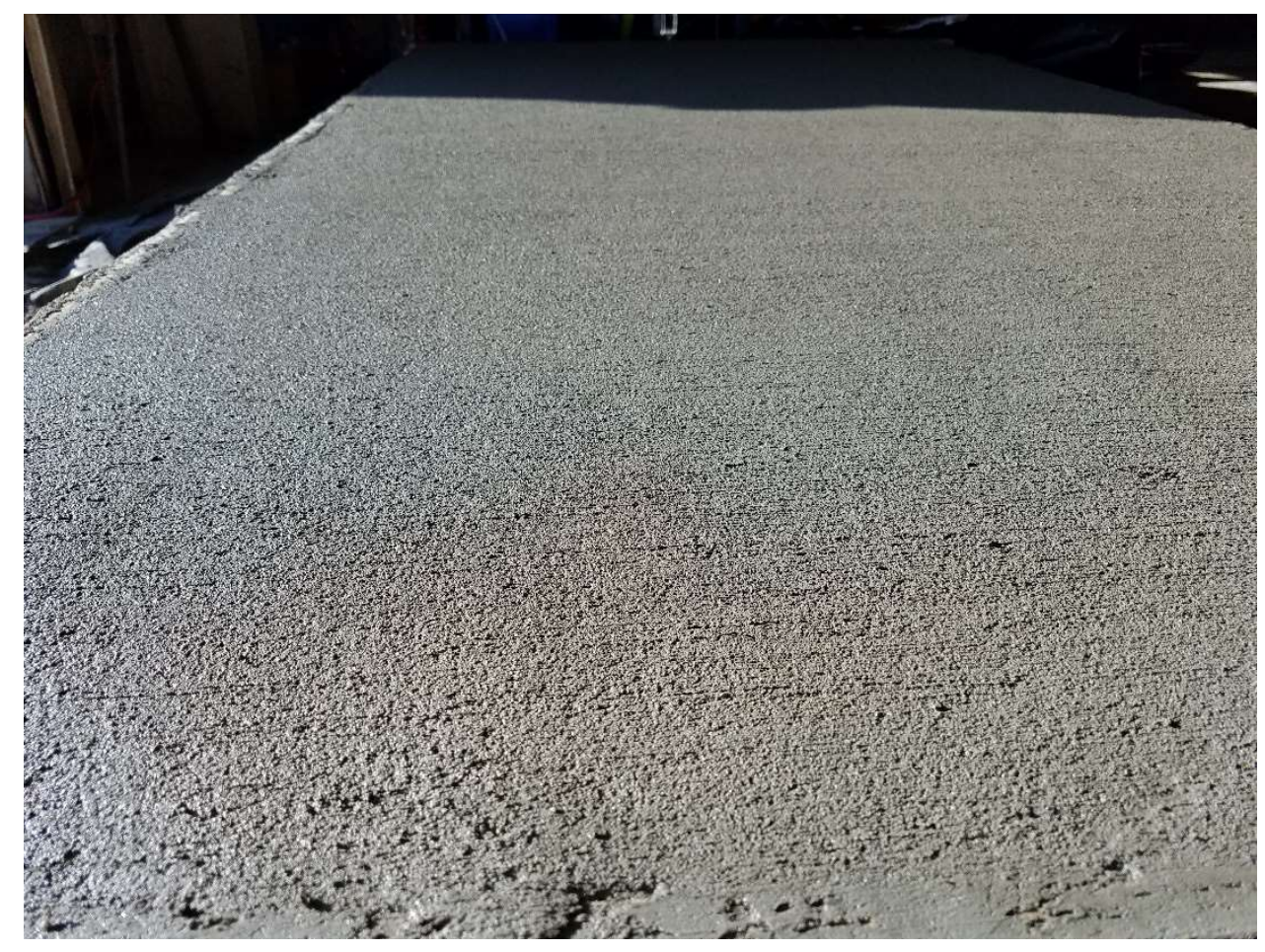

Figure 38 - Broom finish on specimen 2.

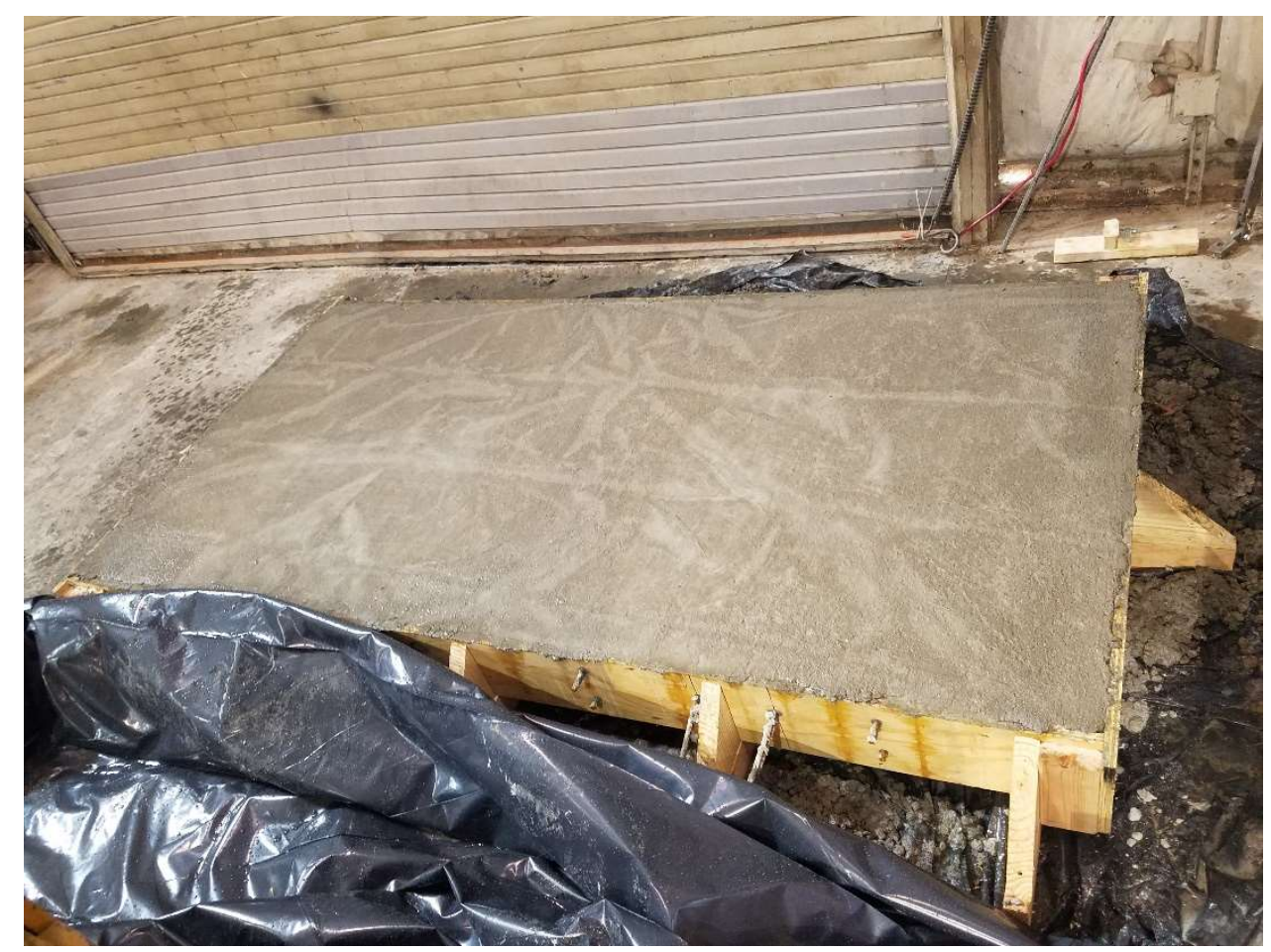

Figure 39 - Specimen 2 after several days of curing in the mold. 
After a week of curing, the forms were removed from the specimen. It was evident that the concrete had either not had a high enough slump value (3.5 inches) or wasn't vibrated sufficiently in certain locations. There were significant voids in cement and concrete coverage of the bottom surface, particularly in the area around the ducts and rebar. Figure 40 is an image of the bottom side of specimen 2 that was face down during concrete placement, showing the voids in the concrete. These voids were filled with a flow able cementitious material.

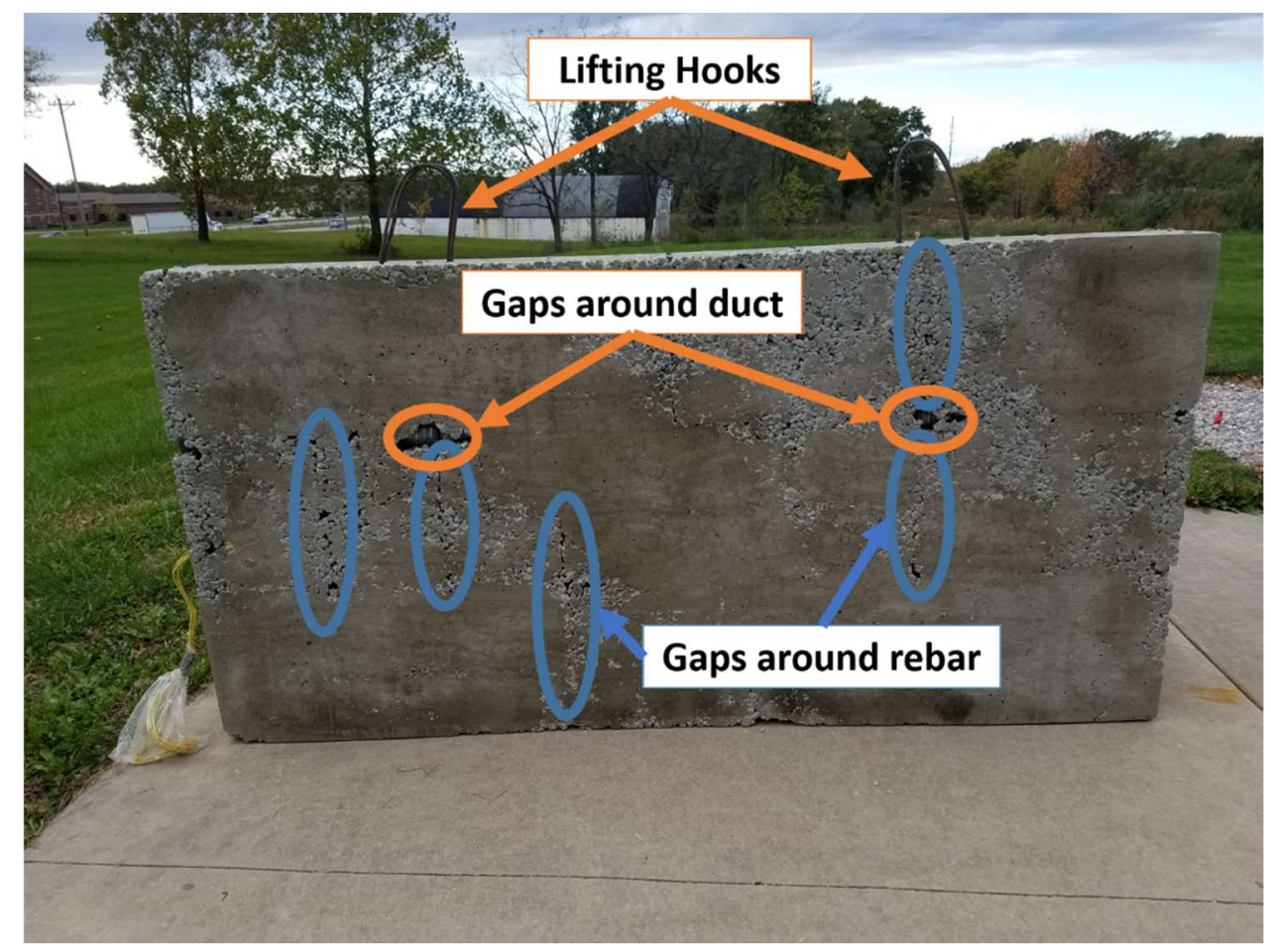

Figure 40 - Gaps around the embedded ducts and rebar post pouring.

Refinishing of the surface was performed using a $40-\mathrm{lb}$. bag of Quikrete Concrete Finisher. A higher than suggested water content was used to obtain a low viscosity mix to easily and fully fill in any gaps or cracks. Even though the entire surface wasn't damaged, the entire surface was refinished to assure more uniform heating and cooling during testing. Figure 41 shows Specimen 2 after 
refinishing of the surface. Due to the voids that were present prior to repair, the refinished side of the specimen was not imaged during testing.

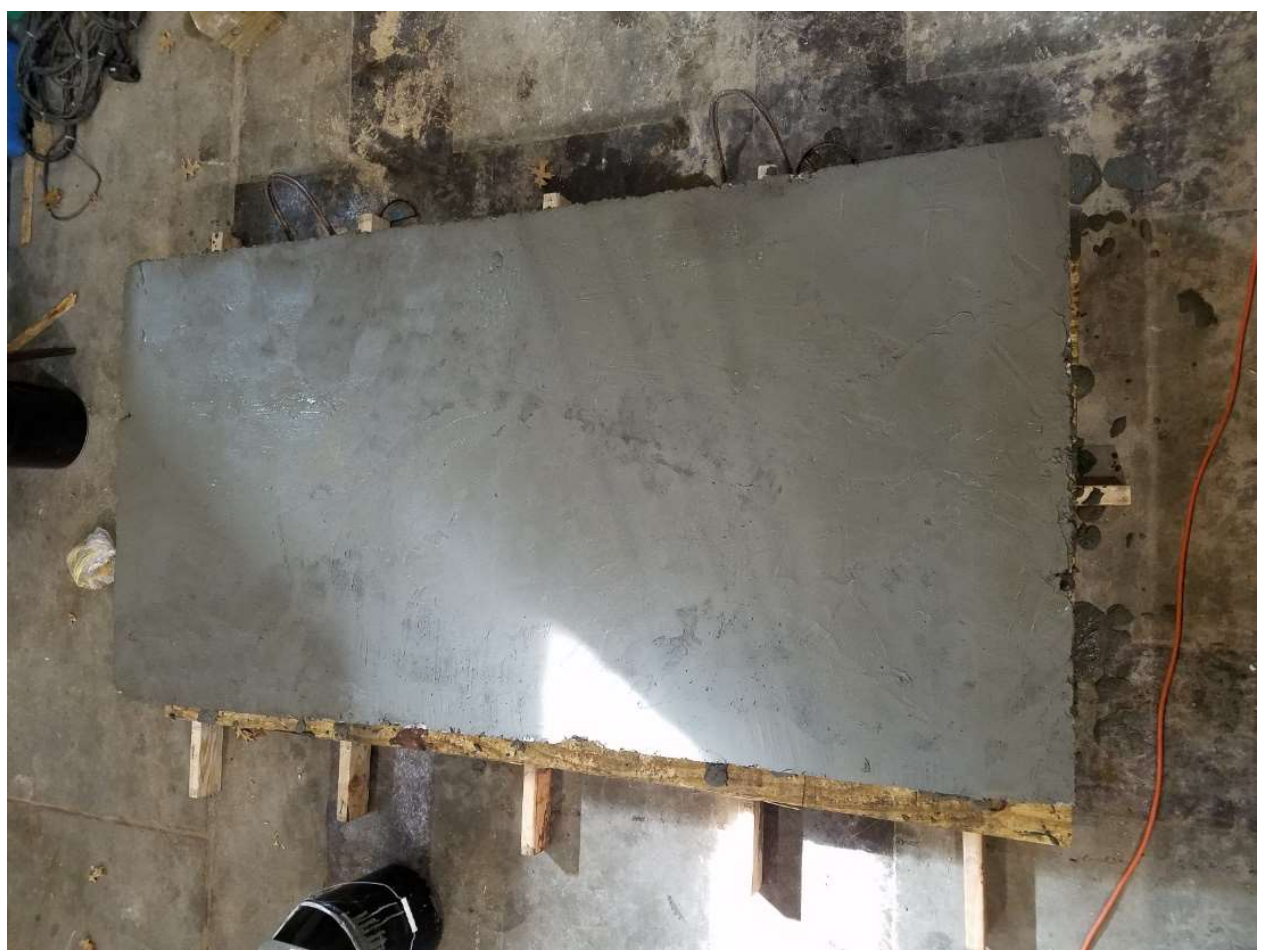

Figure 41 - Damaged side of Specimen 2 after resurfacing.

\subsection{Post Tensioned Experiments}

There were several experiments run for both Post Tensioned (PT) Specimens 1 and 2 . The experiments will be presented in sequential order; testing on Specimen 1 followed by Specimen 2 .

\subsubsection{Data Collection Summary}

\subsubsection{Post Tensioned Specimen 1}

Following the casting of the specimen at Coreslab in Marshall, MO, the specimen was transported to the University of Missouri's Remote Testing Facility (RTF) in Columbia, MO. 


\subsubsection{Box Girder Bridge Simulation}

As discussed in section 3.2.1.1, the inside of a box girder bridge is hollow; the air is insulated on the inside. Because of this, a structure was designed and built around specimen 1 to create considerable amounts of insulation. Also, since one of the previously mentioned heat transfer mechanisms is convection, the temperature difference between the inside and outside ambient temperatures was of importance. Thermocouples were used to track the ambient temperature changes on both the inside and outside of the enclosure. The maximum ambient temperature difference for the inside of an in-service box girder bridge, at any point in the day, varies between 4 and $11^{\circ} \mathrm{F}$ cooler than the outside ambient temperature

$[30,31]$. These values are based on various environmental conditions and were tabulated in various parts of the world.

A simple window fan and $A C$ unit were purchased for temperature control. A LabVIEW program was written and used, along with an Arduino, to control the temperature on the inside of the structure such that it would stay within the chosen temperature tolerances. The LabVIEW program uses both the AC unit and a fan, attached to the side of the structure, to control the inside ambient temperature. In this way, the AC unit can be activated, or the fan can be used to pull in the air from outside, to meet the prescribed criteria. The program utilizes multiple thermocouple wire readings of the inside and outside temperatures to tell when the AC unit and/or fan should turn on. 


\subsubsection{Summary of Experiments}

This section will provide a summary for each type of experiment conducted.

Table 2 displays a summary table of each experiment in this section.

Table 2 -Summary table of experiments.

\begin{tabular}{|c|c|c|c|c|c|c|}
\hline Specimen & Test & $\begin{array}{c}\text { Enclosure } \\
\text { Type }\end{array}$ & $\begin{array}{c}\text { Ambient } \\
\text { Temperature } \\
\text { Offset }\end{array}$ & $\begin{array}{c}\text { Depth } \\
\text { to } \\
\text { Defect }\end{array}$ & $\begin{array}{c}\text { Imaging } \\
\text { Area }\end{array}$ & $\begin{array}{c}\text { Dallection } \\
\text { Rate }\end{array}$ \\
\hline$\# 1$ & 1.1 & None & N/A & $3.5 \mathrm{in}$. & $4 \mathrm{ft} . \times 8 \mathrm{ft}$. & 1 minute \\
\hline$\# 1$ & 1.2 & None & N/A & $3.5 \mathrm{in}$. & $4 \mathrm{ft} \times 8 \mathrm{ft}$. & 1 minute \\
\hline$\# 1$ & 1.3 & None & N/A & $3.5 \mathrm{in}$. & $4 \mathrm{ft} . \times 8 \mathrm{ft}$. & 1 minute \\
\hline$\# 1$ & 1.4 & Enclosed & $0^{\circ} \mathrm{F}$ & $3.5 \mathrm{in}$. & $4 \mathrm{ft} \times 8 \mathrm{ft}$. & 1 minute \\
\hline$\# 1$ & 1.5 & Enclosed & $5^{\circ} \mathrm{F}$ & $3.5 \mathrm{in}$. & $4 \mathrm{ft} . \times 8 \mathrm{ft}$. & 1 minute \\
\hline$\# 1$ & 1.6 & Enclosed & $15^{\circ} \mathrm{F}$ & $3.5 \mathrm{in}$. & $4 \mathrm{ft} . \times 4 \mathrm{ft}$. & 1 minute \\
\hline$\# 2$ & 2.1 & Enclosed & $5^{\circ} \mathrm{F}$ & $1.5 \mathrm{in}$ & $4 \mathrm{ft} . \times 8 \mathrm{ft}$. & 1 minute \\
\hline$\# 2$ & 2.2 & Enclosed & $15^{\circ} \mathrm{F}$ & $1.5 \mathrm{in}$ & $4 \mathrm{ft} \times 4 \mathrm{ft}$. & 1 minute \\
\hline$\# 2$ & 2.3 & None & N/A & $1.5 \mathrm{in}$ & $4 \mathrm{ft} . \times 8 \mathrm{ft}$. & 1 minute \\
\hline
\end{tabular}

The Infrared Ultra Time Domain (IR-UTD) system was placed inside of an aluminum data acquisition (DAQ) system, whose base was bolted to a moveable concrete block. This DAQ was created for the safety of the IR-UTD system from theft and possible damaging environmental conditions. A square window in the side of the DAQ allows for full viewing of the specimen. Figure 44 is an image of the aluminum DAQ whilst set up for testing. Both the DAQ and the specimen were 
placed on top of a previously existing concrete slab in the center of an open field at the University of Missouri's Remote Testing Facility (RTF).

The face of the specimen with 3.5 inches of concrete cover was facing the DAQ system on the north side, while the face with 5.5 inches of concrete cover was facing the south. The infrared camera was placed on the side of the specimen with a smaller concrete to register the largest differences in radiated thermal inertia at the surface. Infrared and thermocouple data were collected at 1-minute intervals.

Following the analysis of the first two experiments, a phenomenon called an edge effect was noticed in each of the final processed infrared images. An "edge effect" occurs as a results of heat transfer around edges exposed to the ambient environment. At these edges or corners, the rate of heating and cooling of the material results in thermal gradients in the concrete. These thermal gradients are evident in both conventional IRT and in the IR-UTD processed data.

To reduce the thermal gradients near the edge of the specimen, 2-inch rigid Styrofoam sheets were attached to the exposed edges of the specimen. The foam sheets were attached using an adhesive ("Beats the Nail") and mechanically using concrete screws with oversized washers.

An enclosure was built to simulate the inside of a box girder bridge. The goal of the designed structure was to:

- Provide adequate insulation for testing.

- Be easy to construct and deconstruct with one person.

- Provide protection from environmental conditions. 
To create a structure with adequate insulation on all sides, $4 \mathrm{ft} . \times 8 \mathrm{ft} . \times 2-$ inch R20 Styrofoam sheets were used in the walls of the structure. These insulated sheets would be placed on the inside of a wooden frame, so that the insulation is touching at every internal corner of the structure. Concrete screws would be used to attach the wooden frame into both the concrete slab underneath the test setup as well as the upright test specimen. Figure 42 is an image of one of the side wall drawings for the insulated structure.

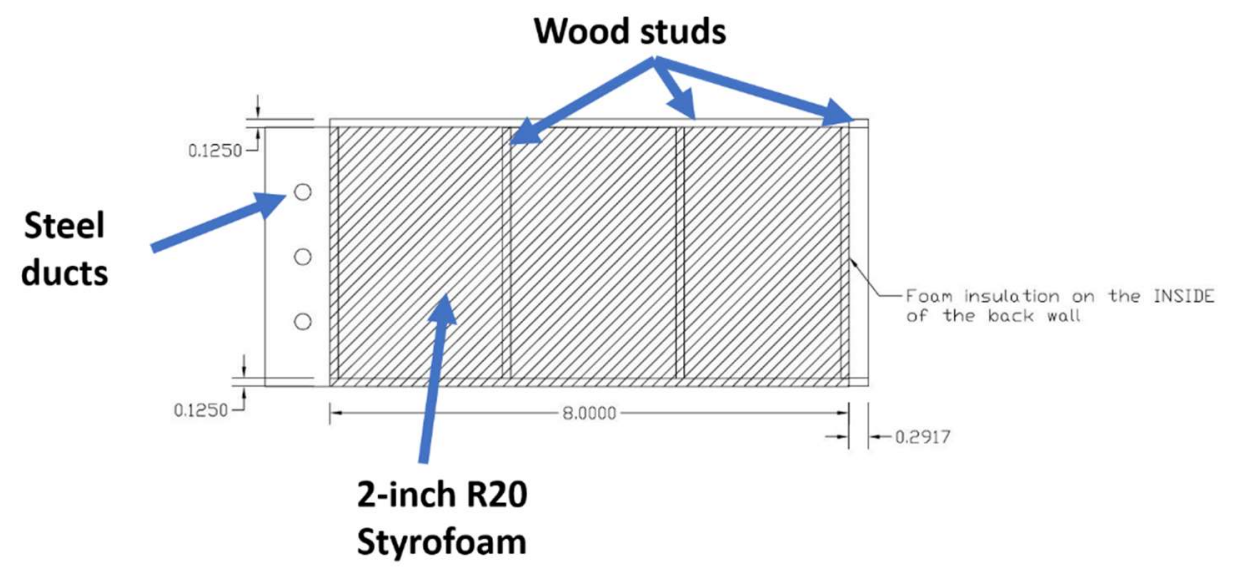

Figure 42 - Side wall drawing for the insulated structure.

The wooden frame for the structure was constructed segmentally; all 3 sides and the roof were constructed prior to putting them all together as one structure. Once the frame was securely attached to the concrete base and the upright specimen, the Styrofoam sheets were attached on the inside of the wooden frame. The needed cutouts for the AC unit, fan and door were also cut out of the Styrofoam sheet as displayed in Figure 43. 


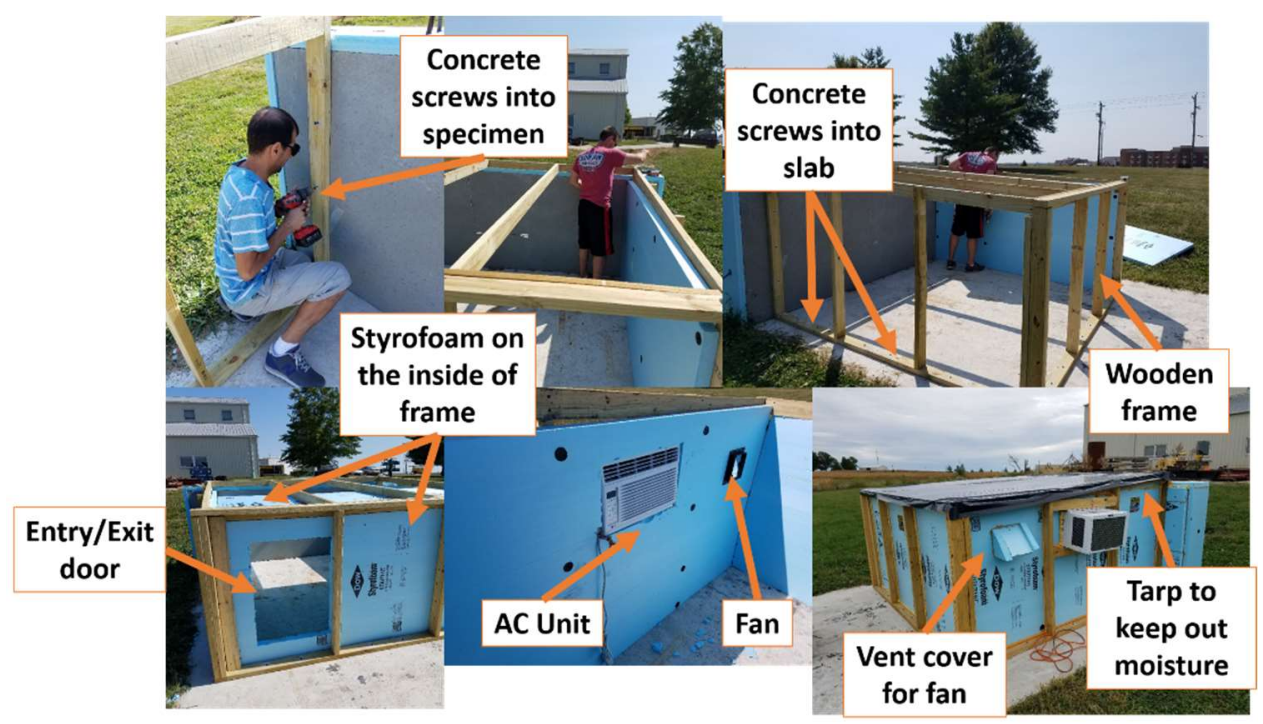

Figure 43 - Multiple stages of construction for the insulated structure.

When the insulated structure was completed, all the infrared, thermocouple, air control and other equipment were placed inside of the structure as shown in Figure 43. All equipment was placed on a platform of wood and Styrofoam pieces to prevent damage from standing water inside of the structure.

Two thermocouples were used to track how the through thickness heating and cooling of the specimen changed throughout the day. One thermocouple was placed on the south side of the specimen, one foot above the concrete slab base and eighteen inches toward the center of the specimen measured from the outer edge. At this position, the thermocouple was located above the embedded duct. The second thermocouple was placed at the same relative location on the north side of the specimen inside of the structure. The thermocouple measurements were used to determine appropriate times for data processing.

Inside of the enclosure, there were two locations the IR camera was placed for data collection. One location involves setting the infrared camera at a centric 
location $8 \mathrm{ft}$. from the specimen such that an area of approximately $8 \mathrm{ft}$. $x 4 \mathrm{ft}$. was captured in the IR image. The second test is performed by relocating the camera to a distance of $4 \mathrm{ft}$. from the surface of the specimen. From this position an area of approximately $4 \mathrm{ft}$. $x 4 \mathrm{ft}$. was captured in the thermal image.

\subsubsection{Test 1.1}

A baseline test, without any embedded voids or grout, was conducted on Specimen 1 following the standard 28-day curing process for concrete. This will verify if the results from the IR-UTD system improves or diminishes with each experiment conducted. Figure 45 displays the initial test setup for specimen 1. The results will be presented in the following chapter.

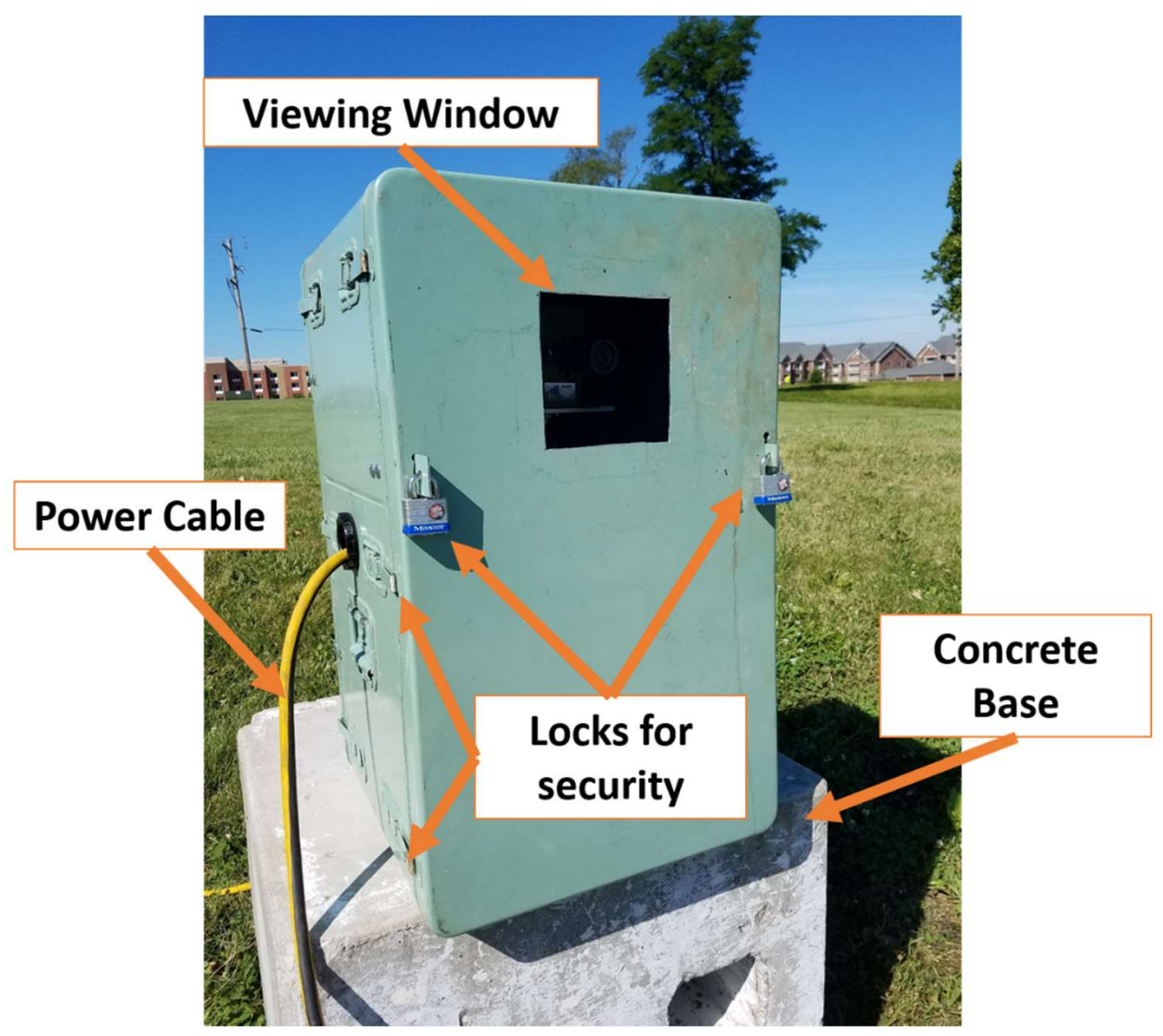

Figure 44 - Aluminum DAQ system for secured viewing. 


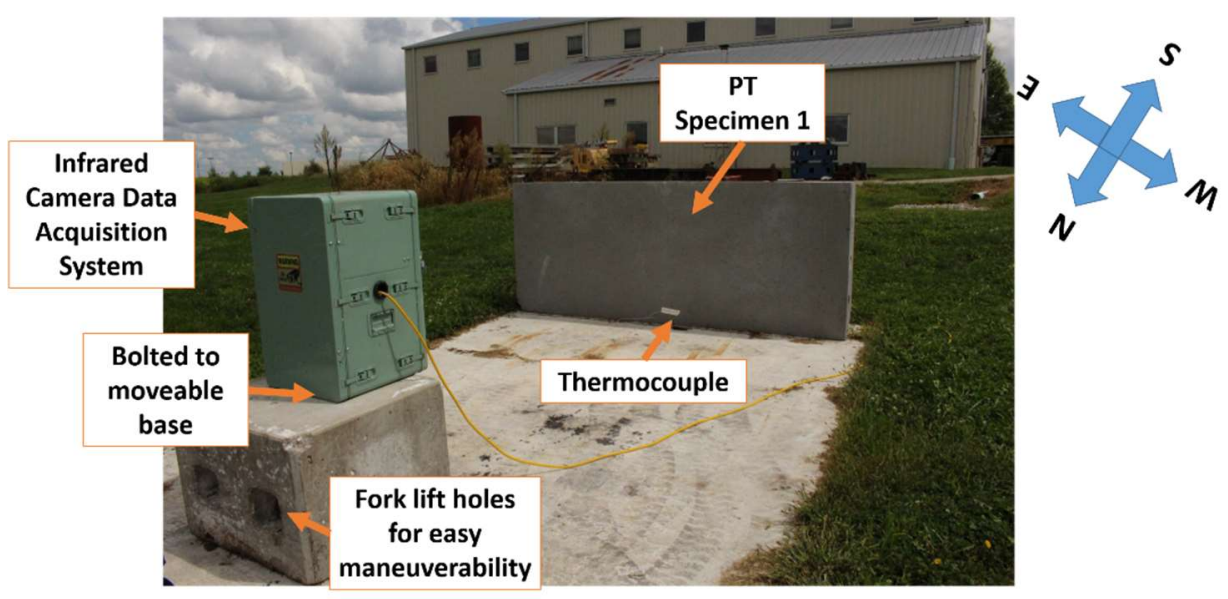

Figure 45 - Test setup for testing of specimen 1 prior to grouting of the ducts and to the insulated structure.

\subsubsection{Test 1.2}

Grout was then poured into the ducts in the locations previously shown in Figure 31 and Figure 32. The specimen was placed in the same location as Test 1.1. Figure 46 displays the grouting profile of the specimen during testing, with a fully filled duct, a half-filled duct and an empty duct called out. Data was collected from August $29^{\text {th }}$ to September $4^{\text {th }}, 2017$. The results of this test will be presented in the following chapter. 


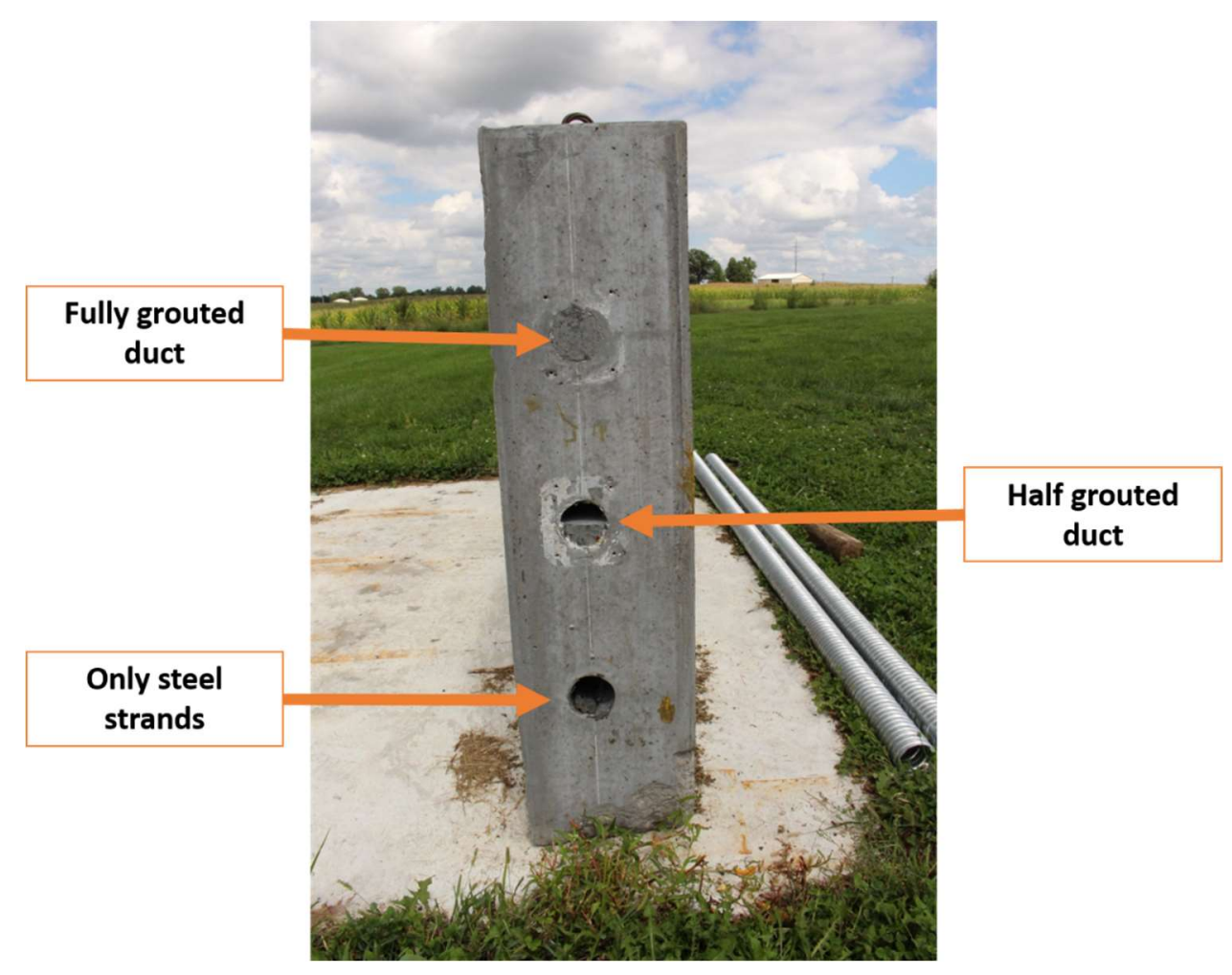

Figure 46 - Grouting profile for test 2 on specimen 1.

\subsubsection{Test 1.3}

Due to edge effects observed, rigid Styrofoam insulation was attached to the side of the specimen. Figure 47 displays the methods used in attaching the Styrofoam to Specimen 1. Data was collected from September $8^{\text {th }}$ to September $12^{\text {th }}, 2017$. The results of this test will be presented in the following chapter. 


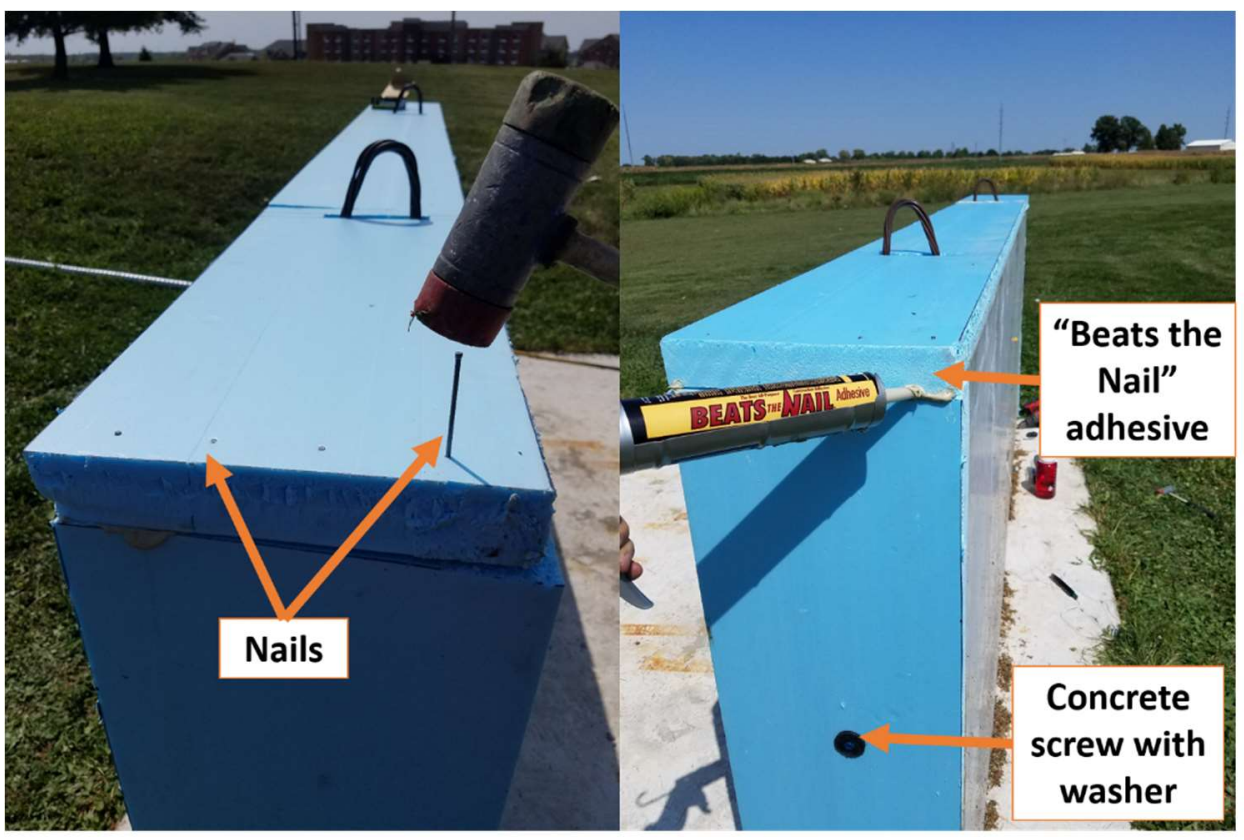

Figure 47 - How Styrofoam insulation was attached to the side of Specimen 1.

\subsubsection{Test 1.4}

This is the first test utilizing the enclosure. Data was collected on the 8-ft. x 4-ft. face of the specimen from September $22^{\text {nd }}$ to September $27^{\text {th }}, 2017 . \quad$ A second test was conducted from September $29^{\text {th }}$ to October $2^{\text {nd }}$ on a 4-ft. $x$ 4-ft. section. The second test contained the completely empty duct and a half-filled duct on the right side. Figure 48 shows the IR camera position of the camera when collecting data for a 4-ft. $x$ 4-ft. section of the specimen. The results of these tests will be presented in the following chapter. 


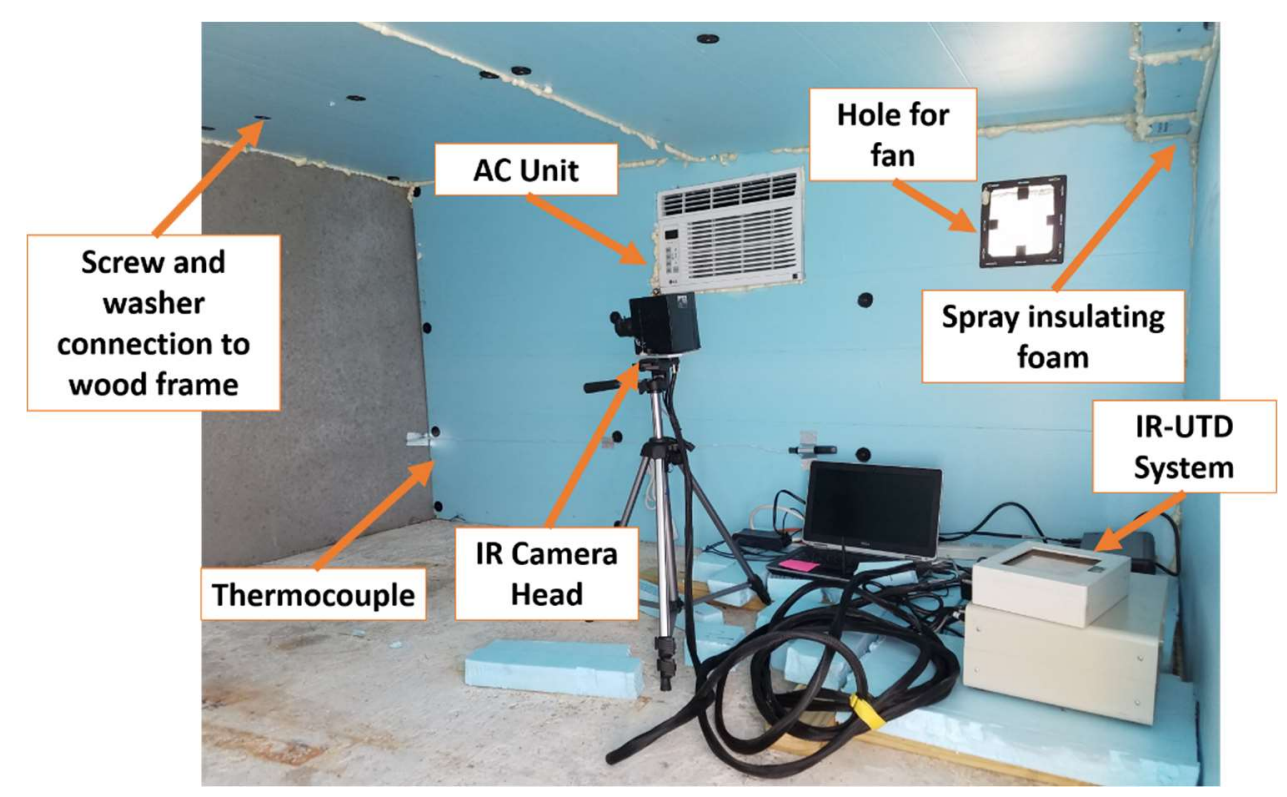

Figure 48 - Inside of the insulated structure without air control.

\subsubsection{Test 1.5}

A $5^{\circ} \mathrm{F}$ offset between the exterior and interior ambient temperatures was maintained throughout the test. The camera head is located in the position necessary to view an 8-ft. x 4-ft. area on the specimen. The thermocouple locations outlined in test 1.4 are the same thermocouple locations used during these tests. Data was collected from October $11^{\text {th }}$ to October $17^{\text {th }}, 2017$. Additional testing was conducted from October $17^{\text {th }}$ to October $19^{\text {th }}$. The results of these tests will be presented in the following chapter. 


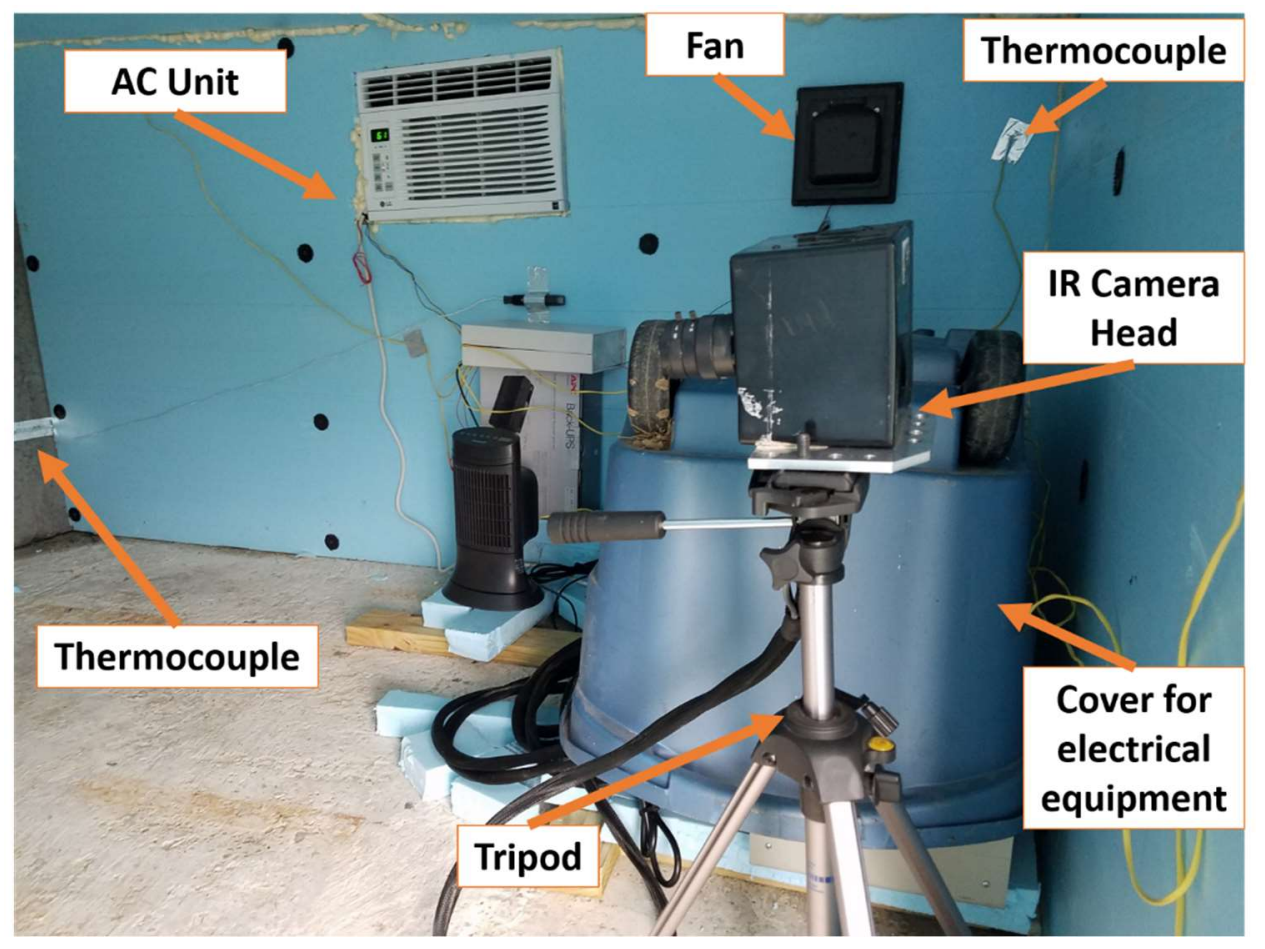

Figure 49 - Inside of the insulated structure with air control.

\subsubsection{Test 1.6}

The final test with specimen 1 was conducted using an ambient temperature offset of $15^{\circ} \mathrm{F}$ cooler on the inside of the enclosure. The IR camera was positioned to image the same $8 \mathrm{ft}$. $\times 4 \mathrm{ft}$. area that data was collected on in previously performed experiments. Figure 49 is the test setup used during this experiment. The thermocouple locations outlined in test 1.4 are the same thermocouple locations used during this experiment. Data was collected from October $19^{\text {th }}$ to October $25^{\text {th }}, 2017$. The result of this test will be presented in the following chapter. 


\subsubsection{Post Tensioned Specimen 2}

Testing on Post Tensioned Specimen 2 was performed at the same location as Post Tensioned Specimen 1. At the conclusion of testing Specimen 1 on October $25^{\text {th }}$, the specimen was removed, and replaced by Specimen 2 .

\subsubsection{Test 2.1 - Grouted - 5F}

A $5^{\circ} \mathrm{F}$ offset between the outside and inside ambient temperatures was used throughout this experiment. The Infrared camera was set to collect data on an 8-ft. x 4-ft. area of the specimen. Internal thermocouple data was collected, in addition to the surface thermocouple data collected in previous tests. Figure 50 shows the internal face of specimen 2, with duct locations called out in the image. The internal thermocouples at location 1 are tracking how the heat propagates through a sound portion of concrete. The internal thermocouples at location 2 are collecting data related to thermal transfer in the area of a void. The surface thermocouple locations are adjacent to fully grouted duct "B2", 32 inches up from the concrete base and 12 inches towards the middle of the specimen from the edge. The thermocouple location is called out in Figure 51. Figure 51 also displays the refinished face of PT Specimen 2. Data was collected from October $25^{\text {th }}$ to October $28^{\text {th }}, 2017$. The result of this test will be presented in the following chapter. 


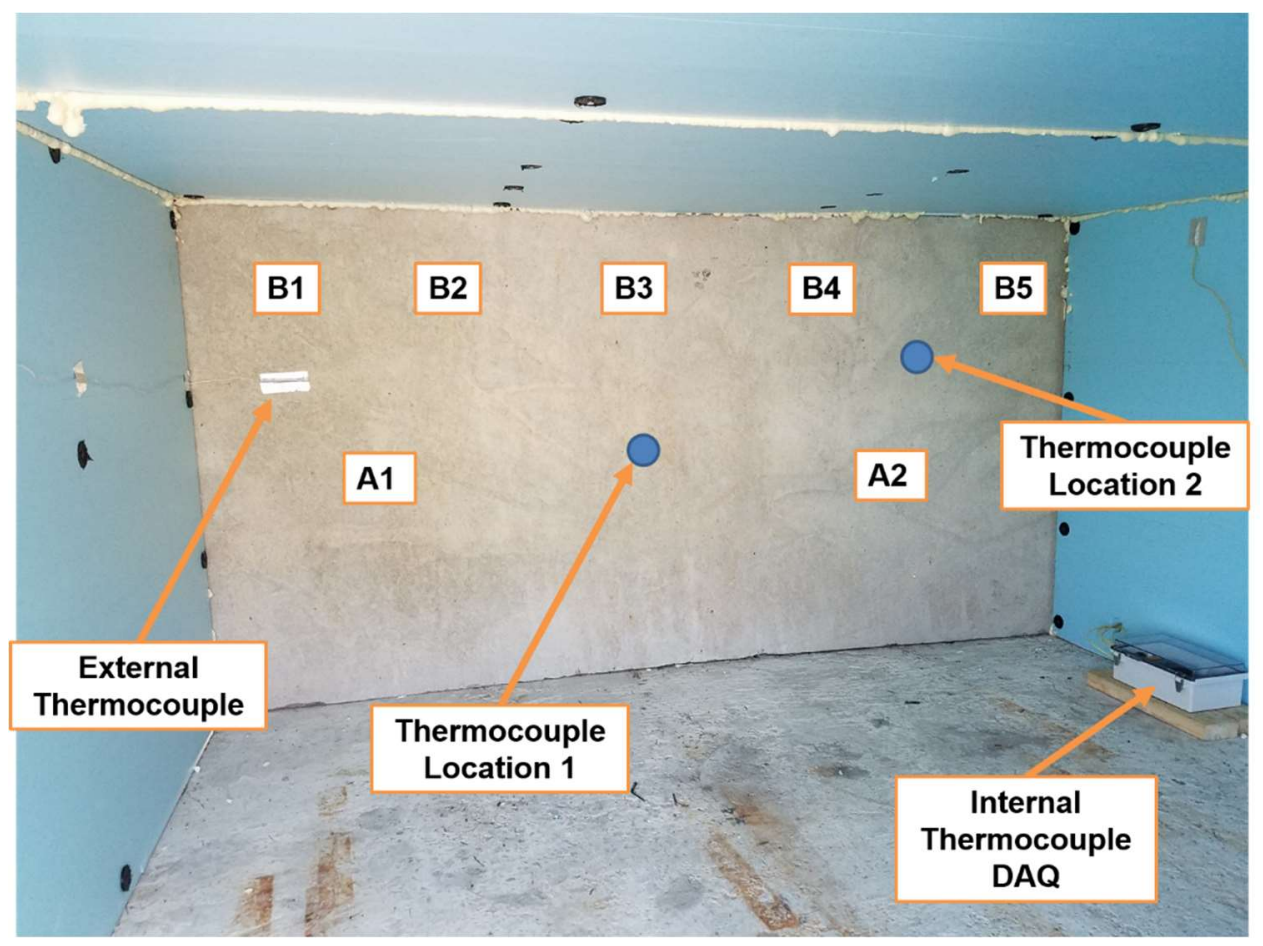

Figure 50 - Internal face of PT Specimen 2 during testing.

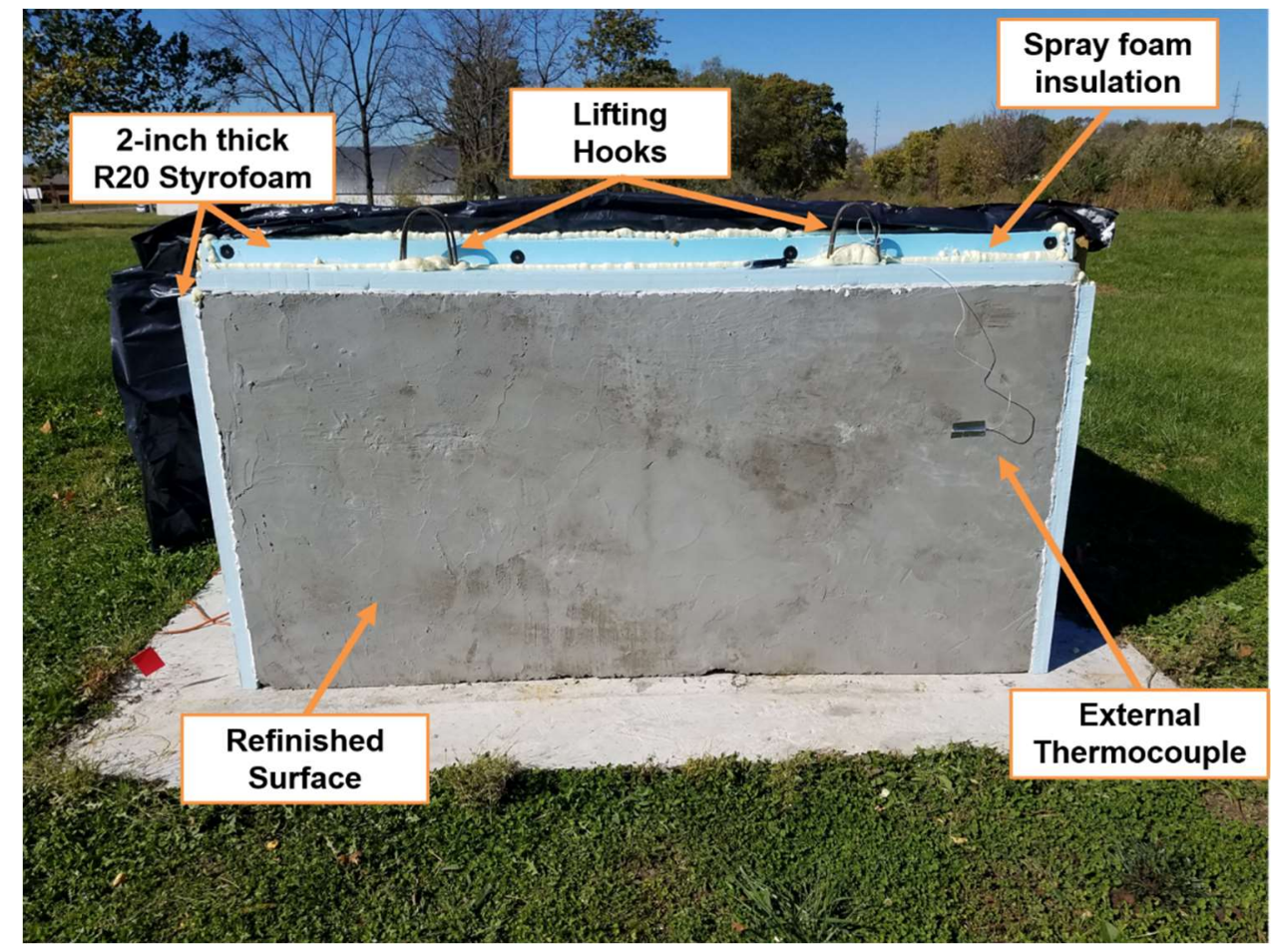

Figure 51 - External surface of PT Specimen 2 during testing. 


\subsubsection{Test 2.2}

Test 2 of specimen 2 included a $15^{\circ} \mathrm{F}$ offset on the inside of the specimen. The Infrared camera was moved forward to image a 4-ft. $x$ 4-ft. area of the specimen on the left side. This area included the six inch fully empty section in the top duct and the half empty section in the lower duct. Data was collected from November $1^{\text {st }}$ to the $4^{\text {th }}, 2017$. Two surface thermocouples were placed adjacent to the half-filled duct "A1" on the inside and outside of the enclosure, 16 inches up from the concrete base and 12 inches towards the middle of the specimen from the edge. The result of this test will be presented in the following chapter.

\subsubsection{Test 2.3}

Figure 52 shows the test setup used during this experiment. Due to previously conducted experiments outlined in this report, it was determined that additional measures should be taken to reduce the conductive heating into the base of the specimen from the concrete slab the specimen was placed upon. At an attempt to remedy this issue, specimen 2 was placed on top of a 2 -inch thick piece of R20 grade Styrofoam insulation. When the specimen was placed on top of the Styrofoam, it was unbalanced due to the soft surface. Two pieces of wood were attached to the frame of the previously utilized insulated structure to aid in balancing the specimen. Figure 53 gives a visual representation of both the Styrofoam base and the supports. 


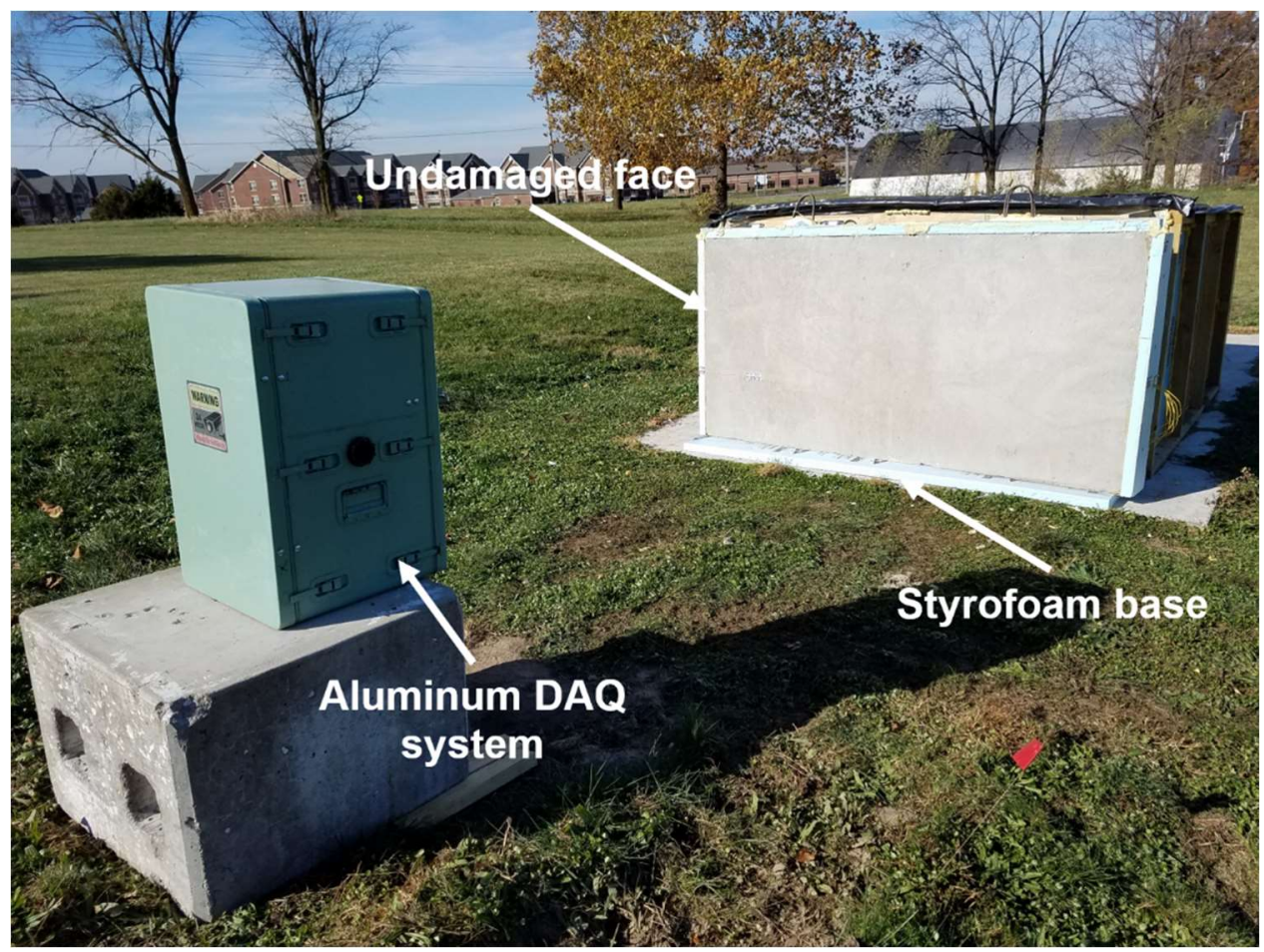

Figure 52 - Test setup used during test 3 on specimen 2.

The external thermocouples were placed at the location of the half empty duct; 16 inches up from the base and 12 inches towards the center of the specimen. These thermocouples were placed at these locations because the halffilled specimen has been the most challenging defect to detect up to this point. Therefore, these data would be the most beneficial during analysis. Data was collected from November $7^{\text {th }}$ to November $10^{\text {th }}, 2017$. The results of this test will be presented in the following chapter. 


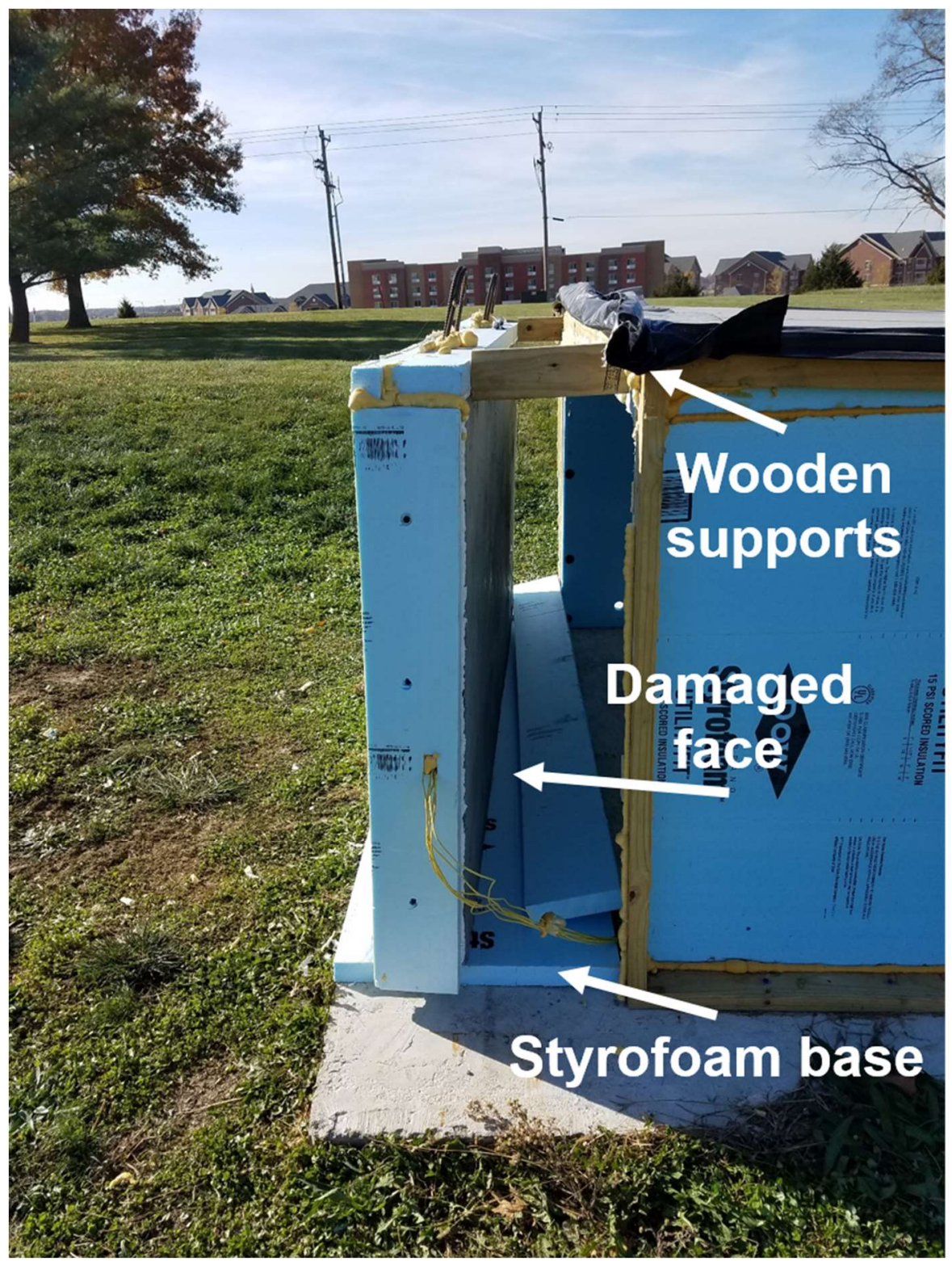

Figure 53 - Test setup for test 3 on specimen 2.

\subsubsection{Processing Techniques}

The following section will describe the processing techniques used to detect defects within each specimen. The results of these techniques will be discussed in chapter 4. 


\subsubsection{ROC and Delta Processing Technique}

Data from the IR-UTD system is analyzed using software provided with the system which includes three primary processing approaches. First, conventional thermal images can be analyzed to identify anomalies in the thermal characteristics of the surface being captured in the thermal images. Second, a delta image can be produced that captures the largest difference in thermal output between any two images in the time period being analyzed. The third method of processing data consist of measuring the rate of change (ROC) of thermal output during the time interval being processed. Data presented in the following sections will provide the results from each of these approaches.

\subsubsection{Quantitative Processing Technique}

The thermal images produced by the IR-UTD can be difficult to analyze and present due to the color scaling used for displaying the images. However, the quantitative data represented in the image can also be presented in $x-y$ plots showing data along a particular segment of the image. In this way, anomalies in the output data resulting from, for example, a subsurface void, can be more clearly presented. In some cases, the plotted data was used to illustrate the results of testing. These data were averaged using five rows of collected data in the area under consideration, normalized against a sound portion of concrete and plotted on a graph to display the difference in data output resulting from the thermal tests.

Red boxes are placed on the IR images to indicate the location of a defect. Five rows of pixel data were chosen near the center of each of the red boxes. All the data was then normalized by dividing each value by the average value of five 
data points at a location of sound concrete, indicated by a red circle. The sets of rows were then averaged together and plotted. 


\section{RESULTS}

This section of the report describes the results of the tests described in Chapter 3. The section begins with an explanation of the data presentations to be used to illustrate the results of testing. This section is followed by the results of each individual test.

\subsubsection{Test 1.1 - Data and Results}

This section of the report describes the results of test 1.1. This section will also be used to describe the format of results presented in the following sections. Figure 54 displays the ambient temperature variations measured by a thermocouple placed on top of the specimen. The data displayed was collected on June $21^{\text {st }}, 2017$. Vertical lines drawn on the image illustrate the time intervals during which data was analyzed. Solid lines indicate the time interval during which the data was analyzed to using the ROC processing approach. Dash lines indicate the time intervals during which the images used for delta processing were captured. The change in temperature (ambient, surface and internal) that occurred during the processing interval is typically marked on the figure. Finally, the peak temperature measured is indicated. A conventional infrared image was typically captured at the peak temperature and displayed. The changes in measured temperature is also called out to illustrate the conditions during which the data was collected.

During test 1.1 the peak temperature for the day occurred at 3:15 PM. ROC processing used the data collected between 7AM - 2:30PM for heating and 5:30 
- 10 PM for cooling. Delta processing utilized data collected between 11 AM 1:30 PM for heating and $7-9: 30$ PM for cooling.

Figure 55 displays the results from each processing technique used during the test. Images A, B and C represent the delta processing, conventional IR image captured, and the results of ROC processing, respectively. Images labeled "1" (i.e. A1, B1, and C1) show the images and typically include notes regarding the processed image. Images labeled "2" show the approximate position of the ducts in the image using longitudinal rectangular frames. These frames indicate the position of the ducts for reference and to illustrate the position of anomalies in the data as compared with the actual position of the ducts in the specimen.

For test 1.1, an indication corresponding to the position of the bottom duct can be observed in the conventional IR image and the ROC image. This indication was not present in the delta image produced. A second indication was observed in the area between the middle and top duct, as shown in the figure, shown as dark blue and purple colors. This indication did not correspond exactly to the position of the duct, and may be the result of the edge effect that can be clearly observed in the image. This indication may be caused by the increased gradients resulting from the edge effect interacting with the ducts, which contained no grout during this test. 


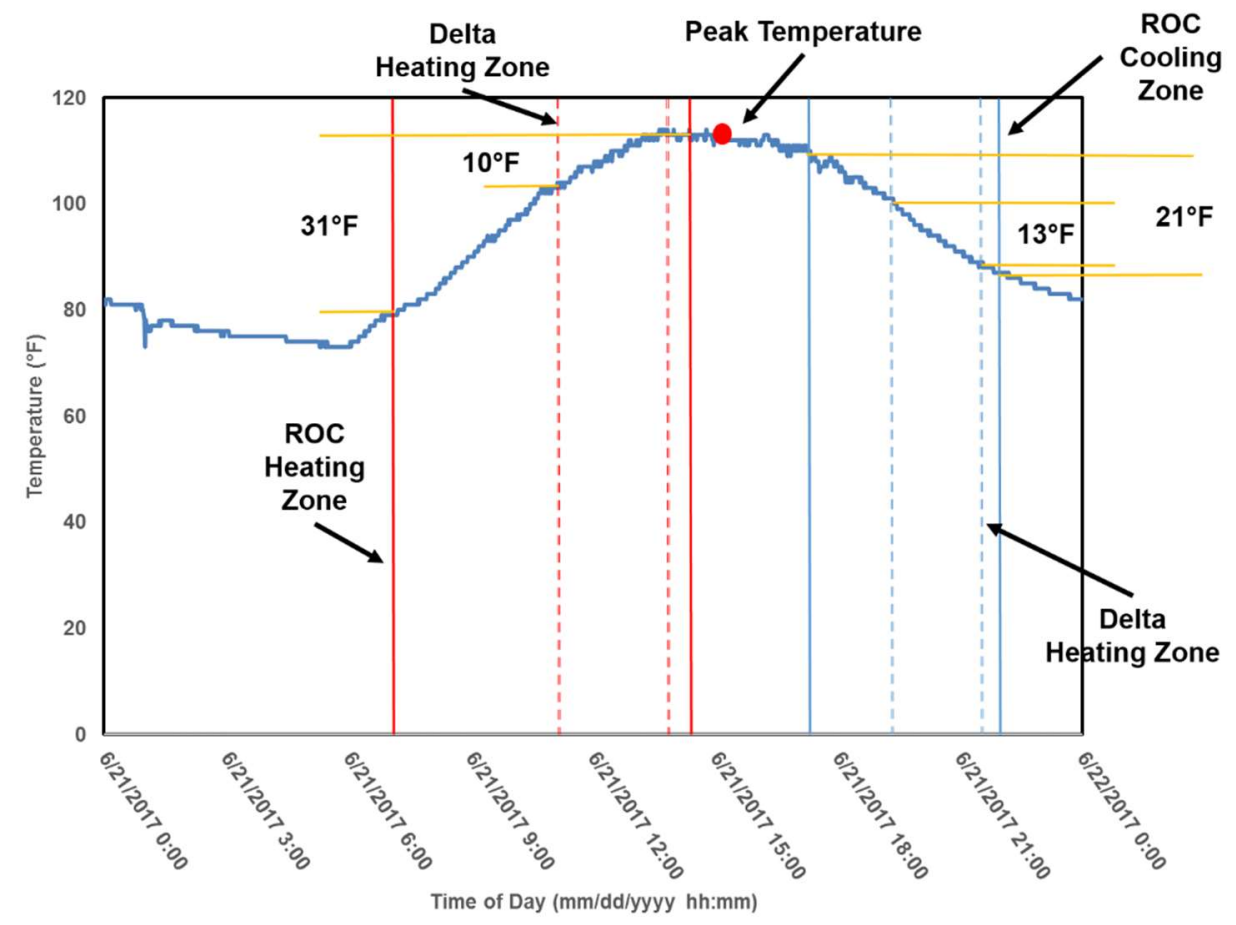

Figure 54 - Surface thermocouple data for PT Specimen 1 - Test 1 on June $21^{\text {st }}$. 

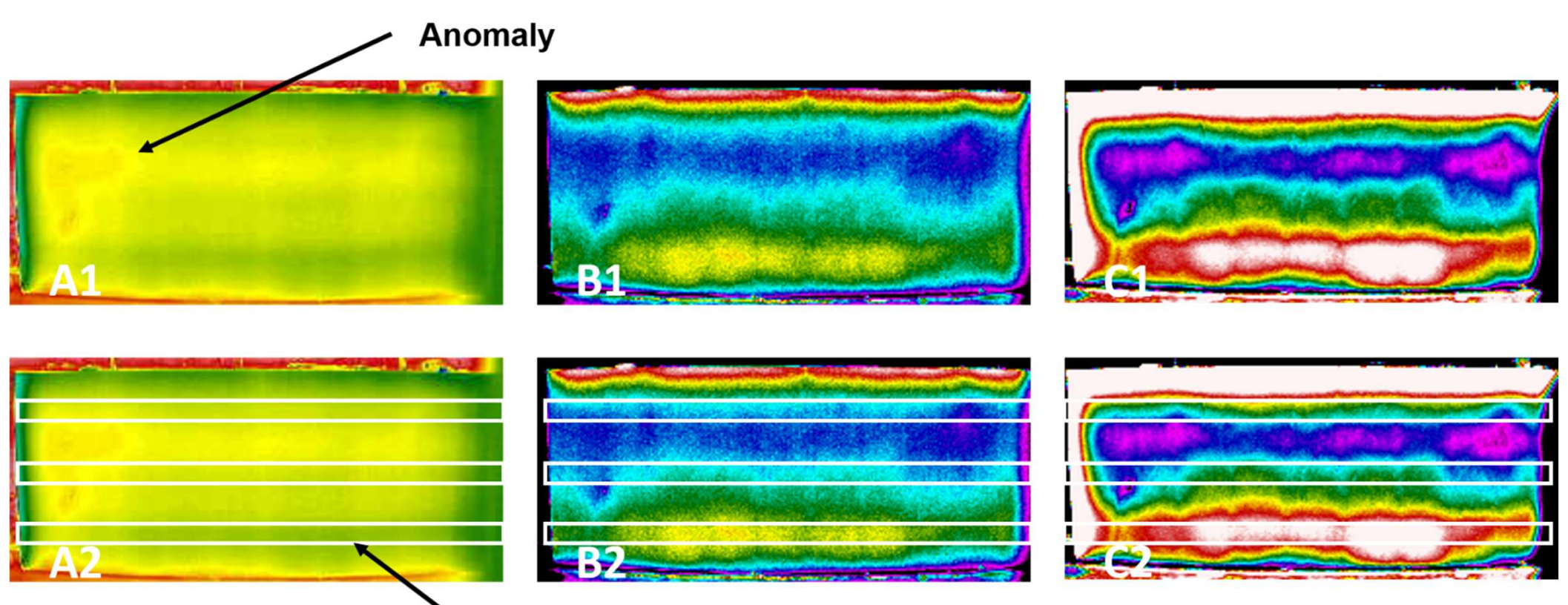

Approximate Duct

Locations

Figure 55 - Results after data processing on June 21 2017. 


\subsubsection{Test 1.2 - Data and Results}

Test 1.2 was conducted after the defects were inserted in the ducts and the ducts were grouted. The position of the grout and voids was shown in Figure 30 . Prior to test 1.2, the thermocouple was placed at the base of the specimen on the north side. Testing was conducted from August $29^{\text {th }}$ to September $4^{\text {th }}, 2017$. Figure 56 displays the thermocouple data collected on August $30^{\text {th }}, 2017$. The conventional IR image was captured at the peak temperature for the day which occurred at 6:11 PM, as shown in Figure 56. The ROC and Delta processing time intervals are also shown in the image. For this test, the ROC and Delta processing time intervals were the same. .

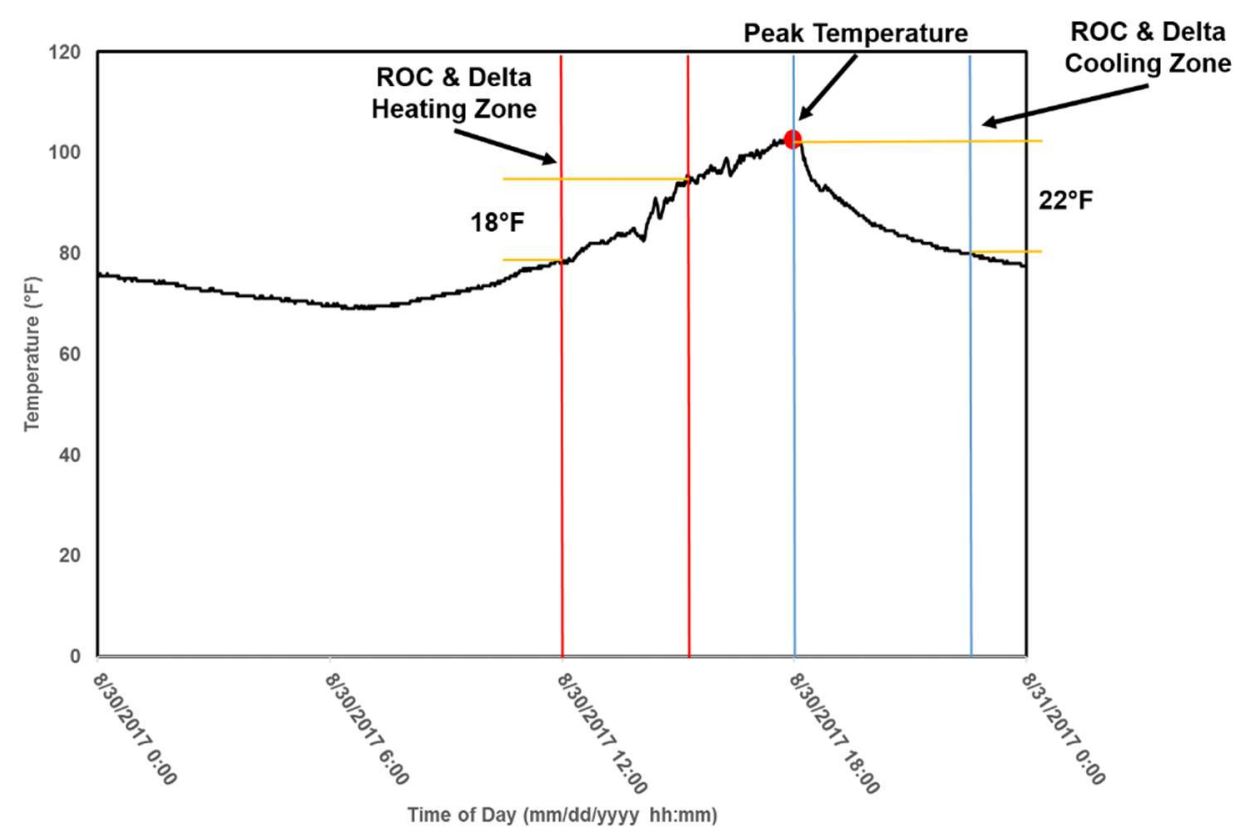

Figure 56 - Thermocouple data collected during Test 2 on August $30^{\text {th }}, 2017$.

Figure 57 presents the analyzed results from Test 1.2. As shown in the figure, the edge effects were less pronounced during Test 1.2 as compared with Test 1.1. This may have resulted from a smaller variation in the surface 
temperature observed during the test. There is also now a significant difference between a conventional infrared image and the two processing techniques, as compared to test 1.1 . This may also be due to the smaller variation in surface temperatures.

An indication can be observed in images $A 1$ and $A 3$ in the area of the bottom duct. This duct was completely empty on the right side, and half-empty on the left, with a segment of foam and full grout in-between, as shown previously in Figure 30. The indication in the area of the bottom duct is separated in the area of the fully-grout portion of the duct, and is diminished in the area of the half-full duct. The middle duct, which includes a 2-ft. section of foam in the middle and a halffilled portion of duct on the right side, also shows a slight indication in the area of the foam in the ROC image. No indications were found in the area of the top duct. 


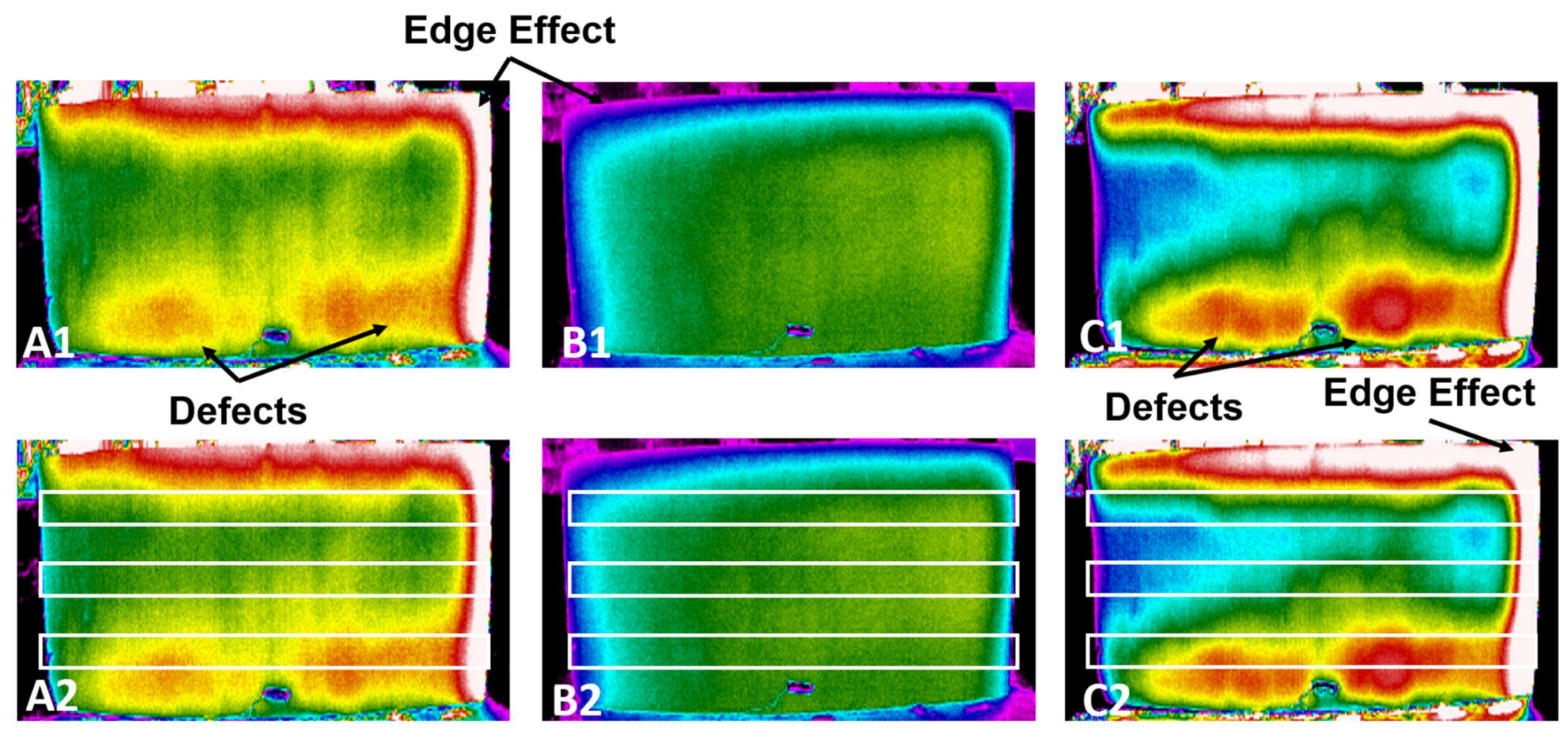

Figure 57 - Image produced from processing thermal data on August $30^{\text {th }}, 2017$. 


\subsubsection{Test 1.3 - Data and Results}

The results from tests 1.1 and 1.2 were analyzed and an additional test setup was formed to minimize the edge effects present in the images. Thermocouple data was collected for both the north and south side of the specimen. Both thermocouples were placed at mirrored positions in the center of the specimen, $5 \mathrm{ft}$. from the edge of the specimen and 18 inches up from the base concrete slab. Data was collected from September $7^{\text {th }}$ until September $13^{\text {th }}, 2017$. Figure 58 shows the measured temperatures for each side of the block for September $10^{\text {th }}, 2017$, and also indicates the time intervals during which data was analyzed. It can be observed in the figure that the maximum temperature on the north side of the block was significantly out of phase with the maximum temperature on the south side of the block. Data processing time intervals were selected based on the temperature data for the north side of the block.

Figure 59 shows the images produced for test 1.3. The thermocouple located on the surface of the specimen can be observed in the images produced. Slight indications were observed in the area of defect in all three ducts during this test. Conventional IR imaging showed an indication in the area of the defects in the bottom duct, while both the delta and ROC processing showed slight indications in all three ducts. However, strong indications were observed for only the bottom and middle duct in the area of the implanted defects. The edge effect appears to be only minimally reduced by use of the Styrofoam sheets around the edges. 


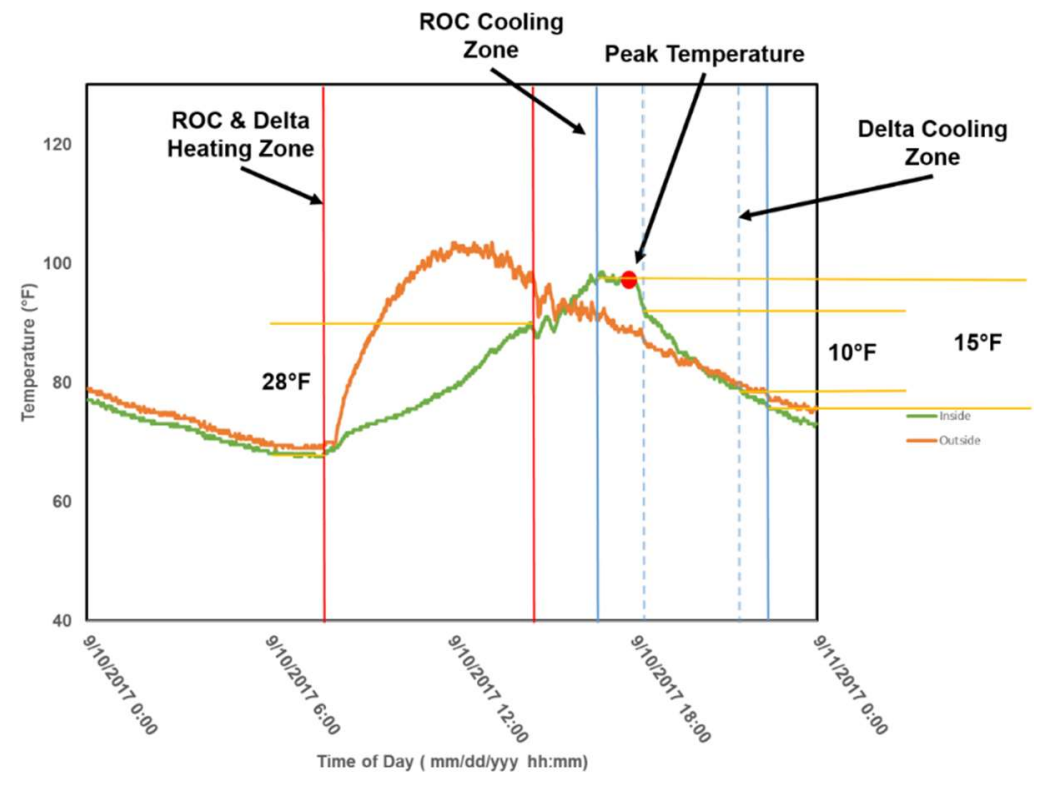

Figure 58 - Thermocouple data collected on PT Specimen 1 on September $10^{\text {th }}$. 


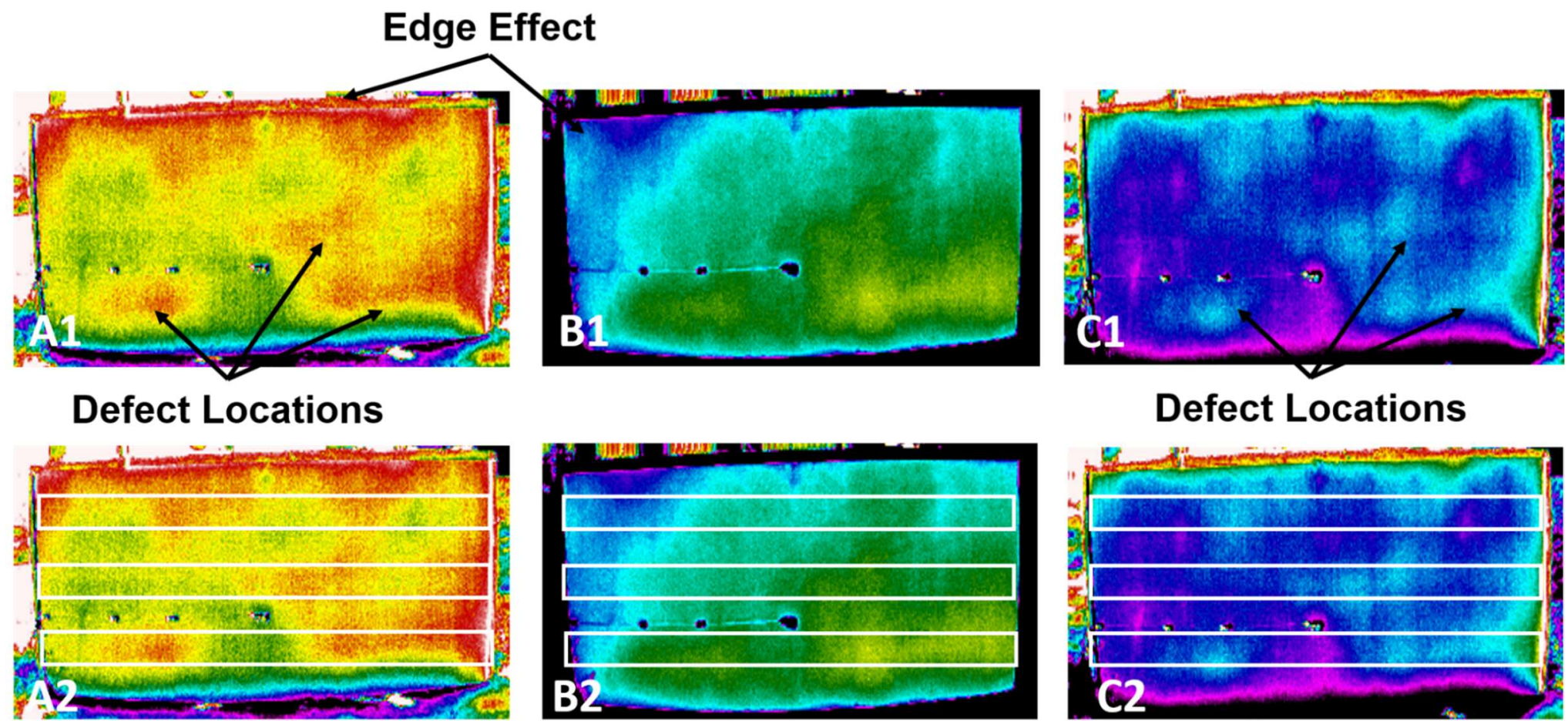

Figure 59 - Processed image from data collected on September $10^{\text {th }}, 2017$. 


\subsubsection{Test 1.4 - Data and Results}

Test 1.4 was conducted with specimen 1 placed against the enclosure constructed to simulate the environment within a PT box girder. The temperature inside the enclosure was uncontrolled for this test. Two thermocouples were placed on the north and south side of specimen adjacent to the completely empty portion of the bottom duct. Data was collected from September $22^{\text {nd }}$ to the $25^{\text {th }}$, 2017. Figure 60 displays the thermocouple data collected for September $24^{\text {th }}$ and the first six hours of September $25^{\text {th }}$. The heating and cooling periods for both the ROC and Delta processing are shown in the image. It can be observed in the temperature data that the rate of change and maximum temperature inside the enclosure was reduced as compared with previous tests outside the enclosure.

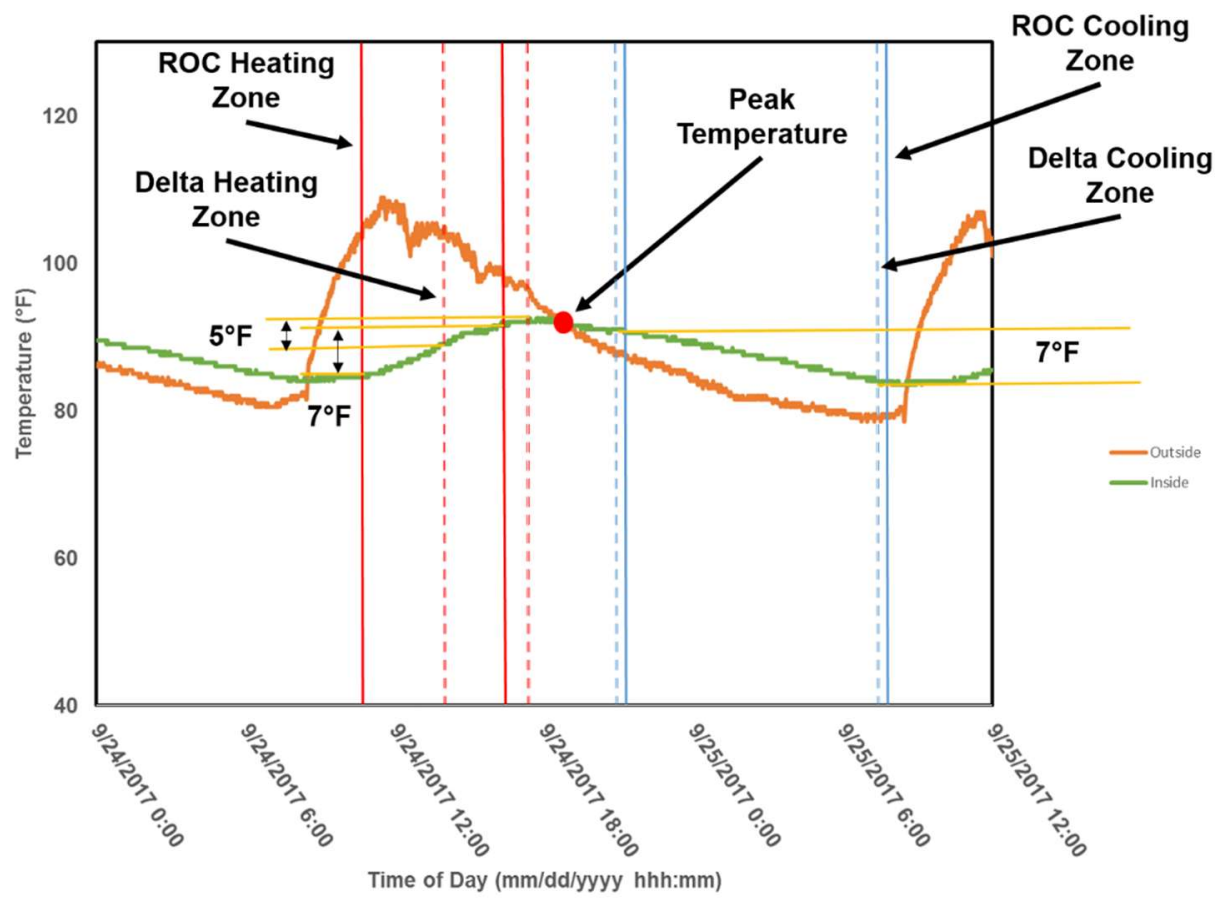

Figure 60 - Thermocouple data from testing conducted on September $24^{\text {th }}$ September 25 ${ }^{\text {th }}, 2017$. 
Figure 61 shows the results of data processing. The results of this test were not as pronounced as previous tests due to the enclosure. The conventional IR image did not indicate any defects, while the Delta and ROC processing shows a slight indication at the location of the half-filled portion of the bottom duct at A1 and C1. The Delta and ROC processing also indicate stronger indications at the location of the fully empty duct. However, these indications were not well defined. 
Delta Processing

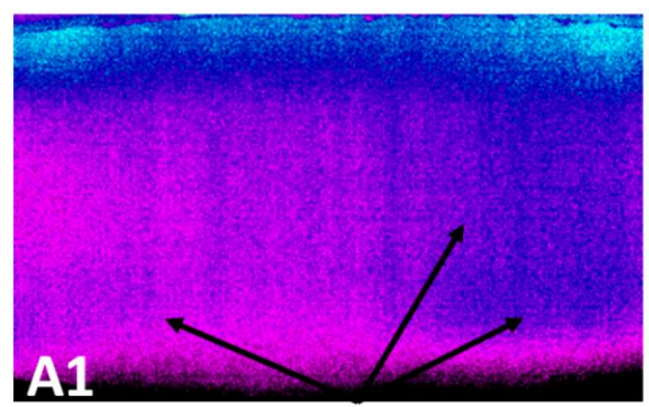

Location of

Defective Ducts

$\stackrel{0}{\rightarrow}$

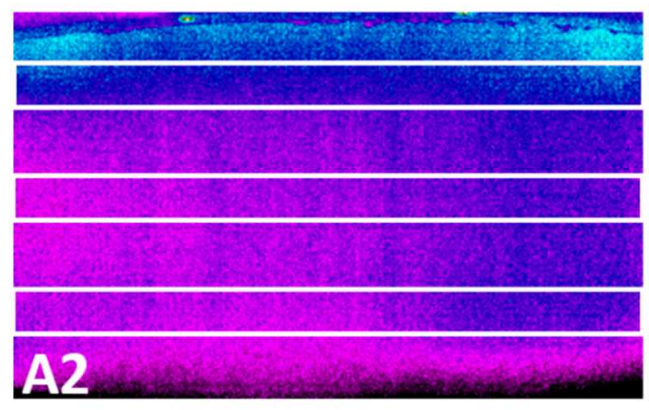

Conventional IR Image

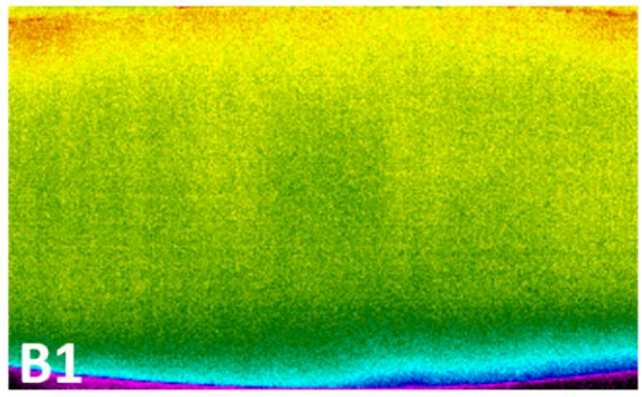

B1

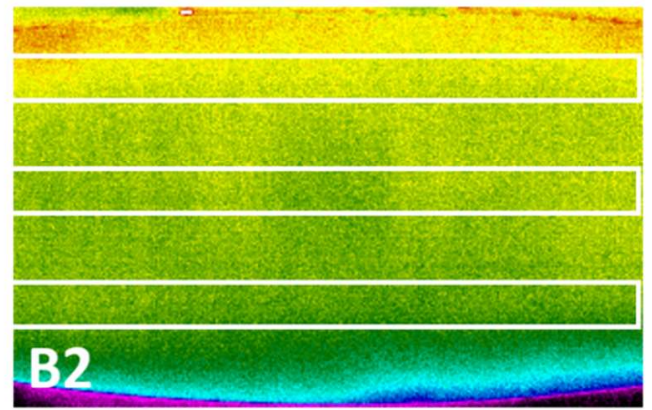

ROC Processing

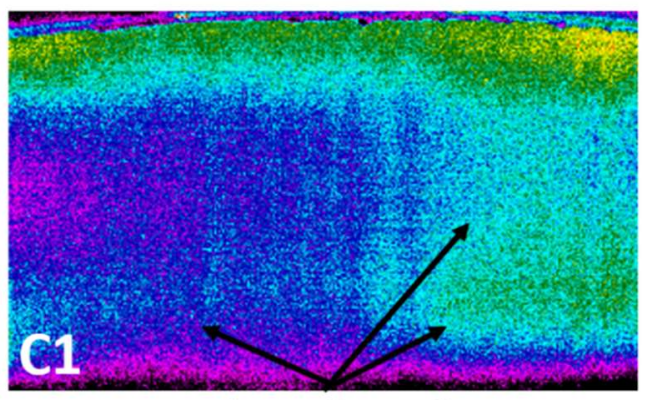

Location of

Defective Ducts

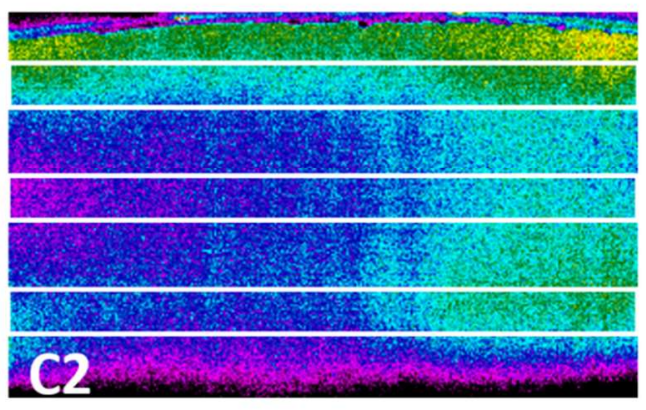

Figure 61 - Infrared results from testing on September $24^{\text {th }} \& 25^{\text {th }}, 2017$. 
The IR-UTD was relocated so that a 4-ft. $\mathrm{x} 4$-ft. area of the specimen was visible. The area of interest was the side of the specimen that contains the completely empty bottom duct and half empty middle duct (right side). Figure 62 shows the thermocouple data collected at the described location on September $30^{\text {th }}$ and part of the morning on October $1^{\text {st }}$. A conventional infrared image was collected at the peak temperature on the inside face of the specimen, at 6 PM. Figure 63 is an image of the infrared results obtained after processing the collected thermal data.

An indication was observed in the area spanning the defect locations in the bottom and middle duct as shown in image $\mathrm{C} 1$ and $\mathrm{C} 2$ in Figure 63. This anomaly is believed to stem from the empty portion of both ducts, and may result from location of the empty duct relative to the base of the specimen, where heat transfer with the concrete slab supporting the specimen is occurring. This anomaly is also located in close proximity to the edge of the specimen, and could be affected by the edge effect. 


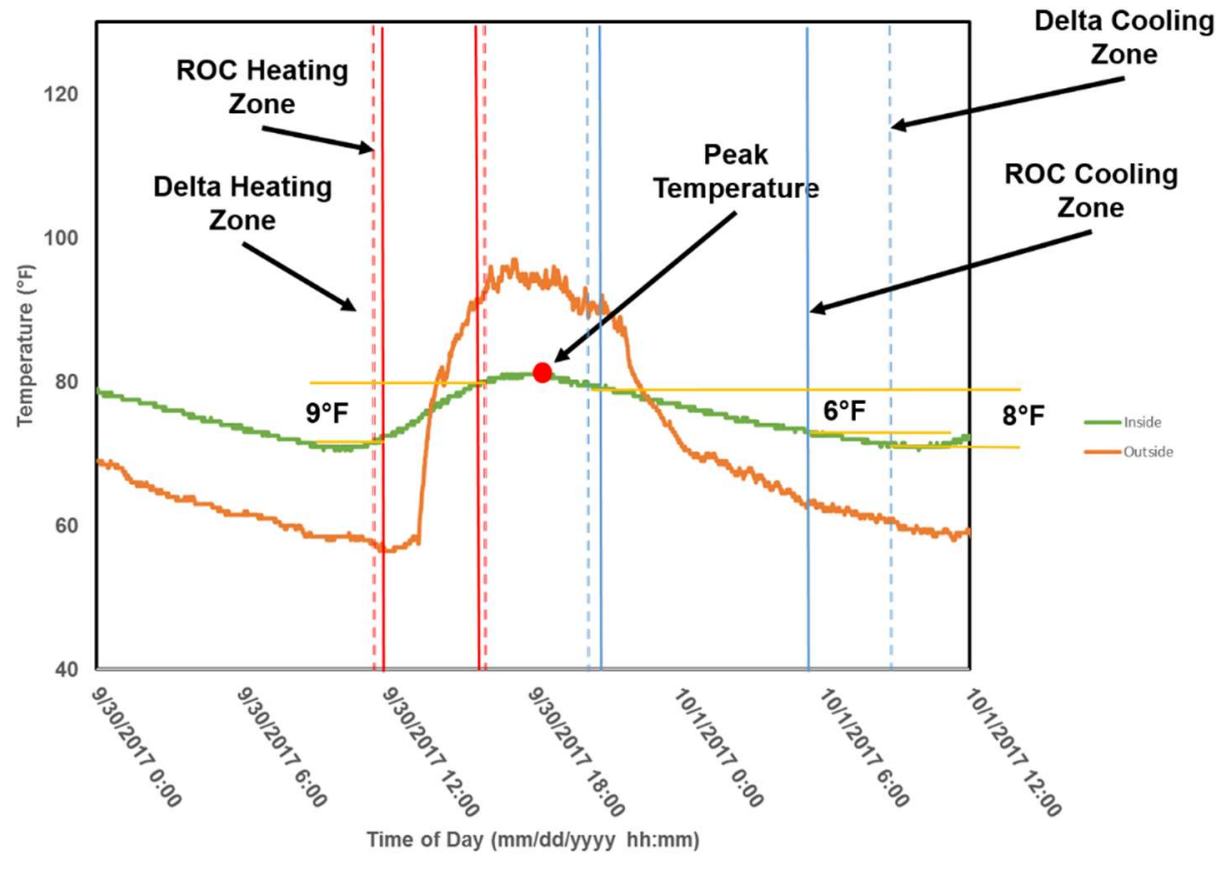

Figure 62 - Thermocouple data collected from September $30^{\text {th }}$ to October $1^{\text {st }}$. 
Delta Processing

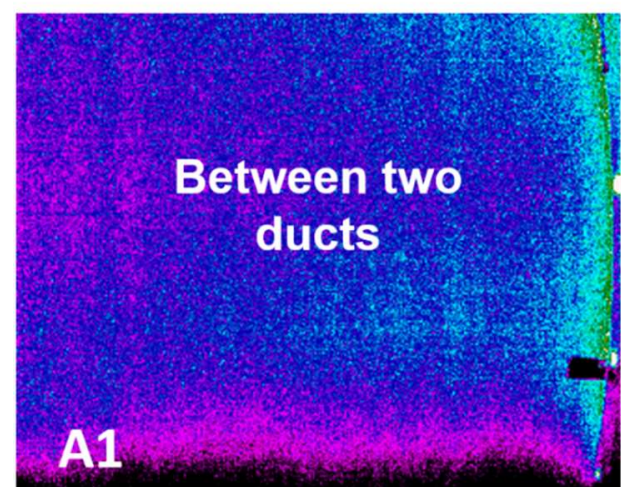

$\stackrel{\wp}{\perp}$
Conventional IR Image
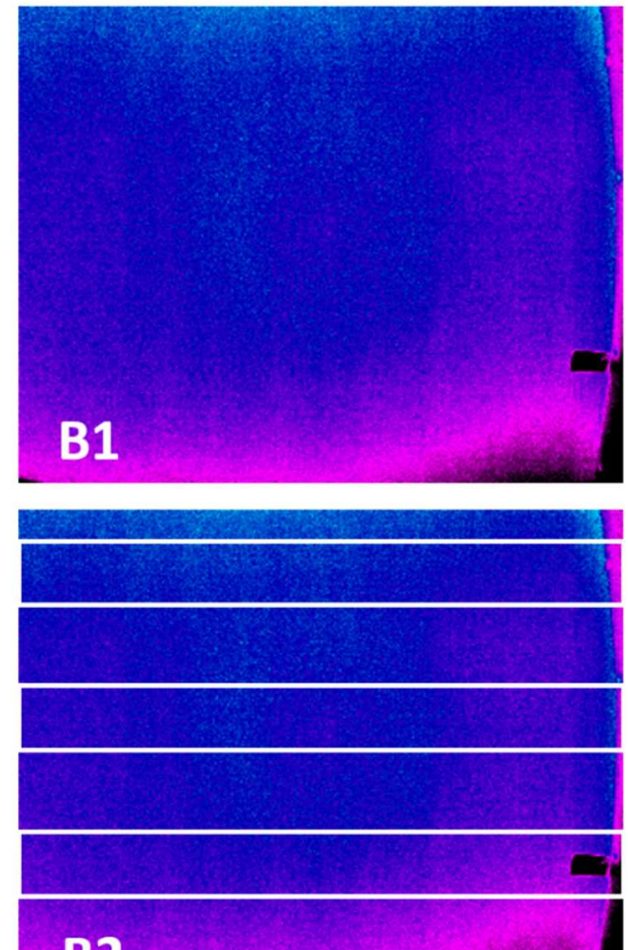

B2
ROC Processing
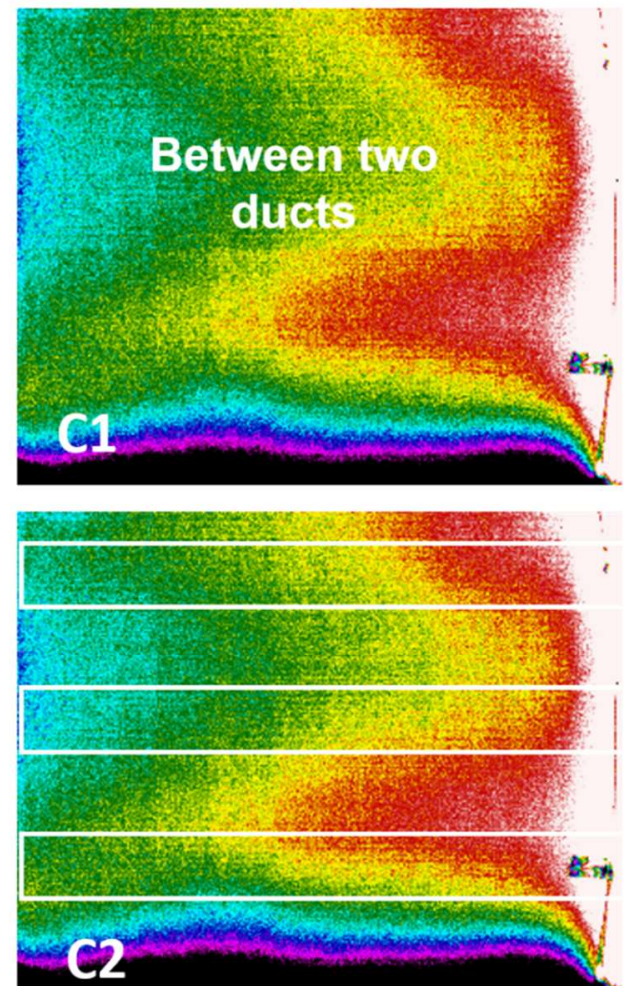

Figure 63 - Infrared results from processing thermal data collected on September $30^{\text {th }}$ and October $1^{\text {st }}$. 


\subsubsection{Test 1.5 - Data and Results}

Test 1.5 consisted of maintaining a $5^{\circ} \mathrm{F}$ offset between the ambient environment and the temperature inside the enclosure. Two different camera positions were used during the test, position 1 capturing an 8-ft. $x$ 4-ft. portion of the specimen and position 2 a 4-ft. $x$ 4-ft. portion of the specimen.

Testing was conducted from October $11^{\text {th }}$ through October $17^{\text {th }}, 2017$. Data was processed for October $16^{\text {th }}$ and part of the $17^{\text {th }}$. Figure 64 displays the collected thermocouple data used in data processing.

Figure 65 is an image of the results produced from processing the collected thermal data.

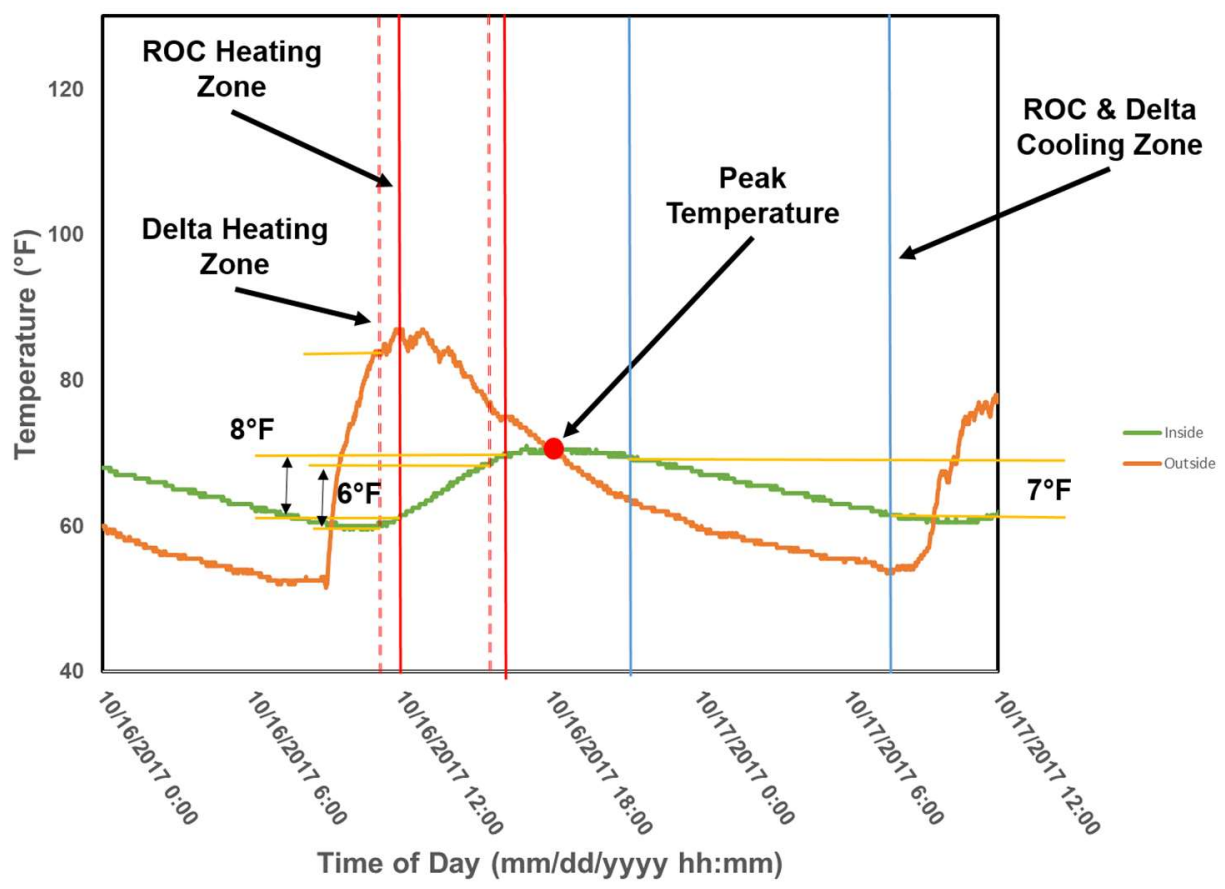

Figure 64 - Thermocouple data collected during test 5 on October $16^{\text {th }} \& 17^{\text {th }}$. 


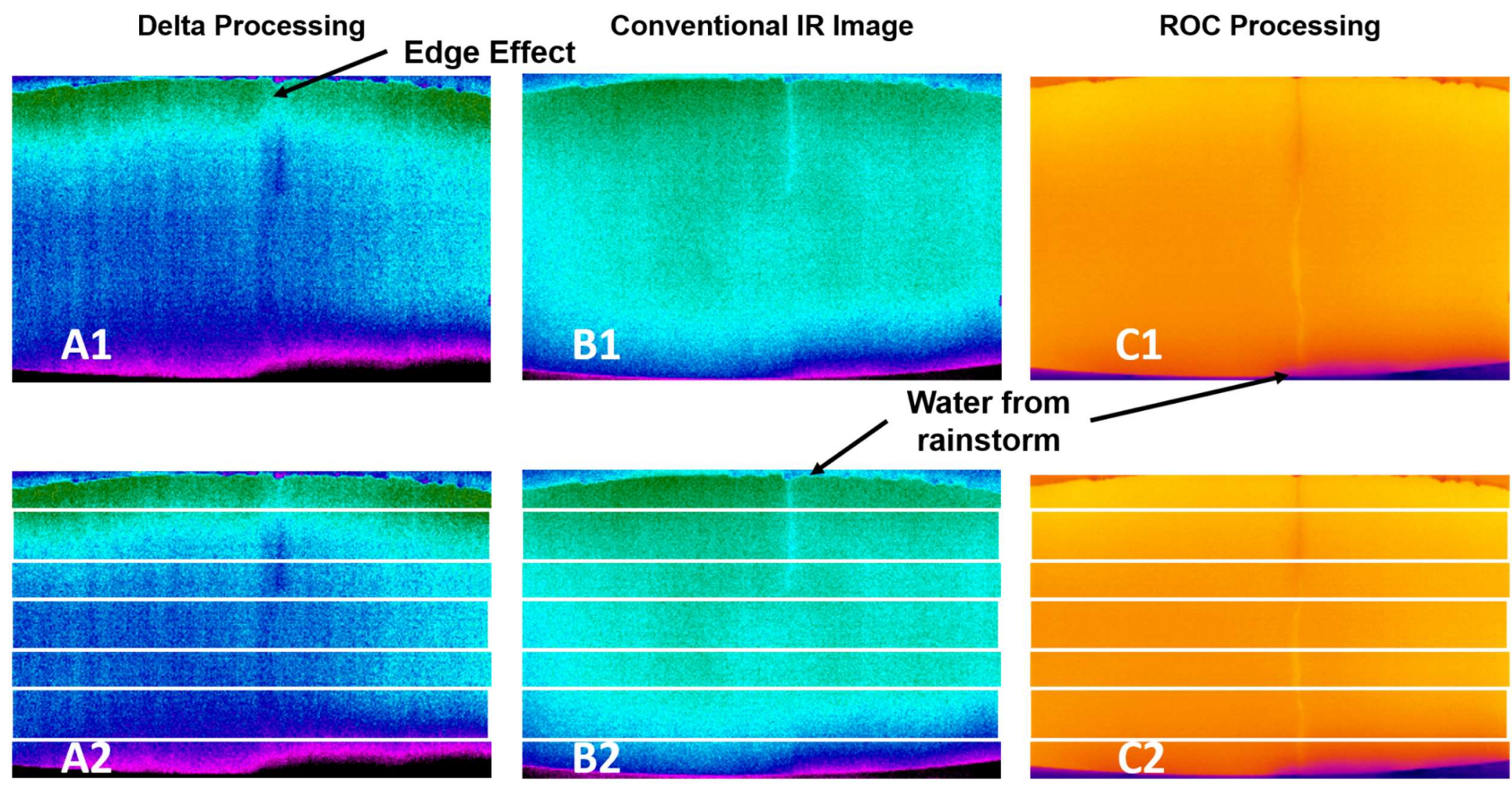

Figure 65 - Processed infrared image from data collected on October $16^{\text {th }}$ and $17^{\text {th }}$. 
Analysis of results did not show any indications stemming from any of the implanted defects. This is most likely due to the fact that several storms passed through the area during the testing period. As Figure 65 points out, water from the rainstorm has run down the face of the specimen, affecting the results.

The camera was placed in position 2 for data collection during the time interval of October $17^{\text {th }}$ to October $19^{\text {th }}, 2017$. Figure 66 is an image of the collected thermocouple data used during data processing. The time intervals during from which data was processed are also shown in the figure.

Figure 67 is an image of the results produced from processing the collected thermal data. The results from the conventional infrared image, the ROC processing image and the Delta processing image coincide with the results from test 4 , which had no air control. There are again thermal abnormalities in between the ducts, pointing to a repeatable phenomenon. Both the Delta and ROC processing techniques detect this thermal indication, while the ROC appears to be well defined. 


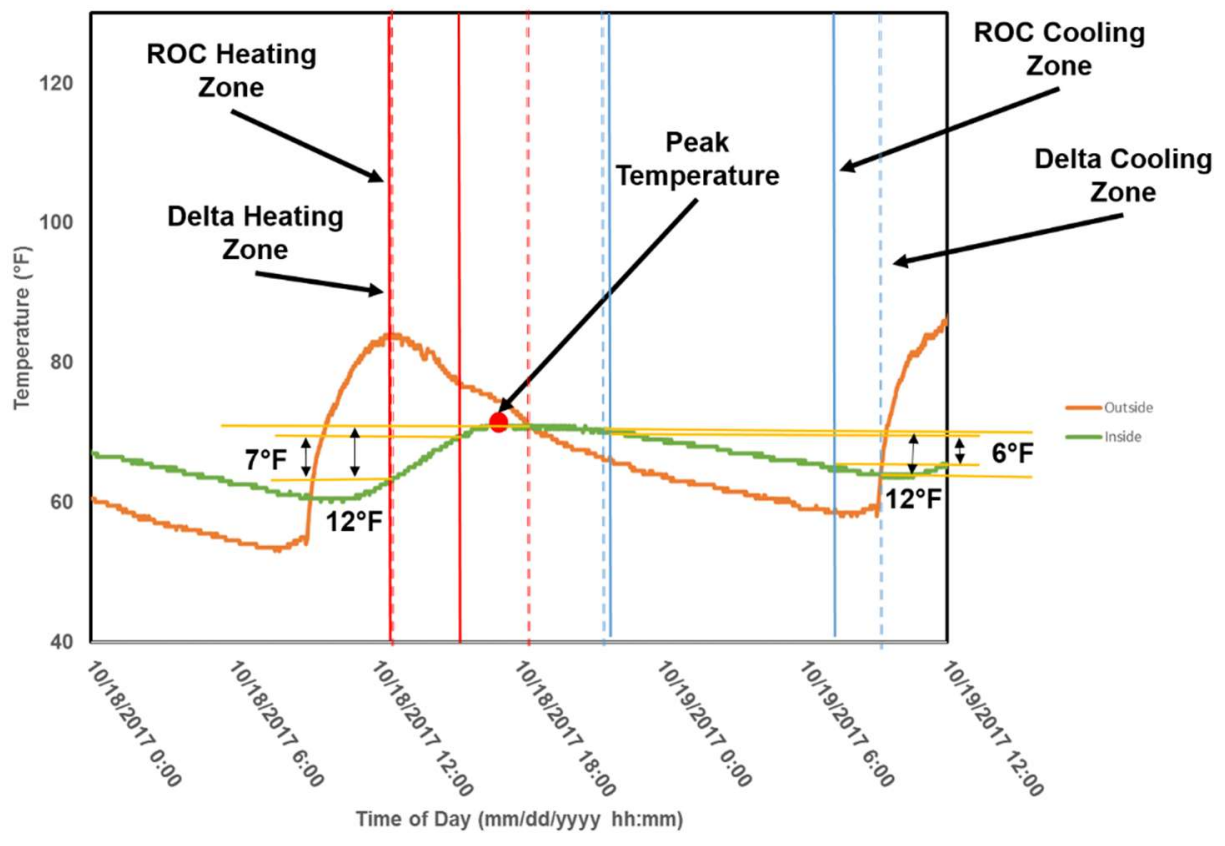

Figure 66 - Thermocouple data collected on October $18^{\text {th }}$ and $19^{\text {th }}$ for test 5. 

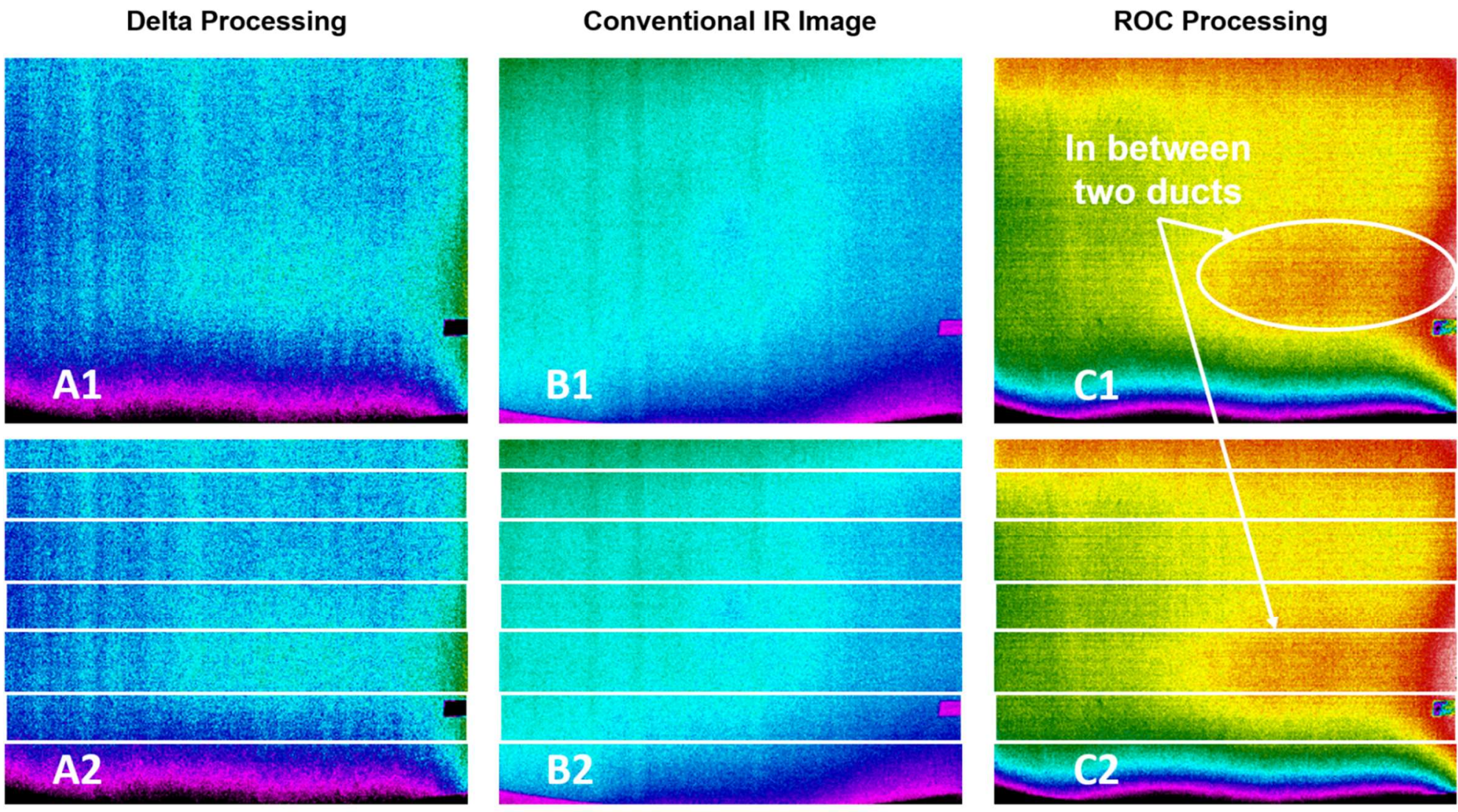

Figure 67 -Processed infrared image collected on October $18^{\text {th }}$ and $19^{\text {th }}$ for test 5. 


\subsubsection{Test 1.6 - Data and Results}

Test 1.6 utilized a temperature offset of $15^{\circ} \mathrm{F}$ between the enclosure and the ambient environment. The IR-UTD camera was placed at the position 2 location described in test 1.5. Data was collected from October $19^{\text {th }}$ to October $25^{\text {th }}, 2017$. Thermocouple data from October $21^{\text {st }}$ and $22^{\text {nd }}$ were used when processing the infrared images, and are displayed in Figure 68. The time intervals from which data were processed is shown in the figure. During this test, a rainstorm occurred that resulted some water on the surface of the specimen.

Figure 69 are the results from infrared image processing. Water on the surface of the specimen can be observed in the images as a vertical indication in image $\mathrm{C} 1$ and $\mathrm{C} 2$. Similar to previous experiments, an indication was observed in the area between the bottom and middle ducts. There appeared to be no major differences in results from the $5^{\circ} \mathrm{F}$ offset to the $15^{\circ} \mathrm{F}$ offset.

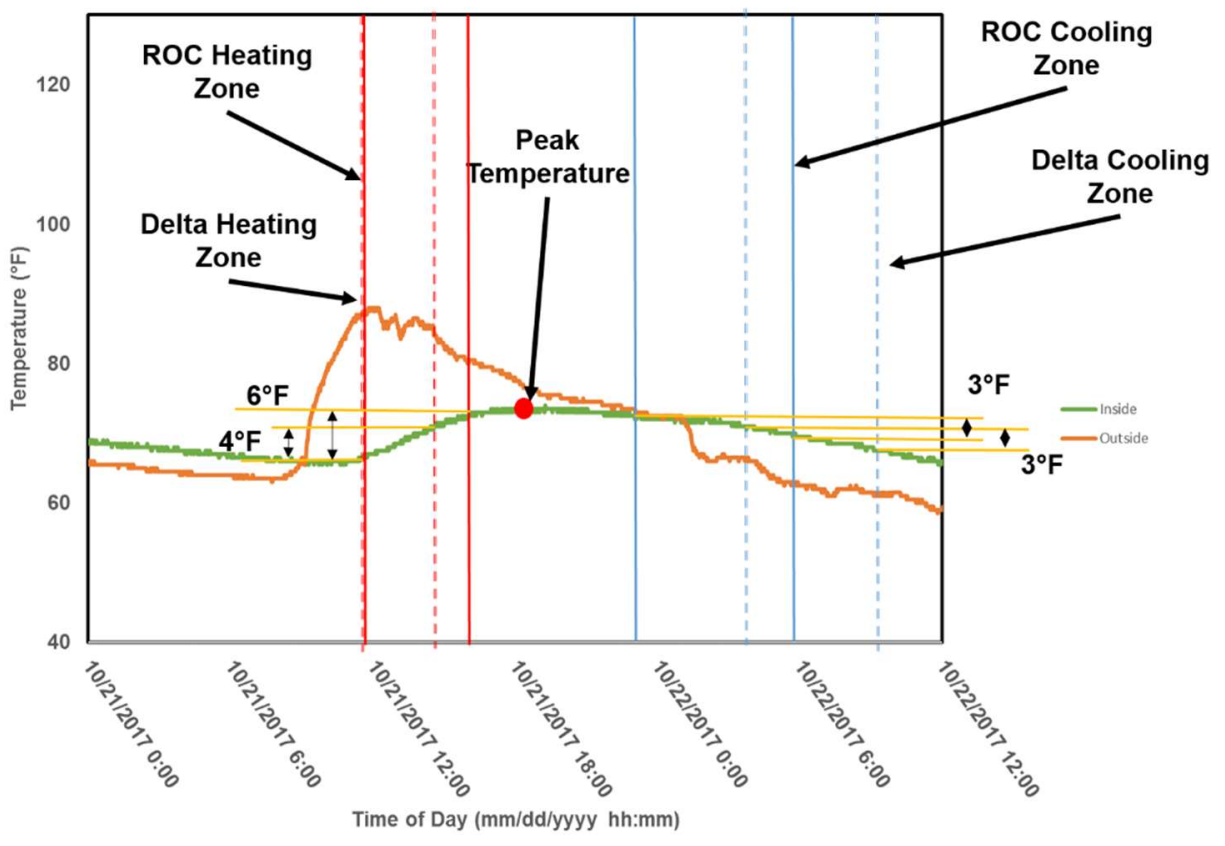

Figure 68 - Thermocouple data collected during test 6 on October $21^{\text {st }}$ and $22^{\text {nd }}$. 
Delta Processing

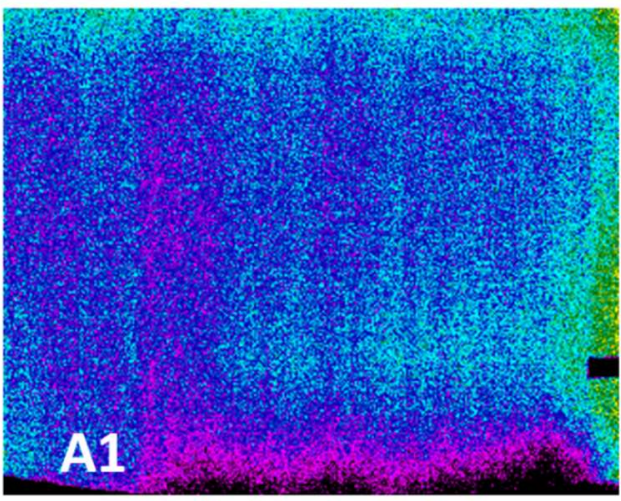

옴

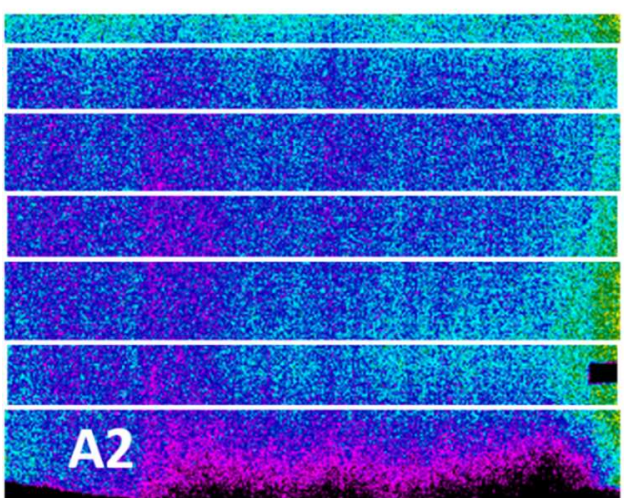

Conventional IR Image
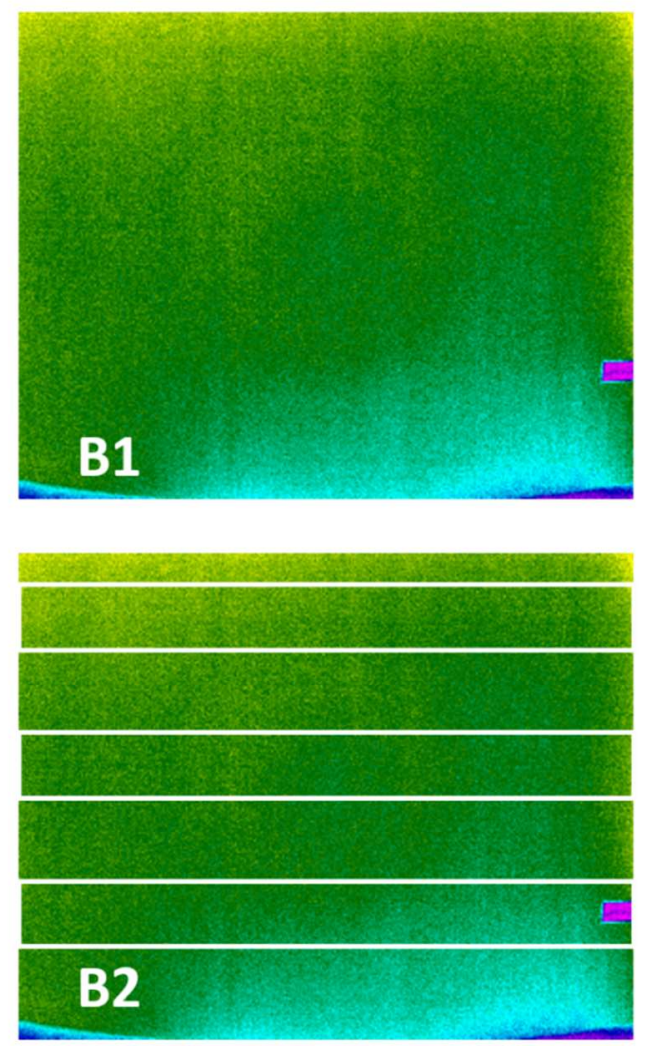

ROC Processing
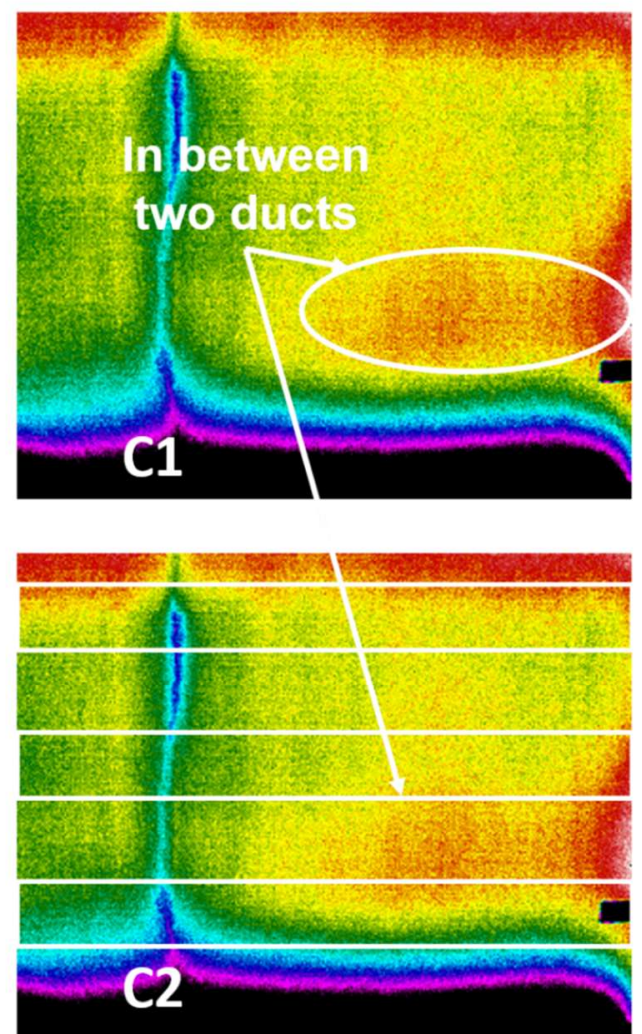

Figure 69 - Processed infrared image from testing on October $21^{\text {st }}$ and $22^{\text {nd }}$. 


\subsubsection{Test 2.1 - Data and Results}

After testing was completed on Specimen 1, Specimen 2 was moved into the same location alongside the structure for testing. A $5^{\circ} \mathrm{F}$ ambient temperature offset between the inside and outside temperatures was used throughout this test. Thermocouple and infrared data were collected from October $25^{\text {th }}$ to October $28^{\text {th }}$, 2017. Thermocouple data for both internal and external temperature changes were collected during testing as described in section 3.3.2.1. The infrared camera was placed at the back of the insulated structure for maximum viewing of the $4 \mathrm{ft}$. $x 8 \mathrm{ft}$. specimen face.

Thermocouple data collected on October $26^{\text {th }}$ and in the early morning hours of October $27^{\text {th }}$ were used during data processing. Figure 70 displays all of the collected thermocouple data during the described processing period. 


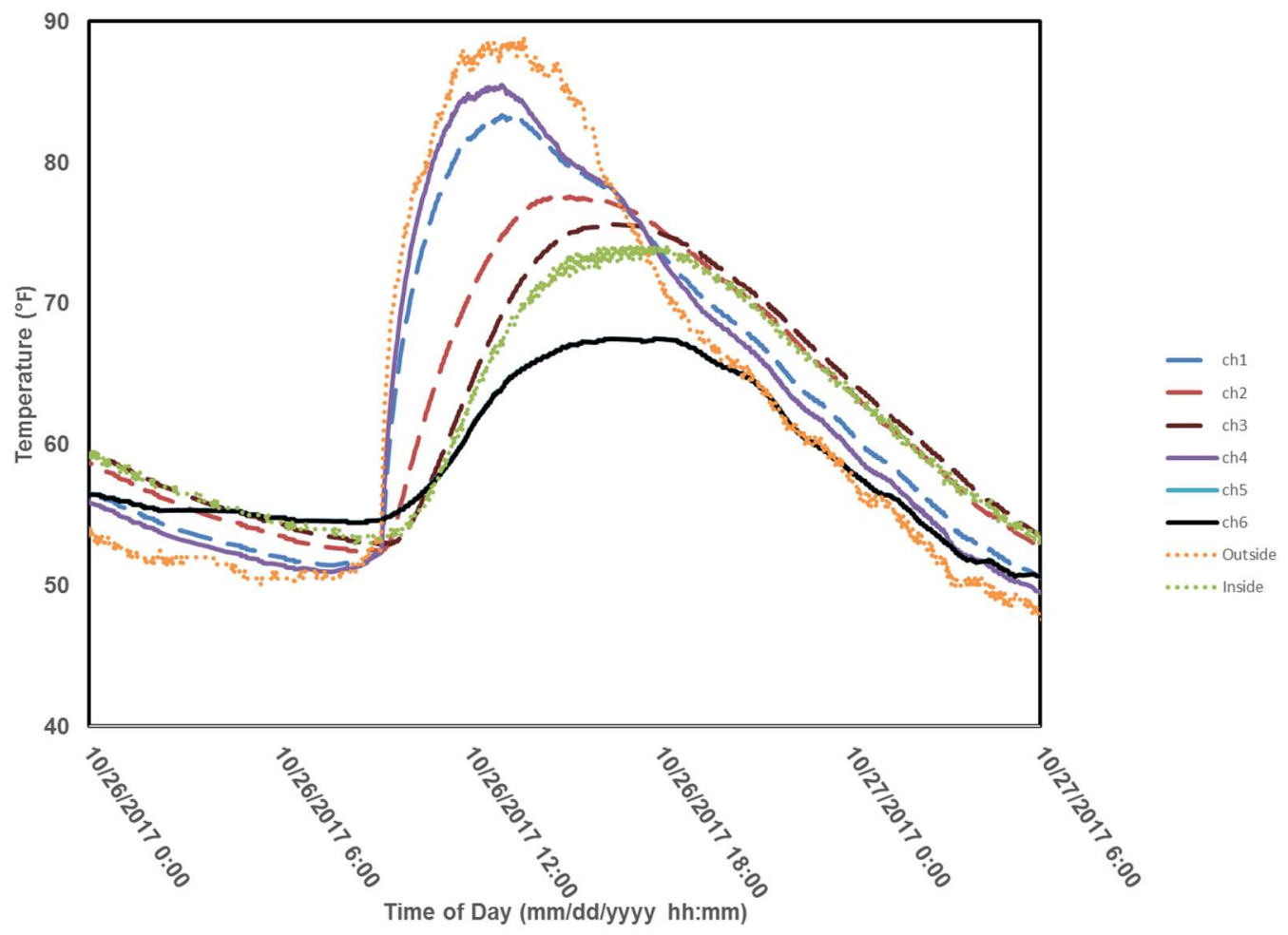

Figure 70 - All thermocouple data collected during test 1 on October $26^{\text {th }}$ and $27^{\text {th }}$.

The legend in the bottom right side of Figure 70 displays eight different thermocouple values being charted. Channel 1 through Channel 6 corresponds to the locations of the thermocouples placed throughout the specimen cross section outlined in section 3.2.2.1. The internal thermocouple locations of greatest interest are that of thermocouples 3 and 6 , which tracks the temperature adjacent to a sound portion of concrete and defective duct, B4. Comparing these to the "Inside" thermocouple, shows the change in temperature just below the surface and the surface temperature.

The "Inside" thermocouple is referring to the temperature at the face of the specimen on the inside of the insulated structure adjacent to a filled duct. Most importantly, the location of the "inside" thermocouple is not adjacent to 
thermocouple 3 or 6 . During testing, several heating and cooling periods were evaluated to find the best possible infrared image that would showcase the ability of the IR-UTD system to detect the embedded defects.

Channel 6 is attached to the rebar under the surface of the specimen facing the inside of the structure, at a location adjacent to duct B4. Since the thermocouple isn't on the inside surface of the specimen, it was assumed that the largest increase in heating and cooling at the specimen surface would occur later in time than indicated by the graphed values. This is because it should take additional time for the heat to transfer through the remaining material to the inside surface. Because of this, files collected later in time from when channel 6 started to increase in temperature were analyzed at first. Though these data produced similar results, the results produced during the presented timeline are better defined.

A conventional infrared image was collected at the peak temperature on the inside face of the specimen, at $5 \mathrm{PM}$. The ROC heating period is from 10:30 11:48 AM, and the cooling period is from $7: 30 \mathrm{PM}$ on the $26^{\text {th }}$ to $1 \mathrm{AM}$ on the $27^{\text {th }}$. The Delta processing heating period is from $11 \mathrm{AM}-5 \mathrm{PM}$ on the $26^{\text {th }}$, while the cooling period is from $10: 15 \mathrm{PM}-3: 40 \mathrm{AM}$ on the $27^{\text {th }}$. Figure 71 is an image of all the processed data when using the previously described heating and cooling periods. 


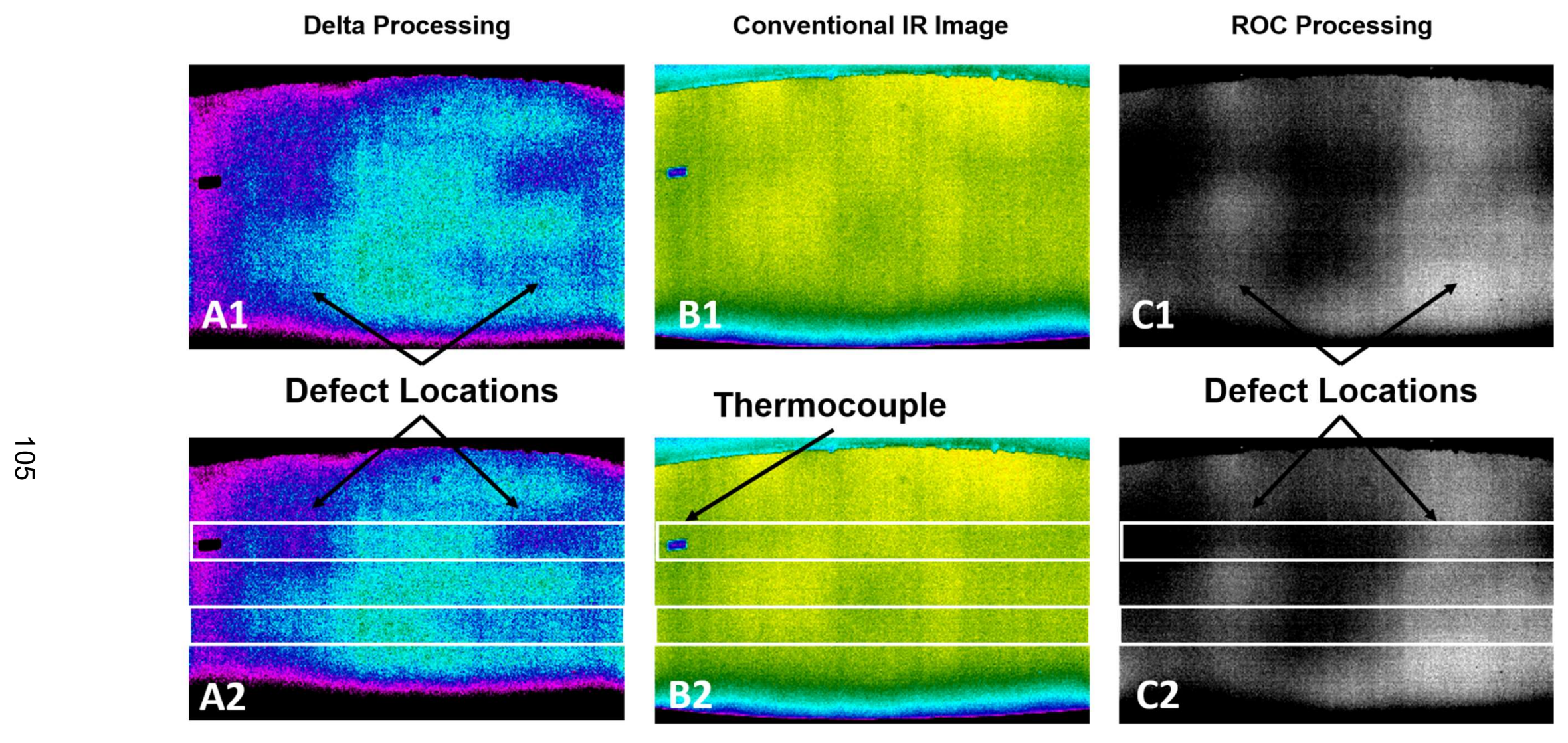

Figure 71 - Processed infrared image for PT specimen 2 on October $26^{\text {th }}$ and $27^{\text {th }}$. 
When analyzing the thermal data in Figure 70 , there is a difference in thermal gradient between thermocouple 6 and 3 . Since thermocouple 6 is near a completely empty duct and thermocouple 3 is above sound concrete, the point in time where the largest differences between these thermocouples occurs should correspond to the point in time where the defective ducts should be at their highest visibility to the infrared camera. Figure 72 is the image taken by the IR-UTD system at this point; 3:47 PM on 10/26/17.

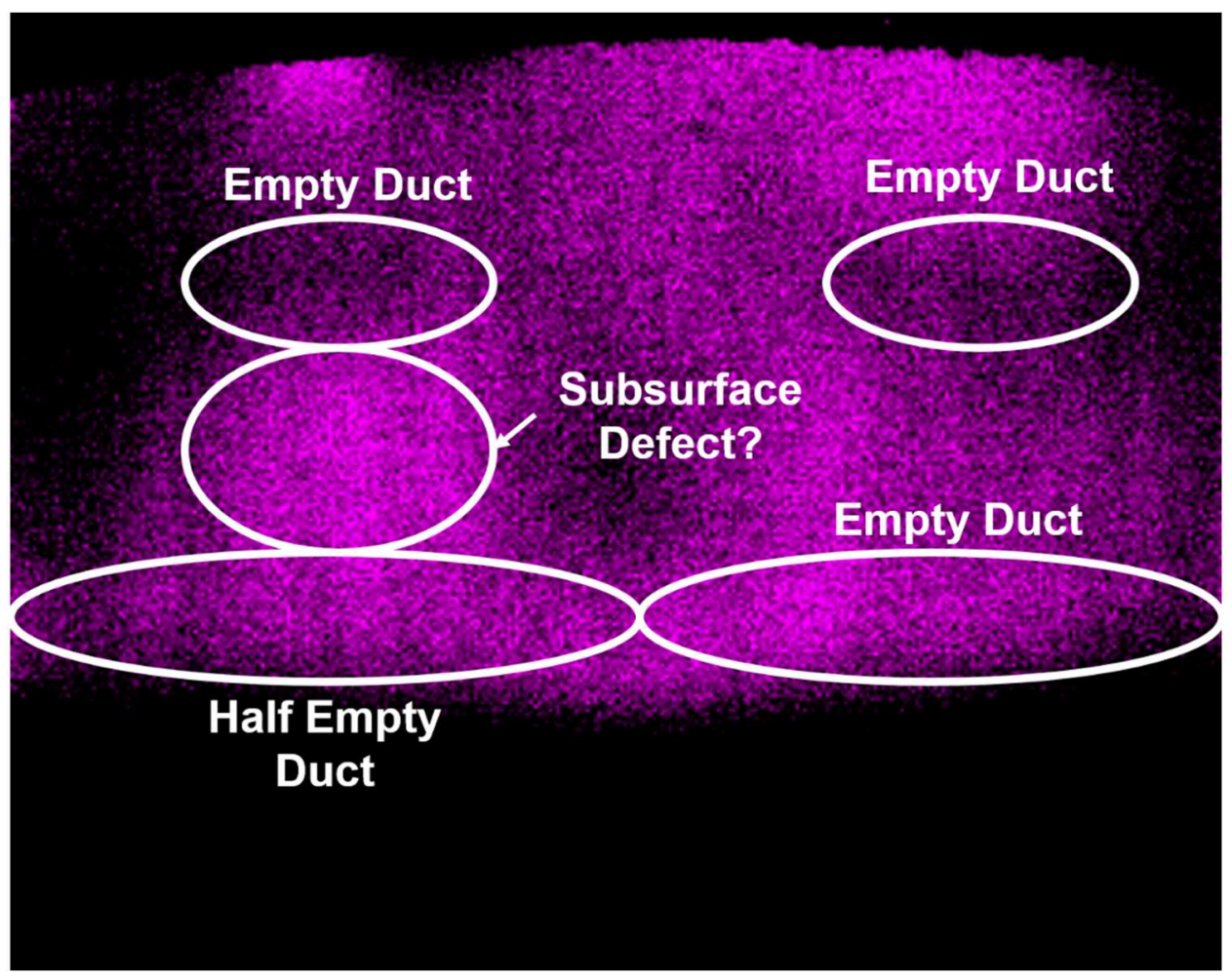

Figure 72 - Infrared image collected at the max difference between thermocouple 6 and thermocouple 3.

Figure 72 appears to show results that are similar to that of ROC and Delta processing previously displayed. The image points to an area near the center of 
the specimen that shows a notable change in thermal inertia. This area has been marked as a possible subsurface defect to be analyzed in future testing.

Additional processing was performed at an attempt to pinpoint the maximum heating and cooling periods. The period used in processing that exposed the half empty duct was later in time when compared to the period used for the completely empty duct. Figure 73 displays the thermocouple data for October $26^{\text {th }}$ and $27^{\text {th }}$. ROC processing gave the best results when using a heating period from to 11:20 AM - 12:50 PM and a cooling period from $6-7: 40$ PM. Figure 74 clearly shows an area of increased thermal inertia along the base of the image, in close proximity to the bottom duct.

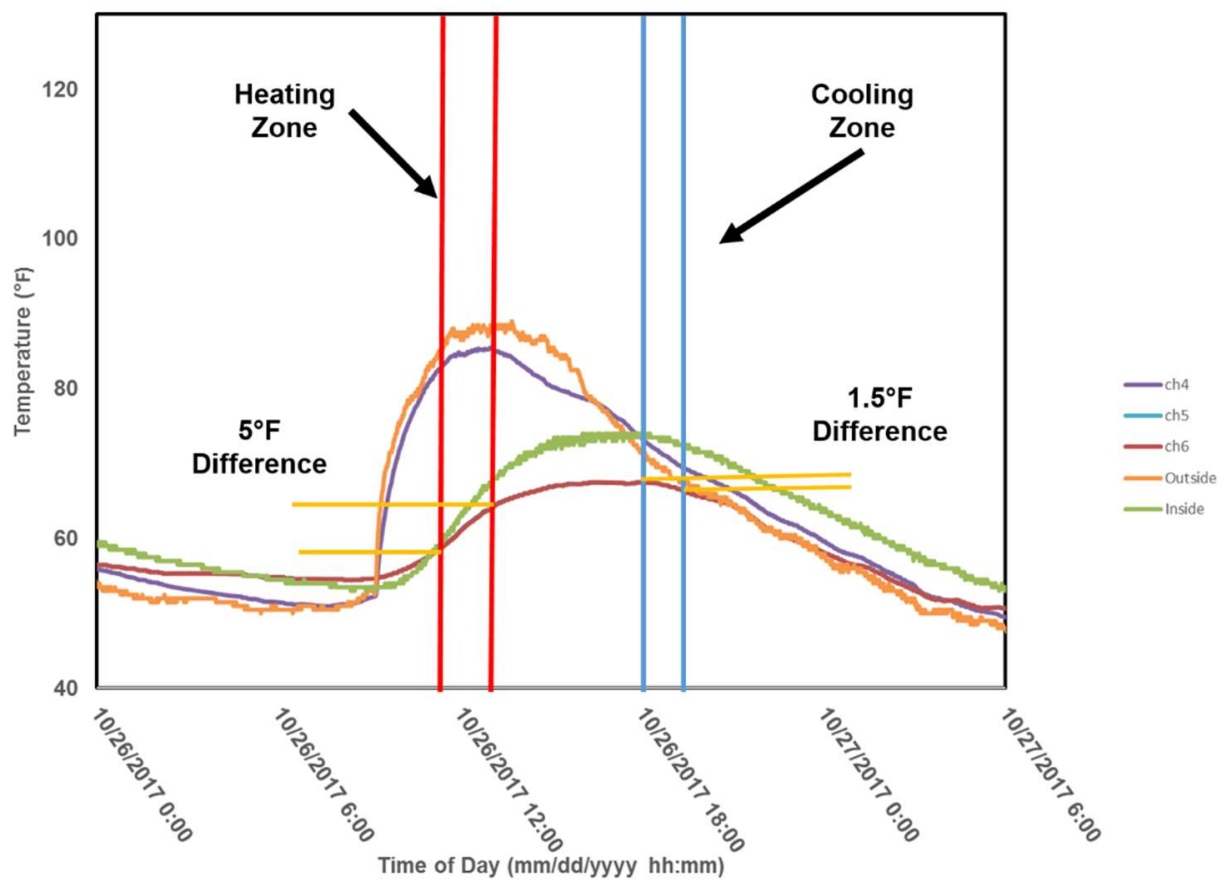

Figure 73 - Collected thermocouple data along with the processing period used to detect the half empty ducts. 


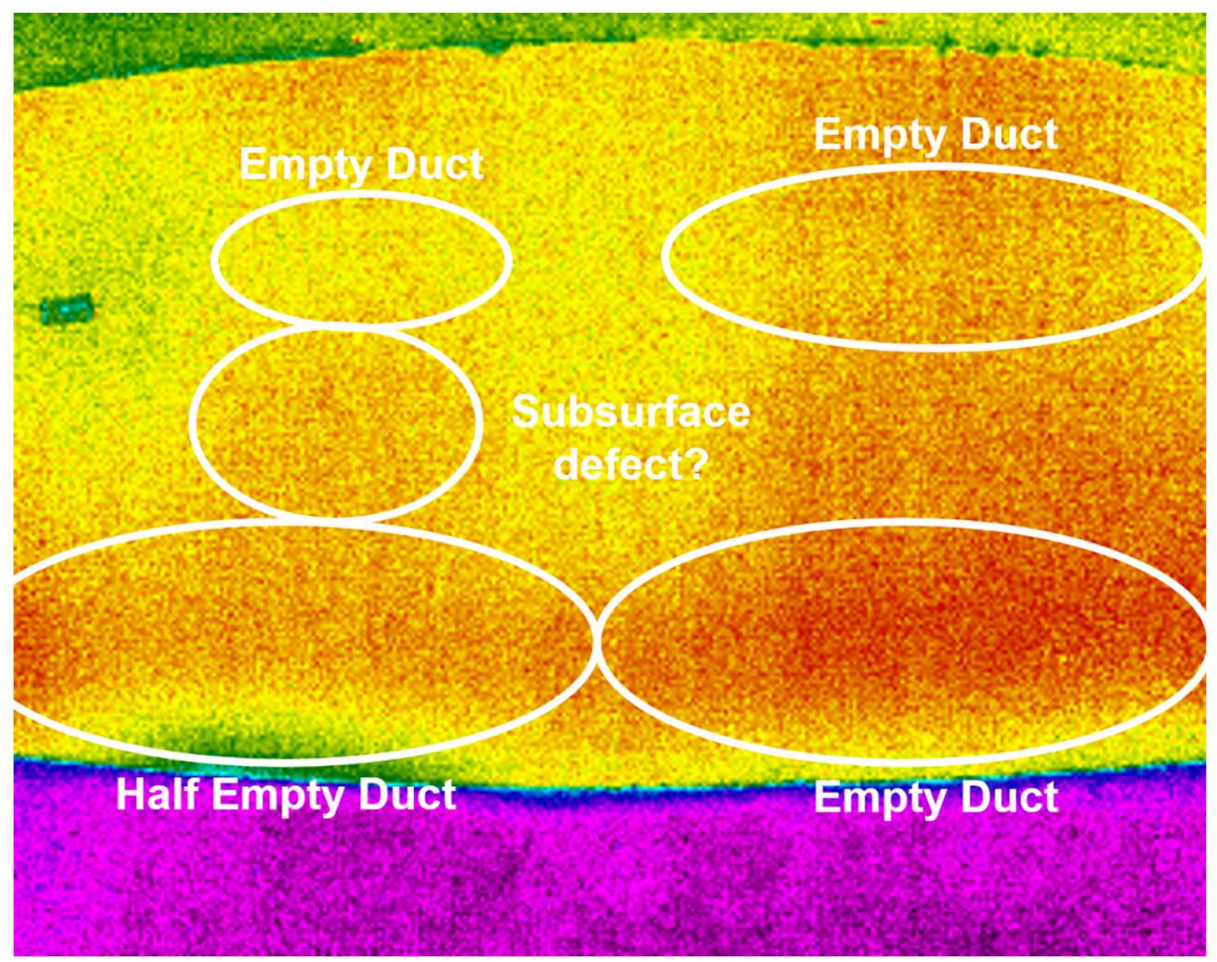

Figure 74 - Processed infrared image displaying the half empty and fully empty duct near the base of the specimen.

Aside from the qualitative results presented to this point, quantitative results could prove to be very beneficial. These quantitative results would not only confirm the qualitative results, but could be used for future data analysis of materials with small thermal differences where color scales aren't as beneficial. For quantitative analysis, image $\mathrm{C} 1$ in Figure 71 was used. Figure 75 displays the location of the data that was collected to perform the quantitative analysis. Refer to section 3.2.4.2 for an explanation of the quantitative processing technique used. Figure 76 displays the two sets of data graphed along the height of the specimen. 


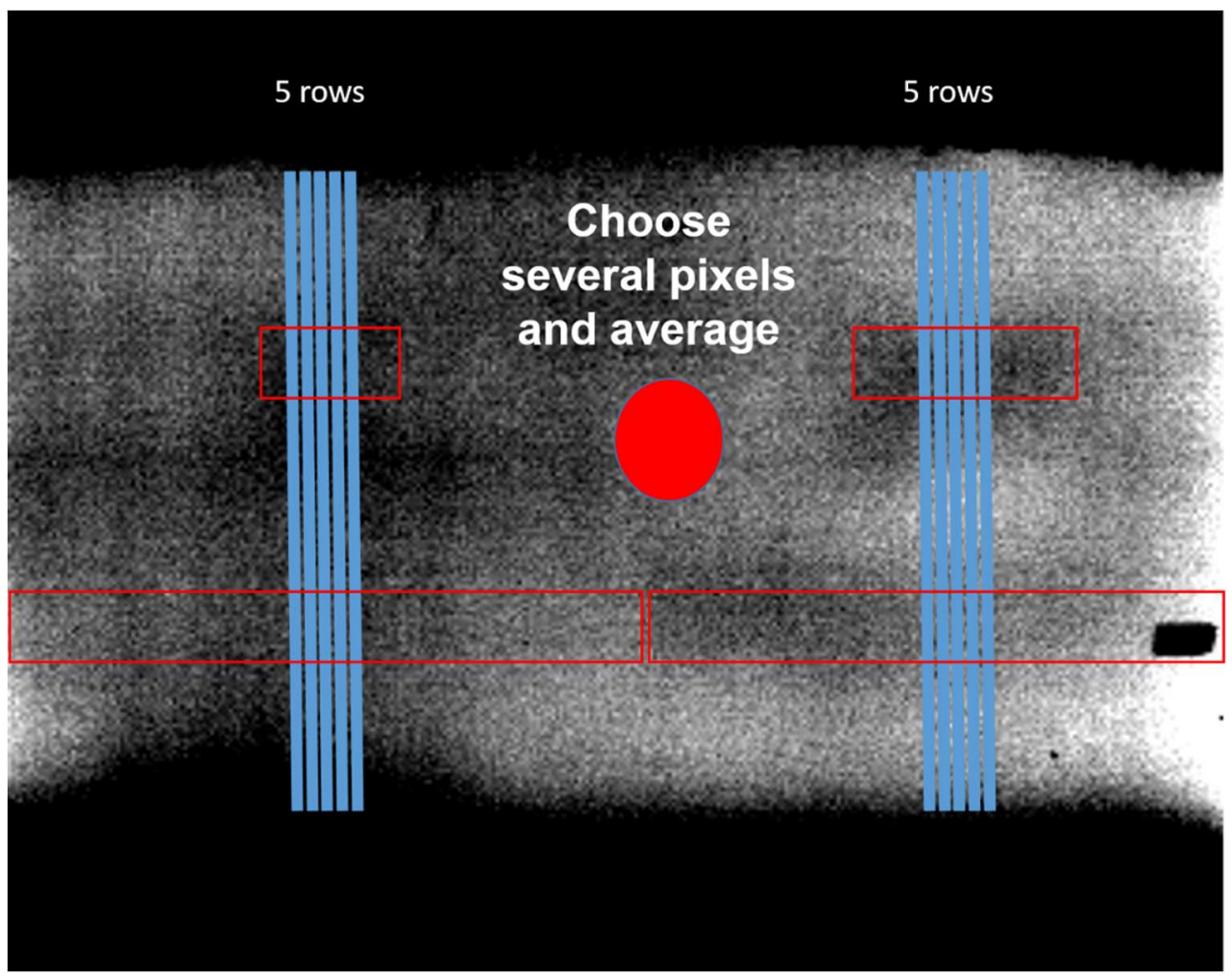

Figure 75 - Infrared image showing how to quantitatively show defective areas.

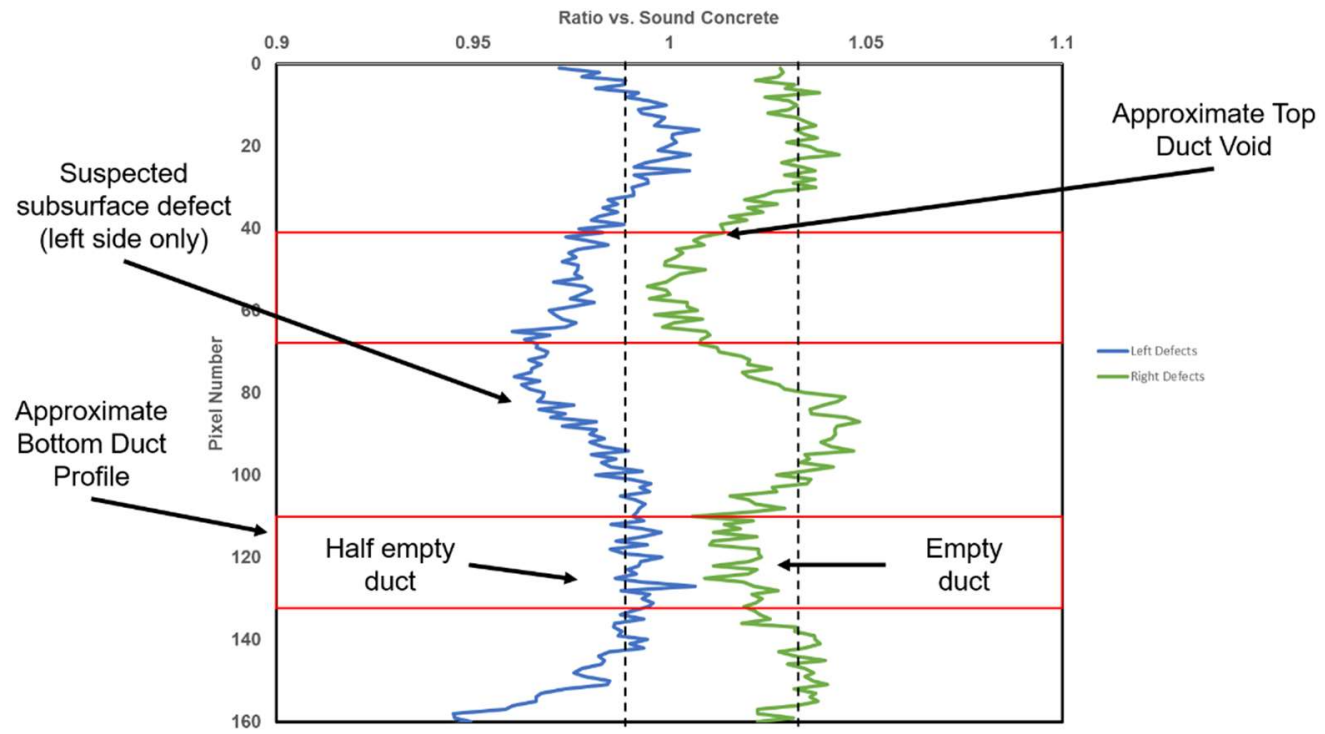

Figure 76 - Normalized and averaged pixel values for the two sets of five rows outlined in Figure 75. 
The green colored set of data corresponds to the five averaged rows on the right side of the specimen, the blue colored line corresponds to the five averaged rows on the left side. The red boxes in Figure 76 correspond to the same location of the red boxes in Figure 75. Based on knowing that the red boxes were placed at areas of known defects, we know that there are at least two areas on both the right and left side that should indicate an area with a defect. There is also an additional area on the left side where a subsurface defect wasn't intentionally placed inside of the specimen, but has shown up in several images and could have formed during the pouring of the concrete due to poor construction. Dotted lines were graphed at the nominal location for each set of data. This helps to illustrate the change in values across the height of the specimen.

The charted values in Figure 76 are very helpful in identifying defective areas along the vertical height of the specimen. The colored lines decrease in value when passing through an area with a known defect. This is true for both of the defects in the data on the right side of the specimen. When the line approaches a defective area, the value steadily decreases, and then increases when leaving the area. The same happens near the defective area on the top left side of the specimen, where there is a completely empty duct and a suspected subsurface defect. However, the quantitative values do not show the half-filled duct on the bottom left hand side of the specimen as being defective.

\subsubsection{Test 2.2 - Data and Results}

The IR-UTD system was placed closer to the face of the specimen, so that it could view a 4-ft. $\times 4$-ft. area of the specimen. The air control was also set to a 
$15^{\circ} \mathrm{F}$ offset during this experiment. Infrared and thermocouple data were collected between October $1^{\text {st }}$ and October $4^{\text {th }}, 2017$. The thermocouple was placed at a location adjacent to the half empty duct in an attempt to find the best time of day to analyze that duct. Data from October $2^{\text {nd }}$ and $3^{\text {rd }}$ were used during data processing.

A conventional infrared image was collected at the peak temperature on the inside face of the specimen, at $6 \mathrm{PM}$. The ROC heating period is from $11 \mathrm{AM}-$ 1:15 PM, and the cooling period is from 6 until 10:20 PM, on the $2^{\text {nd }}$. The Delta processing heating period is from 10:30 $\mathrm{AM}-4 \mathrm{PM}$ on the $2^{\text {nd }}$, while the cooling period is from 4:40 PM on the second until $-9: 10 \mathrm{AM}$ on the $3^{\text {rd }}$. Figure 77 is an image of the collected thermocouple data for October $2^{\text {nd }}$ and $3^{\text {rd }}$. Figure 78 is an image of all the processed data when using the previously described heating and cooling periods.

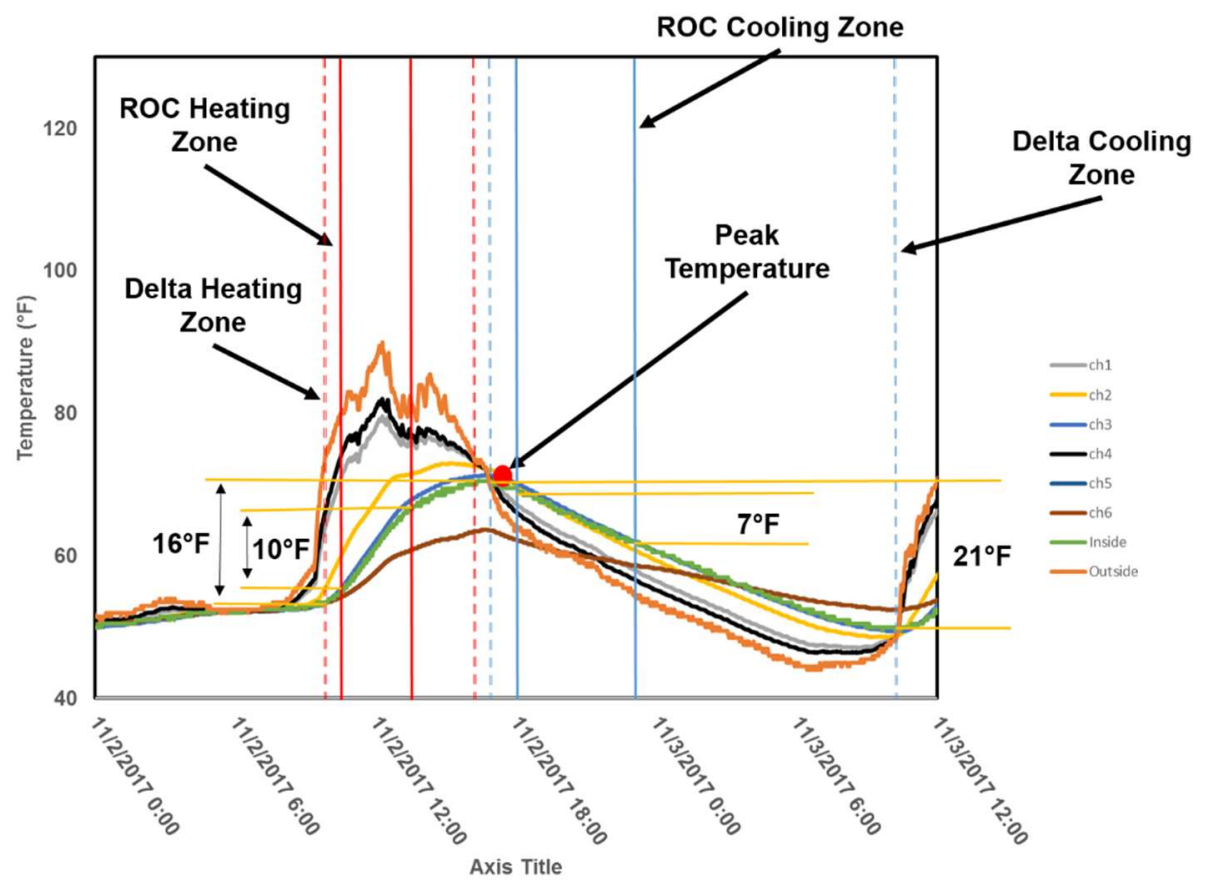

Figure 77 - Thermocouple data for October $2^{\text {nd }}$ and $3^{\text {rd }}$. 


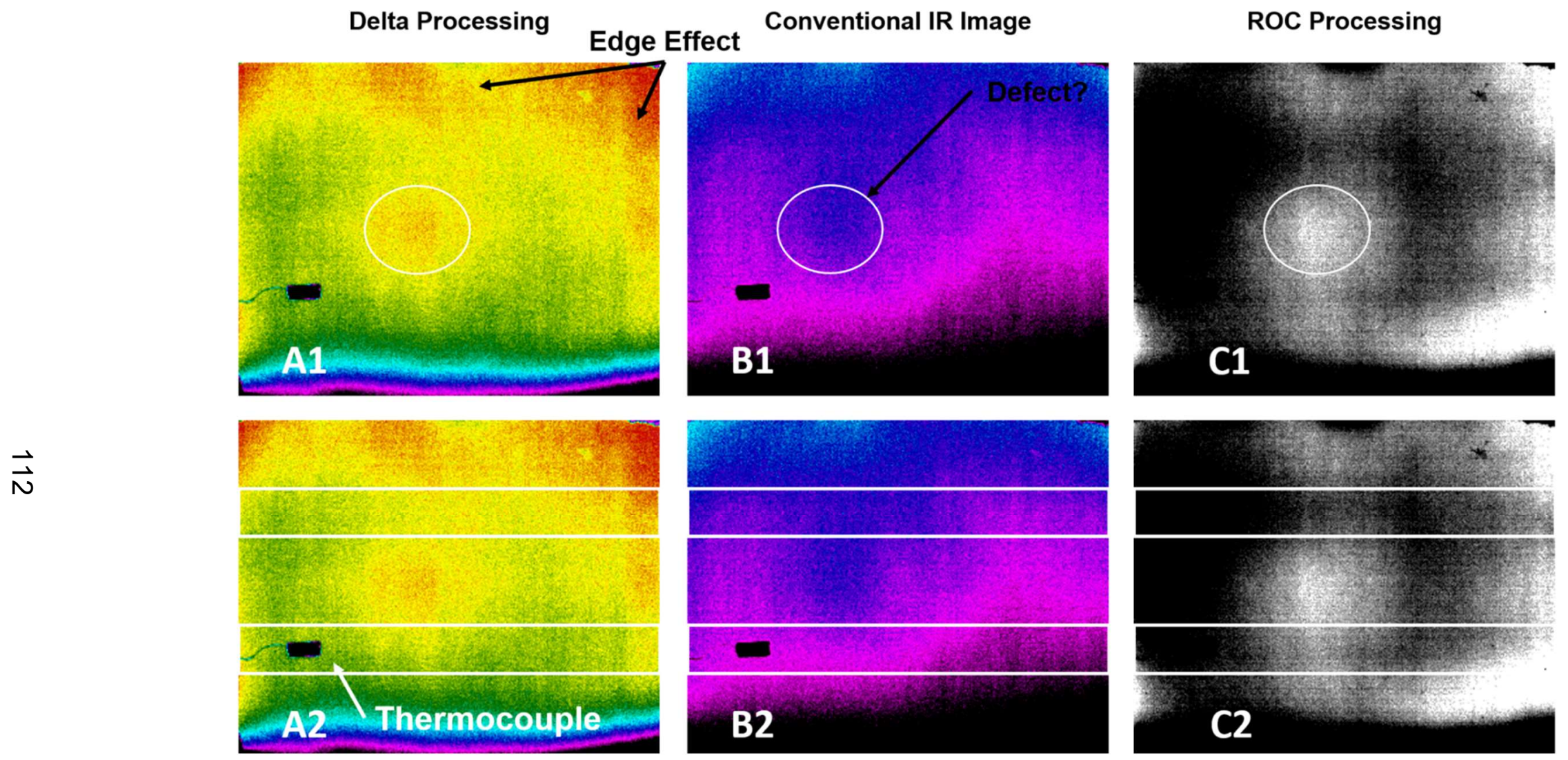

Figure 78 - Infrared images produced from processing conducted on infrared and thermocouple data collected on October $2^{\text {nd }}$ and $3^{\text {rd }}$. 
The results of data processing do not appear to be any more beneficial than previous testing of the specimen. The results from all three types of processing show a significant indication in the location of an unknown defect.

As in the previous experiment, the difference between thermocouple six and three were evaluated, and the image corresponding to the point in time where the difference between the two thermocouples was at its peak was collected. Figure 79 is the infrared image corresponding to the point in time with the largest difference between the two thermocouples; 3:27 PM on October $2^{\text {nd }}$.

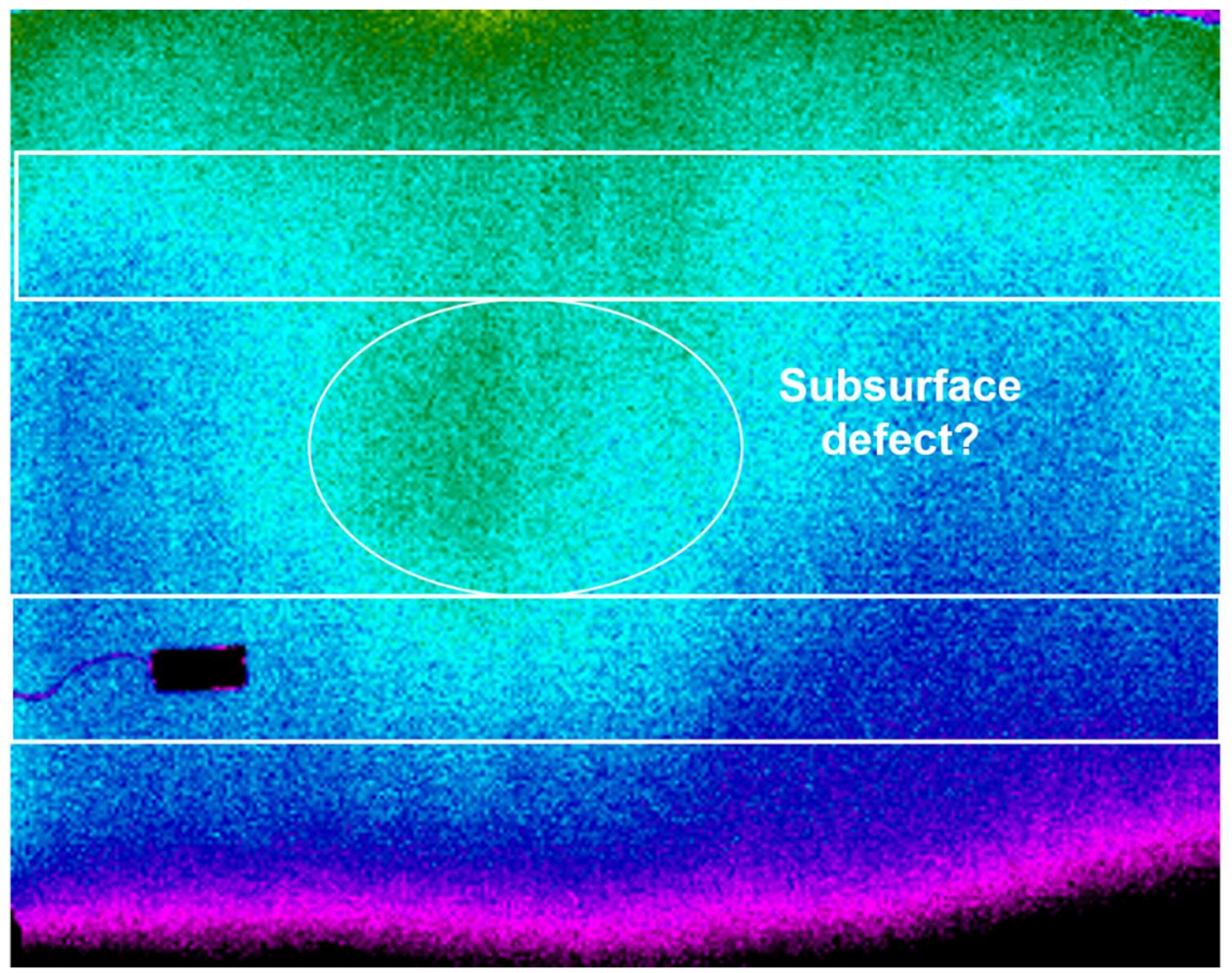

Figure 79 - Singular infrared image collected during the peak difference at 3:27 PM on October $2^{\text {nd }}, 2017$.

A final attempt at detecting the half empty duct was made by using the quantitative processing technique previously outlined. Figure 80 shows where the 
data was collected from to conduct a quantitative analysis. This data set is graphed in Figure 81, and produced some positive results.

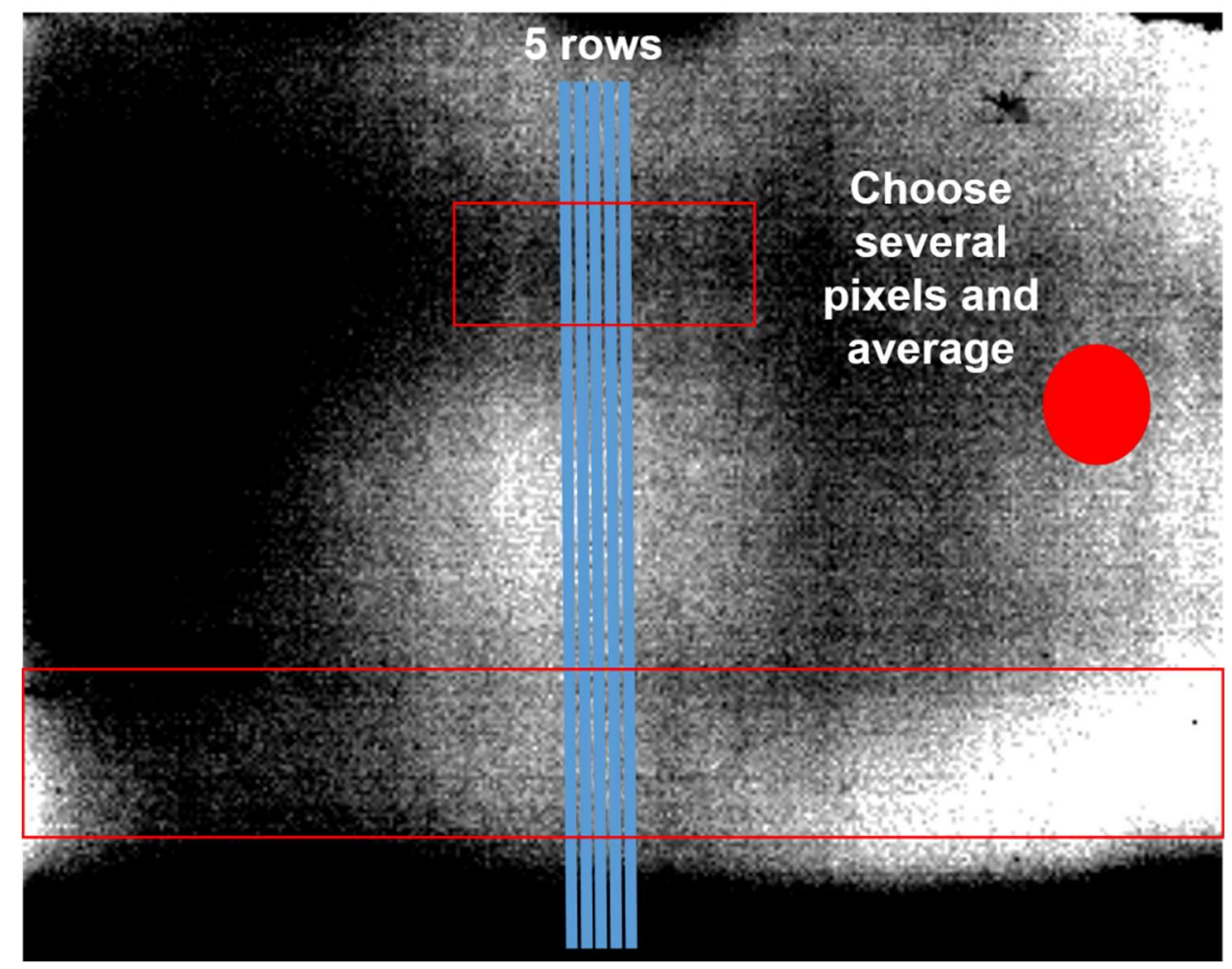

Figure 80 - Image used for quantitative processing to detect the half empty duct. 


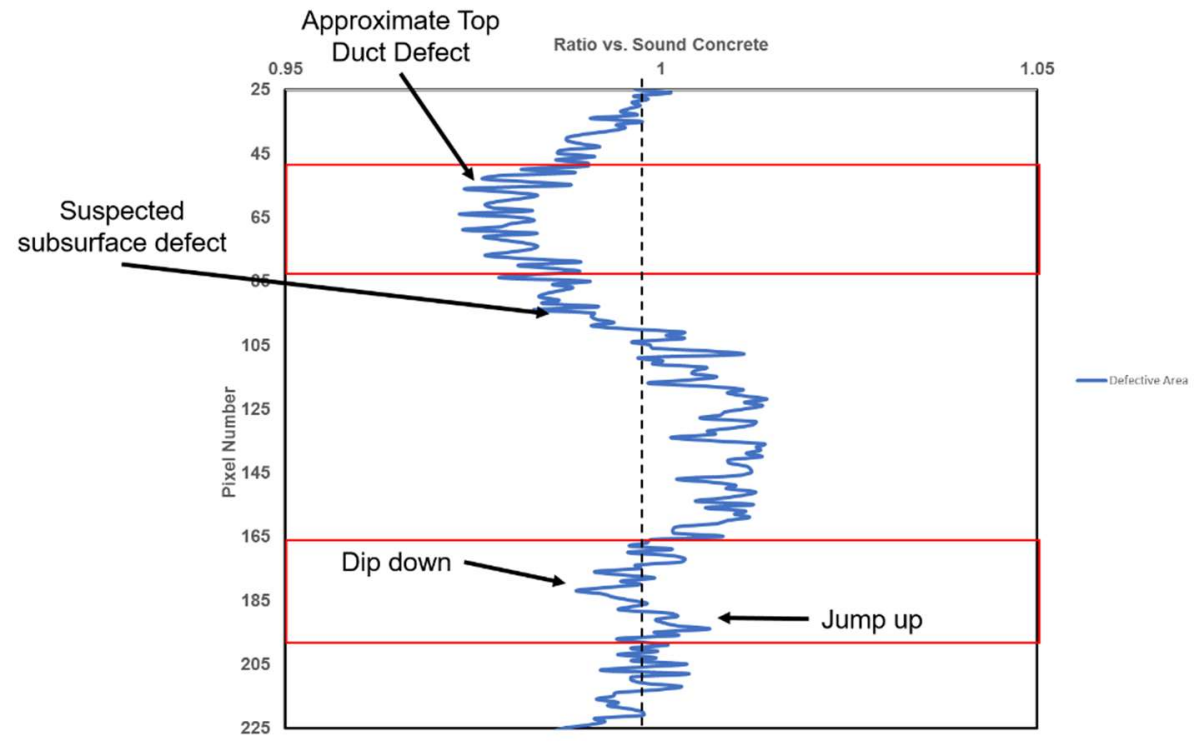

\section{Figure 81 - Averaged and normalized values of the five rows of pixel data called out in Figure 80.}

The red boxes in Figure 81 represent the location of the red boxes in Figure 80, corresponding to the pixel distance from the height of the image. In Figure 81, the approximate top duct location shows a similar dip in values that is consistent with previous testing, and is displayed in Figure 76. The vertical dashed line is again utilized to give a nominal value to show the notable change in values. Contrary to the defective ducts, the location of the suspected subsurface defect produces values that are larger, creating a peak in the opposite direction. This makes sense, as the color in the location of the suspected defect shown in Figure 80 is a much brighter color, corresponding to the top end of the color spectrum, which indicates a larger value.

In the location associated with the bottom duct profile, there appears to be a very slight dip in the values, and then a jump back up. This slight dip in either direction could be due to the presence of the half empty duct, indicating a jump in 
the area without grout and then a jump from the portion of the duct that is filled with grout. Both of the ducts could be detected, but the duct near the base was a much brighter color, while the duct at the top was much darker. This is the same phenomenon witnessed at the start of testing with the completely empty ducts

\subsubsection{Test 2.3 - Data and Results}

A baseline test similar to the one run on specimen 1 was conducted. The specimen was disconnected from the insulated structure and turned so that the face of the specimen analyzed in previous testing was facing the sun in the south. The IR-UTD system was then moved back into the aluminum data acquisition (DAQ) system for data collection. Infrared and thermocouple data were collected from November $7^{\text {th }}$ to November $10^{\text {th }}, 2017$. The external thermocouples were placed at the location of the half empty duct; 16 inches up from the base and 12 inches towards the center of the specimen.

For the data collected, November $9^{\text {th }}$ gave the largest increase and decrease in surface temperature of the specimen. Figure 82 is the collected surface temperature data for November $9^{\text {th }}$. The green line is for the surface temperature on the face of the specimen on the north (shaded) side. The orange line represents the surface temperature of the side of the specimen facing the sun in the southern sky. Unlike previous testing, that used the inside temperature for data processing, this test utilizes the temperature change on the sunny side of the specimen. 


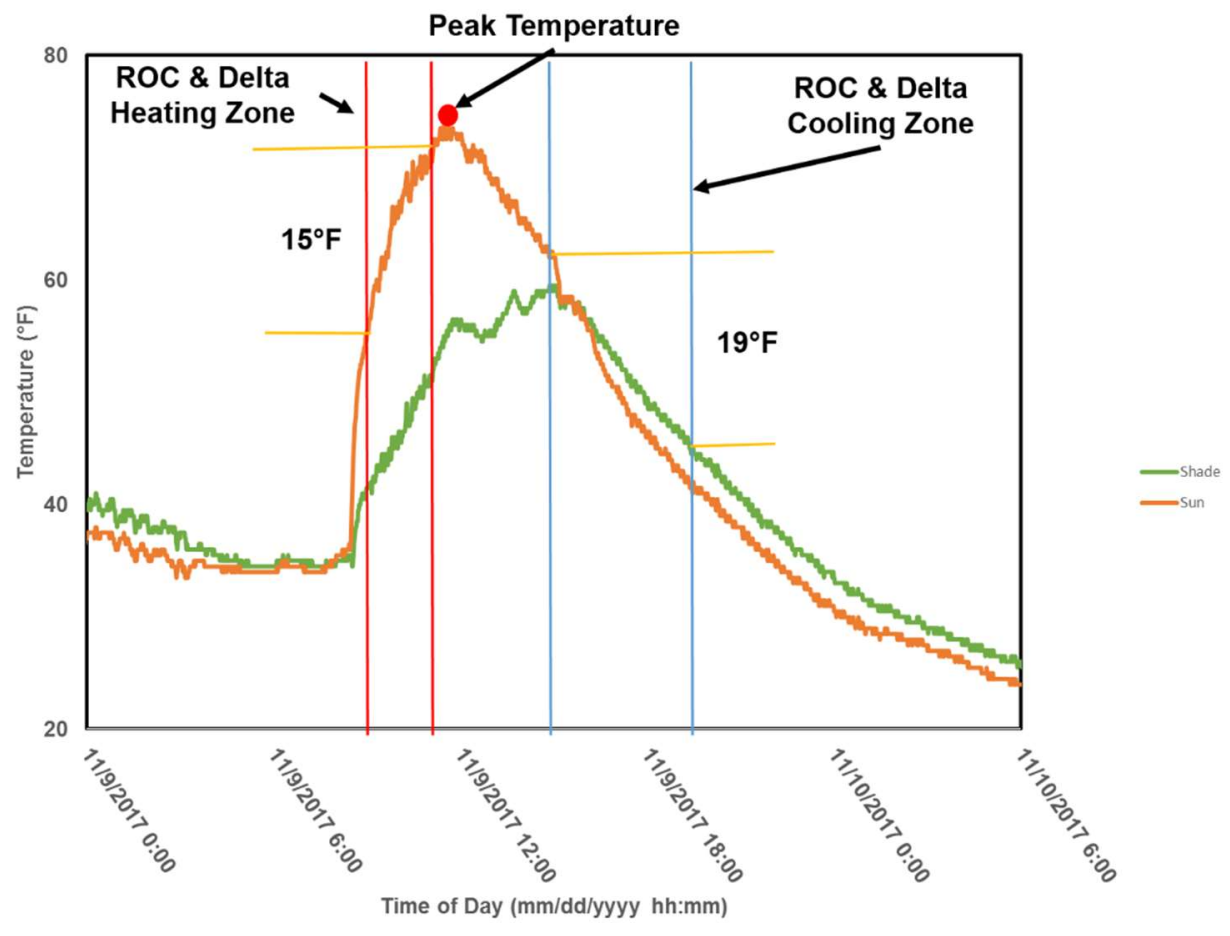

Figure 82 - Thermocouple data for test 3 on specimen 2

For these data, a singular infrared image was collected at the peak surface temperature, and the data was processed using ROC and Delta analysis. The singular infrared image was collected at 11:35 AM on November $11^{\text {th }}, 2017$. The Delta and ROC processing were identical during these tests. The heating cycle was from $9-11 \mathrm{AM}$ and the cooling cycle was from $3-7 \mathrm{PM}$, on November $9^{\text {th }}$, 2017. Figure 83 shows the results for each type of processing used. 


\section{Delta Processing}
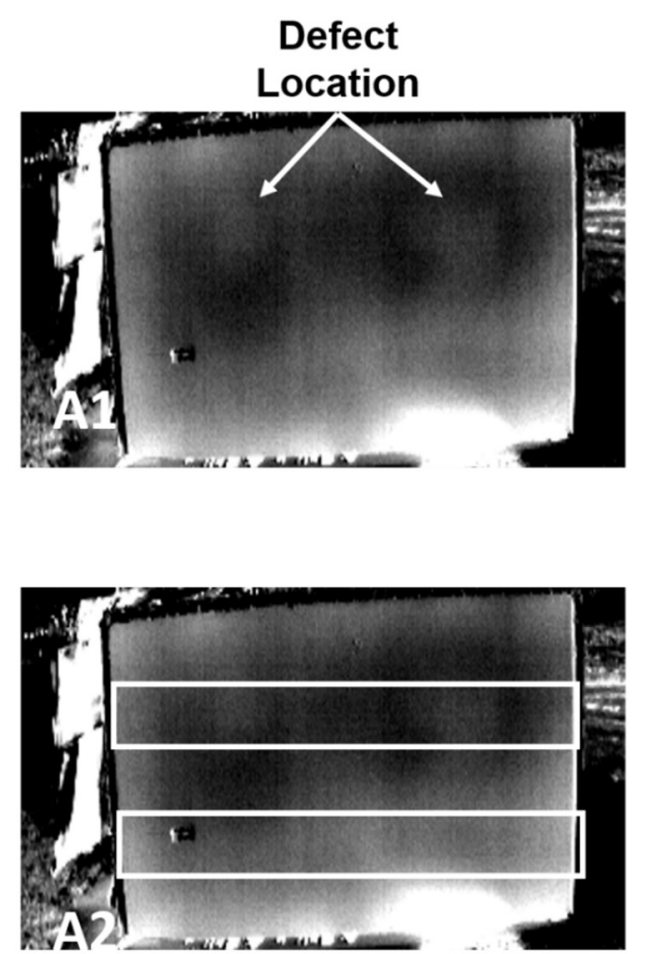

Conventional IR Image
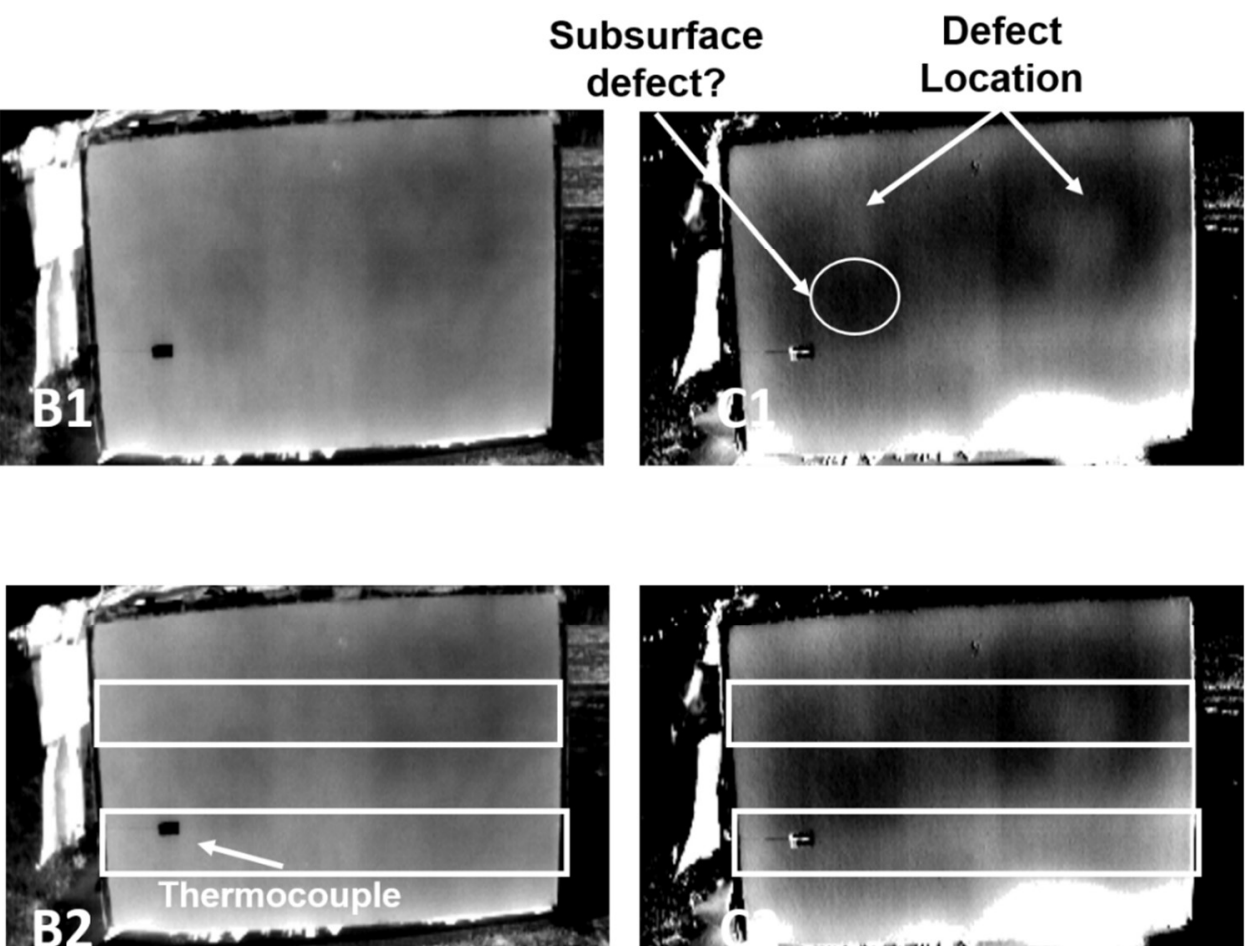

ROC Processing

Defect

ocation

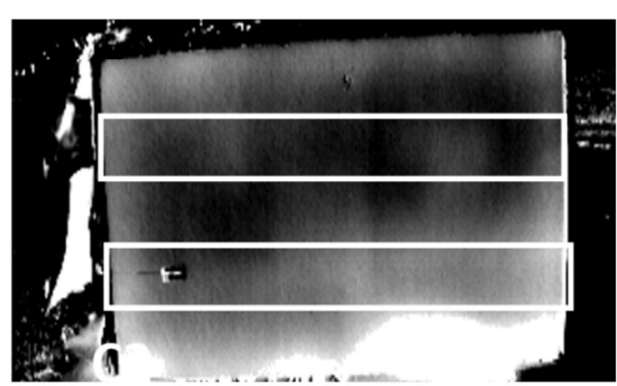

Figure 83 - Infrared processing results for the baseline test on specimen 2. 
Unlike previously conducted testing, the defects near the base of the specimen were very difficult to detect. Without the additional thermal energy emitted into the base of the specimen through the slab, these defects weren't experiencing as large of a temperature increase. Even though the defects are visible, the results shown in Figure 83 aren't as well defined as the defects detected when analyzing the structure from the inside of the insulated structure. The ROC processing was able to detect the large fully empty duct on the bottom right side of the specimen. The Delta and ROC processing techniques were able to detect slight indications in the top ducts in images $\mathrm{A} 1$ and $\mathrm{C} 1$. However, none of these indications are well defined.

Quantitative processing was used once again with the qualitative results to reach a reasonable conclusion. Figure 84 is a visual representation of the processing conducted. Figure 85 is the chart of the quantitative results processed for the baseline test on specimen 2. The blue line represents the normalized and averaged values of the 5 rows on the left side of the infrared image, while the gray line represents the right. 


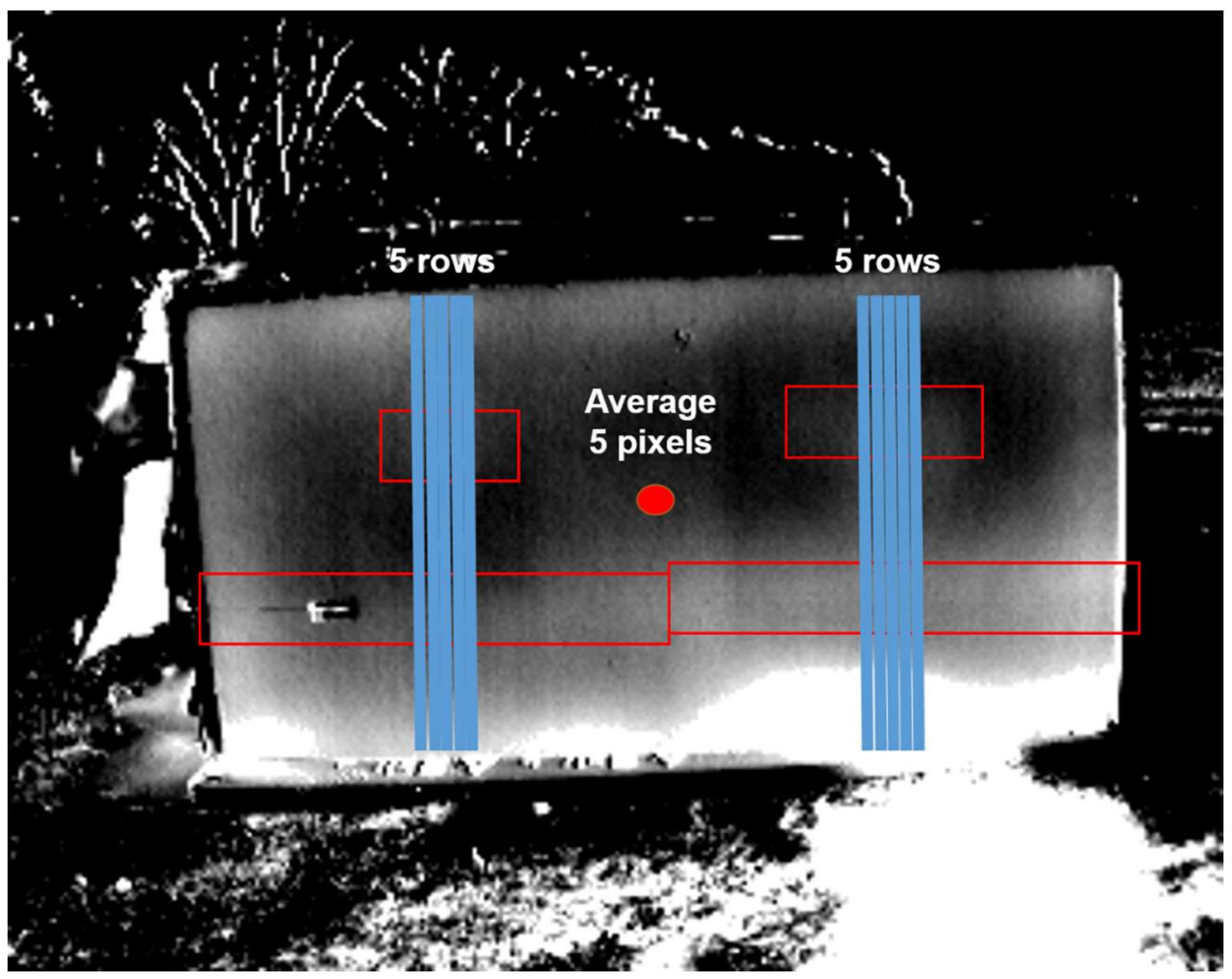

Figure 84-Quantitative outline for processing of ROC results.

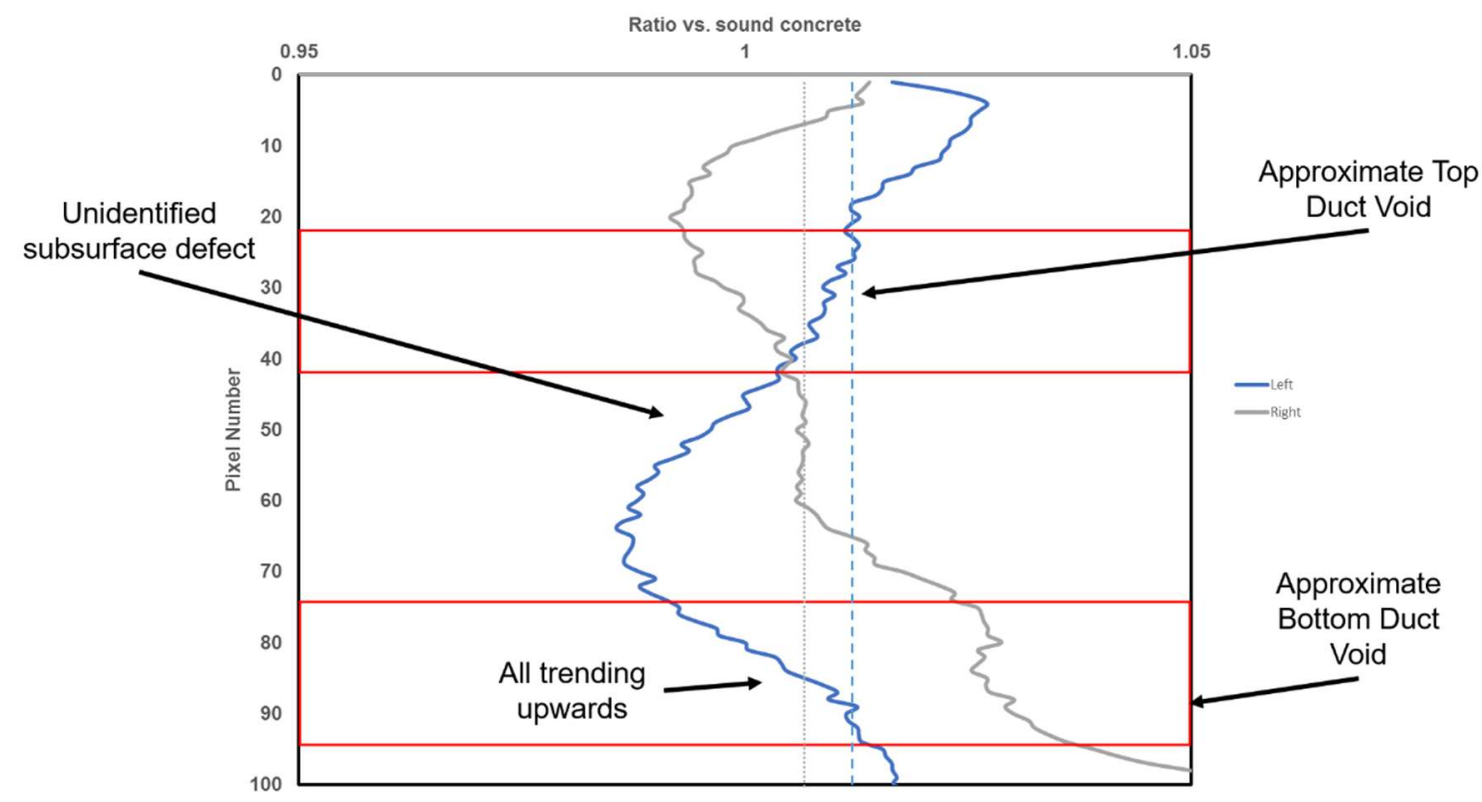

Figure 85 - Quantitative results for the baseline test of specimen 2. 


\section{CONCLUSION}

The objective of this research was to assess the capabilities of the transient based Infrared Ultra Time Domain (IR-UTD) system to detect defects in galvanized steel ducts embedded within two concrete post tensioned specimens.

In summary to the research here within, the following conclusions can be made:

- In direct sunlight, the IR-UTD processing produced indications from implanted defects of varying sizes inside of a galvanized steel duct

- Diurnal heating and cooling cycles from the sun created enough thermal contrast for defect indications to be observed in the processed IR-UTD data

- In most cases, the conventional infrared imaging did not produce indications. The ROC and Delta processing techniques produce improved results

- The effect from having air control on the inside of the structure did not significantly affect results.

- A phase change between the peak heating and cooling cycles on the imaged surface was observed comparing a sound area of concrete and an area adjacent to an empty duct

- The peak heating and cooling occurs later in time for the surface area adjacent to the defective duct area

- A quantitative procedure was developed and implemented to spatially detect defects in ducts 


\subsection{Future work}

Based on the conducted research, future work is needed to fully access the abilities of the IR-UTD system to detect defects in the walls of a post tensioned box girder bridge.

- Cast specimens with embedded ducts at varying depths, defect sizes, duct diameter and gauge

- Evaluate defects in both galvanized steel ducts and thick corrugated plastic ducts

- Utilize thermocouple wiring to develop quantifiable guidelines to detect defects based on the concrete cover and defect size

- Determine effective procedures to properly insulate the edges of the tested specimen

- Use professional services to properly cast all future concrete specimens

- Perform testing during the summer months, where the sun is in the sky for several hours longer during any given day 


\section{REFERENCES}

1. Administration, F.H. Deficient Bridges by Functional Classification Count 2015. 2015.

2. Youn, S.-G. and E.-K. Kim. Deterioration of bonded posttensioned concrete bridges and research topics on the strength evaluation in ISARC. in Proceedings of JSCE-KSCE Joint Seminar on Maintenance and Management Strategy of Infrastructure in Japan and Korea. 2006.

3. (FDOT), F.D.o.T. Post-Tensioned Grouting and Corrosion Issues in Florida.

4. Washer, G., et al., Guidelines for thermographic inspection of concrete bridge components in shaded conditions. Transportation Research Record: Journal of the Transportation Research Board, 2013(2360): p. 13-20.

5. Clemena, G.G. and W.T. McKeel, Detection of delamination in bridge decks with infrared thermography. Gerardo G. Clemena and Wallace T. McKeel, JR., Transportation Research Record, 1978(664): p. 180-182.

6. Malhotra, V.M. and N.J. Carino, Handbook on Nondestructive Testing of Concrete Second Edition. 2003: CRC press.

7. Vaghefi, K., et al. Application of thermal IR imagery for concrete bridge inspection. in Proceedings of the $\mathrm{PCl}$ National Bridge Conference (PCI/NBC'11). 2011.

8. Washer, G., R. Fenwick, and N. Bolleni, Effects of solar loading on infrared imaging of subsurface features in concrete. Journal of Bridge Engineering, 2010. 15(4): p. 384-390.

9. Hasan, M., et al., Boiling burnout during crossflow over cylinders, beyond the influence of gravity. ASME JOURNAL OF HEAT TRANSFER, 1981. 103(3): p. 478-484.

10. Washer, G., et al., Effects of environmental variables on infrared imaging of subsurface features of concrete bridges. Transportation Research Record: Journal of the Transportation Research Board, 2009(2108): p. 107-114. 
11. Starnes, M.A., Development of technical bases for using infrared thermography for nondestructive evaluation of fiber reinforced polymer composites bonded to concrete. 2002, Massachusetts Institute of Technology.

12. Manning, D.G. and F.B. Holt, Detecting delamination in concrete bridge decks. Concrete International, 1980. 2(11): p. 34-41.

13. Maldague, X., Applications of infrared thermography in nondestructive evaluation. Trends in optical nondestructive testing, 2000: p. 591-609.

14. Manning, D.G. and F. Holt, Detecting deterioration in asphalt-covered bridge decks. 1983.

15. Unger, H.-G. and J.H. Hinken, Elektromagnetische Wellen auf Leitungen. 1986: Hüthig Heidelberg.

16. Derobert, X., C. Aubagnac, and O. Abraham, Comparison of NDT techniques on a post-tensioned beam before its autopsy. NDT \& E International, 2002. 35(8): p. 541-548.

17. Maierhofer, C., Nondestructive evaluation of concrete infrastructure with ground penetrating radar. Journal of Materials in Civil Engineering, 2003. 15(3): p. 287-297.

18. Zhu, J. and J.S. Popovics, Imaging concrete structures using air-coupled impact-echo. Journal of engineering mechanics, 2007. 133(6): p. 628-640.

19. Muldoon, R., et al., Identifying voids in plastic ducts in post-tensioning prestressed concrete members by resonant frequency of impact-echo, SIBIE and tomography. Construction and Building Materials, 2007. 21(3): p. 527-537.

20. Jaeger, B.J., M.J. Sansalone, and R.W. Poston, Detecting voids in grouted tendon ducts of post-tensioned concrete structures using the impact-echo method. ACl structural journal, 1996. 93(4): p. 462-473.

21. Tinkey, Y. and L. Olson, Applications and limitations of impact echo scanning for void detection in posttensioned bridge ducts. Transportation 
Research Record: Journal of the Transportation Research Board, 2008(2070): p. 8-12.

22. Crigler, Electrically Isolated Tendons in Precast Segmental Bridges, in PostTensioning Institute Technical Conference. 2009.

23. Elsener, B., Long-term monitoring of electrically isolated post-tensioning tendons. Structural Concrete, 2005. 6(3): p. 101-106.

24. Della Vedova, M. and B. Elsener. Enhanced durability, quality control and monitoring of electrically isolated tendons. in Proc. 2nd International fib congress. 2006.

25. Iyer, S., A.J. Schokker, and S.K. Sinha, Ultrasonic imaging-A novel way to investigatecorrosion status in post-tensioned concrete mambers. Journal of the Indian Institute of Science, 2013. 82(5 \& 6): p. 197.

26. Salamone, S., et al., Health monitoring of prestressing tendons in posttensioned concrete bridges. Transportation Research Record: Journal of the Transportation Research Board, 2011(2220): p. 21-27.

27. Youn, S.G., S.-K. Cho, and E.K. Kim. Acoustic emission technique for detection of corrosion-induced wire fracture. in Key Engineering Materials. 2005. Trans Tech Publ.

28. Giannopoulos, A., et al. GPR detection of voids in post-tensioned concrete bridge beams. in SPIE proceedings series. 2002. Society of Photo-Optical Instrumentation Engineers.

29. Dupuis, K.J., Nondestructive testing of concrete box girder bridges using thermal imaging. 2008, Washington State University Pullman, Wash, USA.

30. Tan, Y. and D. Han, A Study on Temperature Distribution in a Cross Section of Concrete Box Girder Bridge, in Computational Methods in Engineering \& Science. 2006, Springer. p. 286-286.

31. Nam, S. and T. Habib, Measured thermal response of concrete box-girder bridge. Transportation Research Record, 1994(1460): p. 94-105. 